QL
444
C7N83
1888
INV. ZOOL. 


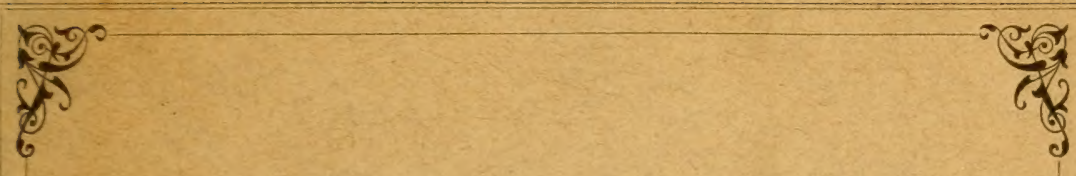

DIE CALANIDEN FINLANDS

VON

OSC. NORDQVIST.

ABDRUCK AUS ${ }_{\text {BIDRAG TILL KÄNNEDOM AF FINLANDS NATUR }}$ OCH FOLK“, HEFT 47.
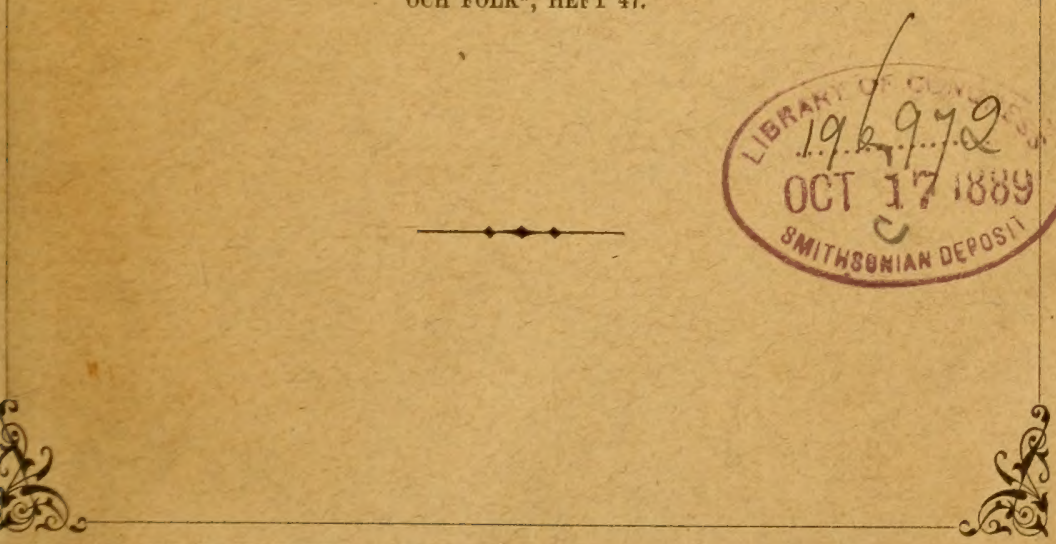



\section{Die Calaniden Finlands}

von

Osc. Nordquist.

$\ldots$

„Erweitert man den Umfang eines Artbegriffes, indem man nachweist, dass Thiere eines neuen, mit eigenthümlichen physikalischen Eigensehaften ausgestatteten Fundortes nur Varietäten bereits bekannter Formen sind, so wird man den Ursachen der Entstehung und Ausbildung lokaler Varietäten näher geführt, während die vorschmelle Erhebung lokaler Varietäten zu neuen Arten von der Erkennung dieser Ursachen ableitet". (MöвIUs Die wirbellosen Thiere der Ostsee).

Helsingfors,

Druckerei der Finnischen Litteratur-Gesellschaft,

1888. 



\section{W}

ährend die Vertebraten und Insekten Finlands sehr fleissig studirt worden sind, hat man bei uns die übrigen Thierklassen fast gar nicht berücksichtigt. Seit einigen Jahren mit dem Studium unserer Crustacéen beschäftigt, ist es meine Absicht zu versuchen die Lücke bezüglich dieser Thierklasse nach Vermögen einigermassen auszufüllen.

Hiermit wird ein Theil meiner Untersuchungen, derjenige den ich über die Calaniden angestellt habe, überliefert. Es war meine Absicht alle unsere freilebenden Copepoden zu bearbeiten, aber die kurże Zeit, die mir zu Gebote stand, hat es nothwendig gemacht mich auf eine einzige Familie zu beschränken. Dass ich gerade diese Familie gewählt habe, beruht darauf, dass sie eine von den interessantesten unter allen bei uns vorkommenden Crustacéen ist.

Ihre meisten Arten leben wie bekannt im Meere, wo sie öfters in grossen Massen vorkommen, und in der Ostsee ist es fast ausschliesslich diese Familie, welche die grossen Wasseröden bevölkert. Ausser denselben leben nämlich in der pelagischen Region der mittleren und nördlichen Ostsee in einer beträchtlichen Menge nur drei Cladoceren (Podon minutus G. O. Sars, Evadne Nordmanni Lovén und Bosmina sp.) und einige Räderthierchen. Die Skandinavischen Landseen bergen eine ziemlich grosse Anzahl von Calaniden-Arten. Von denselben kommen einige 
wie Limnocalanus macrurus, Diaptomus gracilis und Heterocope appendiculata in enormen Massen vor. Die Calaniden spielen also die grösste Rolle unter allen unseren sowohl Landsee- wie Meeresthieren als Vertilger der kleineren mikroskopischen Thiere und als Nahrung der Fische (die Heringe und "Muikka“ (Coregonus albula) leben fast ausschliesslich von solchen).

Wie hieraus ersichtlich ist, kann diese Familie ein grösseres Interesse als irgend eine andere Gruppe der bei uns vorkommenden Crustacéen beanspruchen. Die wissenschaftlichen Aufgaben, welche ich zu beantworten versucht habe, sind weiter unten angeführt. Hier will ich nur einige Worte über den Plan dieser Arbeit sagen.

Für den wissenschaftlichen Zweck wäre es vielleicht genug gewesen von den Beschreibungen nur das mitzutheilen, was ich von dem vorher bekannten abweichend gefunden habe. Da aber bis jetzt keine einzige Beschreibung über die in Finland lebenden Crustacéen vorhanden war, so hatte ich ausser dem rein wissenschaftlichen Zweck noch einen zweiten, nämlich den Versuch eine Arbeit, nach welcher man unsere Arten leicht bestimmen könnte, zu liefern.

Darum habe ich in den Beschreibungen wie in den Abbildungen hauptsächlich die am meisten characteristischen Merkmale dargestellt. 
Der erste Forscher, der bei uns seine Aufmerksamkeit den Crustacéen zugewandt hat, ist J. A. Malmgren. Er hat in mehreren von den grösseren Seen Finlands, wie Pyhäselkä, Pyhäjärvi, Höytiäinen, Ladoga, Rehja und Uleåträsk draggirt und das Vorkommen der interessanten Meerescrustacéen Mysis oculata v. relicta Lovén, Pallasea cancelloides v. quadrispinosa (Esmark) G. O. S., Gammaracanthus loricatus $v$. lacustris G. O. S., Pontoporeia femorata, Kröyer, daselbst zum erstenmale nachgewiesen ${ }^{1}$ ). Malmgren hat sich jedoch nur mit den Malakostraken beschäftigt.

In A. H. Cajanders Aufsatz „Bidrag till kännedomen om sydvestra Finlands crustacéer" ${ }^{2}$ ), welches nach dem Tode des Verfassers gedruckt wurde, finden wir zum erstenmale einige Copepoden aus Finland angeführt. Da der Verfasser aber seine Hauptaufmerksamkeit den Cladoceren zuwandte, hat er die Copepoden sehr wenig beachtet. Die ganze Anzahl von diesen beträgt darum auch nur fünf Arten. Diese sind: Cyclops quadricornis Linn.,

1) A. J. Malmgren, Kritisk öfversigt af Finlands Fisk Fauna. Helsingfors 1863. Sid. IX.

Sv. Lovén, Till frảgan om Ishafs faunans fordna utsträckning öfver en del af Nordens fastland. (Öfv. K. Vet. Akad. Förhandl. 1862). Om Östersjön. (Förhandlingar vid de Skandinaviske Naturforskarenes 9:de möte i Stockholm 1863. Stockholm 1868).

2) Notiser ur Sällskapet pro Fauna et Flora fennica förhandlingar X. 1869. 
Diaptomus castor Jurine, Canthocamptus mimutus Müll., Temora velox Lilljb. und Tachidius brevicornis Müll. Von diesen ist die erste eine kollectiv-Art, welche mehrere verschiedene Arten umfasst. Es ist also unmöglich zu sagen, welche von diesen der Verfasser vor sich gehabt hat. Diaptomus castor kommt vielleicht bei uns vor, obwohl ich dieselbe nie gesehen habe, aber muss doch in Landseen viel seltener sein als D. gracilis. Es ist also fraglich, ob Cajander wirklich Diaptomus castor oder Diaptomus gracilis vor sich gehabt hat. Wie wir nunmehr wissen, hat Lilljeborg unter dem Namen Temora velox zwei verschiedene aber nahestehende Arten mit einander verwechselt, so dass er das Männchen der einen und das Weibchen der andern Art beschrieben hat. Diese drei Arten sind also fast unmöglich zu identificieren.

Seit dem Erscheinen von Cajanders Verzeichniss war eine Reihe von Jahren verflossen ohne dass irgend eine Arbeit über unsere Crustacéen erschien, bis ich im Jahre 1884 eine kleine Notiz über neue Fundörter und die Lebensverhältnisse der relicten Malakostraken veröffentlichte ${ }^{1}$ ). Im Jahre 1886 wurde meine „Bidrag till kännedomen om crustacéefaunan i några af mellersta Finlands sjöar" 2) gedruckt, welche sich doch lediglich mit den pelagischen Formen einiger grösseren Seen nämlich Kallavesi, Maaningajärvi, Päijänne und Pielisjärvi beschäftigte. In dieser Arbeit wurden folgende Calaniden besprochen: Diaptomus gracilis G. o. S., Diaptomus laticeps G. O. S., Heterocope appendiculata G. O. S., H. saliens Lilljeb. und Limnocalanus macrurus G. O. Sars. Von diesen muss

1) Nordqvist, Om förekomsten af Ishafscrustacéer i några af mellersta Finlands sjöar. (Medd. af Soc. pro Fauna et Flora fennica, 11. 1884 .

2) Acta Societatis pro Fauna et Flora fennica T. III, N:o 2. 


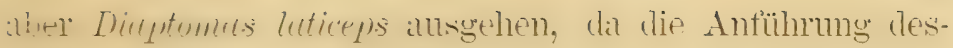
seiben auf' tehlerhafter Bestimmung heruht. Im nächstfolgenden Jilhre veröffentlichte ich eine Abhandlung über hie. Crustalcéfama des Larloga ${ }^{1}$ ) auf Grund dar gemachter [ntersuchungen im Sommer 188.). Von Callaniden habe

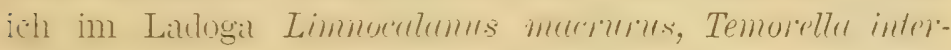
medlia mihi ( $=T$. lacustris Poppe), Diaptomus gracilis

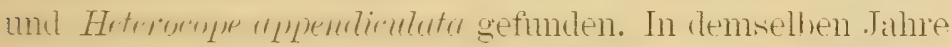
warde anch mein Aufsitz übre lie pelagische mol Tiefsee Filma der grösseren fimnischen Seen ${ }^{2}$ ) gedruckt. Darin warle aluch theilweise der Resultate meiner Lntersuchung Ainer Peihe im nöndlichen Finland liegenter seen erwähnumg yorham. Ton Caliminen hathe ich doch zu den früher von min aufgezählten Arten durch diese Arbeit keine neue hinzugefügt ${ }^{3}$ ).

Dieses ist alles was über die Calaniden Finlands er-

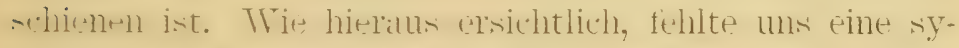
-tematische Bearheitung von Finlinels Crustacéen.

If rine erste Aufgabe warr derum die Calaniden-Fauna Finlanuls festzuntellen. Ich hatte also zu erforschen, welche Arten in unseren Meeren und sïssen Gewässern leben, und ihre Verbreitung daselbst zu bestimmen. Difuses finfache

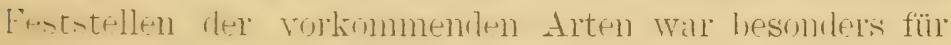
masere Mfere von grosinem Interesse, da die Lehenshedinsungen hiter dureh den geringetl Silzgehalt des TVassers mol ulif klimatischen Verhältnisse - Eishedeckung im Winter; in den waniger tiefen drerestheilen ziemlich hohe

1) Nordqvist, Bidrag till kännedomen om Ladoga sjös crustacéfauna. (Medd. af Soc. pro Fauna et Flora fennica, 14. 1887.

2) Zoologischer Anzeiger 1887 N:o 254 und 255.

$\left.{ }^{3}\right)$ Der daselbst erwähnte Diaptomus laticeps ist nur eine Form vog D. nracilis mit kürzeren Antennen. Siehe unter Diaptomus gracilis. 
Sommertemperatur, in den grossen Tiefen eine niedrige Temperatur das ganze Jahr hindurch - sehr eigenartig sein müssen, also nur für eine geringe Anzahl von Arten geeignet. Dann galt es den Ursprung der verschiedenen Elemente dieser Fauna wo möglich zu verfolgen. Wie bekaunt sind die Meinungen über den Ursprung der Ostsee-Fauna noch streitig. Alle stimmen wohl doch darin überein, dass der grösste Theil (der Meeresformen) dieser Fauna aus der Nordsee stammt. Aber ausser dieser Nordsee Arten finden sich hier noch einige Meeresarten, welche in der Nordsee nicht rorkommen. Von diesen behaupten einige Forscher (Lovén, Malmgren, Möbius u. a.), dass sie in inren gegenwärtigen Fundorten Überbleibsel aus einer 'Zuit sind. wo die Ostsee ein Meerbusen des Eismeeres gewesen wäre, währent antere, die wie Fr. Schmidt, 0. Grimm es für wahricheinlicher halten, dass die Ostsee cin Lantsee war, annehmen diss die genannten Arten durch Flüsse oder anders wie activ oder passiv dahin eigewandert sind.

Ein eingehendes Studium der Calaniden-Fauna unserex Mfece kömnte wahrscheinlich auch einige Aufschlüsse zur Beantwortung dieser Fragen geben.

Wrie lekamnt sind die Calaniden hauptsächlich Meeresbewohner. Sehr bemerkenswerth ist daher, dass gerade solche Theile der Erde, welche nach geologischen und anderen Merkmalen während des posttertiären Zeitalters unter dem Meere versenkt waren, einige Calaniden in ilıren Sünsgewässern bergen, welche in anderen Theilen fehlen. Wie soll man sich dieses und überhaupt das Anpassen der Calaniden an das Leben im Süsswasser denken?

Einige Forscher (Parresi, Imhof, Zacharias) haben in der lotzten Zeit behauntet. dass die eupelagische Fauni 
der Landseen eine Relictenfaunal wäre. Zu dieser Fauna wären dann alle unsere Süsswassercalaniden, nämlich Diç)tomus gracilis. Heterocope appendiculata, H. saliens, T⿰㇒一 morella lacustris und Limnocalamus macrurus zu zählen. Die Zahl der Relictenformen wäre dadurch sehr erweitert. Dies würde aber seinerseits eine beträchtliche Errveiterung des ehemaligen Meeres, ron welchem die Relictenseen Reste sind. fordern. Eine gründliche Prüfung was als Relictenform anzusehen ist, und was nicht, dürfte also sehr wichtig sein.

Kehren wir nun wieder zu den Neeresformen zurück. Die äusseren Lelenshedingungen kömen ausser einem Einfluss auf die Tertreitung der Thiere auch ihre Organisation leeeinflussen. Mögen diese Einflüsse direkt oder inclirekt durch selection wirkell, so ist es immer nothwendig erst festzustellen, ob irgend welche Veränderungen in der Organisation parallel mit den veränderten äusseren Verhältnissen nachweisbar sind, und wenn so ist, welche die Verändernngen sind. Bei der allmählichen Verminderung des salzgehaltes des Wassers ron süden nach Norden bietet die Ostsee und der bottnische Meerbusen eine guimstige Gelegenheit solche Lntersuchungen anzustellen.

\section{Über die Verbreitung der Calaniden in der nördlichen 0stsee.}

In Cajanders Terzeichniss über die im südwestlichen Finland rorkommenden Crustacéen ${ }^{1}$ ) ist nur ein MeeresCalanir nämlich Temora relox Lillj. angeführt (in den Skären ron Abro und Áland), unter welchem Namen er wahr-

1) Cajander, Bidrag etc. p. 876 . 
scheinlich die in diesen Gegenden häufige von mir als Temorella affinis $\imath$. hirundoides bezeichnete Form meint. M. Braun ${ }^{1}$ ) hat auch eine Art hinzugefügt, nämlich Dias discuudutus Ciesbrecht (Revaler Rhede). In dem verzeichniss seiner Crustacéen-Sammlung auf der Fischerei-Ausstellung in London 1883 hat Lilljeborg eine ziemlich grosse Anzahl von Calaniden aus der Ostsee aufgezählt. Da er aber für die meisten von denselben keinen bestimmteren Fundort als „Baltic Stea" angiel)t, kömen von diesen hier nur Temorella affinis $v$. baltica Lillj. ${ }^{2}$ ) (von Dalarö bei stockhohm) und Trmorella hirmulo Giest)r. (Baltic Sea, Golf uf Bottnia"), von welchen also gesagt ist, dass'sie in der nörtlichen Ostsee gefunden worden sind, mitgerechnet werden.

Im Jahre 1886 hat J. de Guerne einen Calaniden centropunges Givimuldii alus dem fimnischen Meerhusen beschrieben. Derselbe ist aber identisch mit dem schon trüher von (i. U. Silrs in den Landseen Norwegens gefundenen Limnocalamus macmurus, was ich schon in meiner Crustacéfauna des Ladoga Sees angegeben habe. In einem anderen von Poucher und de Guerne geschriebenen Auf-

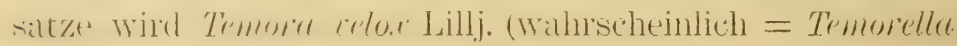
uffinis var. hirundoides $m$.) aus der nördlichen Ostsee erwähnt.

Bis jetzt war also nur Temorella affinis var. baltica, $T$.

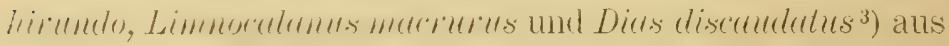
der nörellichen Gstree lekannt. Hicrzu kamn ich folgende Formen hinzufüge'n, nämlich, Centropergess hermatus, Temord

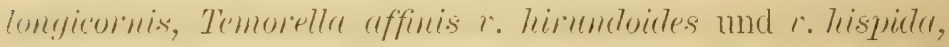

1) M. Braun, Physikal. und biol. Unters., p. 98.

2) Ohne Beschreibung:

3) Von diesen habe ich Temorella hirundo und Dias discaudatus nicht gefunden. 
T. Clansii, Clunsiue elongate, Diass bifitosies und Dies longiiemis.s. Die Gesimmten Zahl von den gegenwärtig aus ler nördlichen Ostsee bekamnten Calaniden-Arten wäre also zehn.

Wenn man dieses Verzeichniss mit dem von Gieshrecht üher die Calaniden der Kieler Foehrde rergleicht, $\therefore$ tindet man, dass kein einziger der letzteren in der nördlichen Ostsee fehlt. Es sind aber doch noch zwei Arten

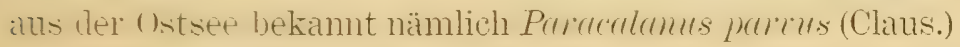
nach Lillelory ${ }^{1}$ ) aus .. Baltic Sea" whe näher angegehenen Fumcurt ume nach Möbius ${ }^{2}$ ) dieselbe Art und Caluuns finmurchirus Gumn. aus der Kieler Foehrde. Dieses Terhalten ist sehl merkwürdig, wenn man den grossen Unterschied im salzgehalt des Wassers, dem wichtigsten Yroment beäiglig der Terhneitung von Meeresthieren, ins Augr falsst. Der Salzgehalt des Wassers ist mämljeh in ter Kieler Foehrde an ler Oherfläche 1,60\% und am Boden 2.06\% \% zwischen den skären östlich von Aland variirt derFilhe zwischen 0,-21 am Borten umel 0,576\% an der Oberflärdhe. In dirsem Dreare kommen noch alle die genannten Arten mit Ansnalnme von Diras discrudratus, welche ich - thist nie bei uns gefunden habe, vor. Dies scheint aher tül die meisten derselloen rer nierlrigsteerträgliche Salzgehallt des Trassel's zu sim. In diessen Skären liegt nämlich

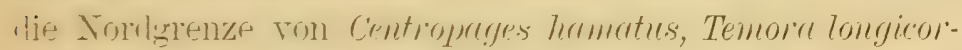
wis, Clansine elomgaten und Dirrs longiremis. Dagegen habe

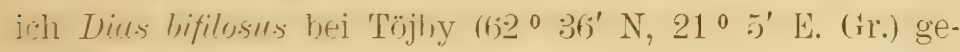
tumlen, wo der Salzgehalt les TVassers nur $0,524 \%$ war.

1) Lilljeborg, W., Collection of chiefly fresh-water Crustacea from Sweden, p. 8.

2) Möbius, Nachtrag zu dem in Jahre 1883 erschienen Verzeichniss der Wirbellosen Thiere der Ostsee. (1884). 
Weiter nördlich kommen nur die Temorella-Arten und Limnocalanus vor. Diese gehen aber bis zum nördlichsten Ende des bottnischen Meerbusens hinauf, wo das Bodenwasser kaum $0,3 \%$ Salz hält, das Oberflächenwasser z. B. bei Malörn (nicht weit von Torneâ) nur $0,15 \%$.

Wenn man also Limnocalanus macrurus, und die Gattung Temorella, welche theilweise auch im Süsswasser leben, ausnimmt, so fordern alle übrigen hier angeführten Arten Wasser von venigstens $0,5 \%$ Salzgehalt.

\section{Über den Ursprung der Calaniden Fauna der 0stsee.}

Woher sind die in der Ostsee lebenden Calaniden dahin gekommen? Darauf hat schon Griesbrecht in seinem wichtigen Werke über die Copepoden der Kieler Foehrde, in Übereinstimmung mit Möbius geantwortet. dass die Ostseefauna ein verarmter Zweig der NordseeFauma ist ${ }^{1}$ ). Die einzigen ron den von Gieshrecht angefülıten Cilluniden welche in der Nordsee nicht gefunden worden sind. sind Temorella hirume und Dias discandatus. Jener steht aber der an den Nordsee-küsten von Popue heschriebenen Temorella affinis sehr nahe, und stammt darum vielleicht auch ursprünglich aus der Nordsee. Ton diesem Meere, kann man auch amnehmen dass Temorella cffuis $x$. himuduides, welche sich von der Stammfurm in dersellsen Richtung aber nicht so viel wie $T$. hitrundo verändert haben, und die Varietät hispida wie auch T. Clunsii in die Ostsee gekommen sind. - Es bleiben

2) Giesbrecht (1. c. p. 92) und Nachtrag pp. 167 und 168. 
noch Dius discaudatus und Limnocalames macmuns übrig, welche in der Nordsee nicht gefunden worden sind. Was Dias disccuudatus anlangt, so ist es nicht unmöglich, dass derselbe in der Nordsee noch gefunden wird. Dagegen ist es höchst unwahrscheinlich, dass eine so characteristische Form wie Limnocalamus unbemerkt geblieben wäre. Man muss also annehmen entweder dass dieselbe sich in der Ostsee oder den Landseen gebildet hat oder auch dass sie wie die übrigen Relictenformen ein Überbleibsel der Eismeer-Fauna ist. Gegen die erste Annahme spricht aber der L'mstand, dass diese Art auch in den Landseen ron Tord-Amerika vorkommt. Es ist daher viel wahrscheinlicher, dass sie sowohl in die Nord-Amerikanischen wie Skandinavischen Seen aus dem Eismeere gekommen sei. Da aber der L'mstand, dass die Eier nicht von rem Weibchen herumgetragen werden, sondern, nach dem Austreten bald auf den Borlen sinken, den passiven Transport durch Tägel sehr unwarscheinlich macht, so bleibt es nur übrig dieselbe als eine Relicteform anzusehen. Einen weiteren Beleg für diese Ansicht findet man auch rarin, dass Limmocrlrmus nie in grösserer Meereshöhe als die übrigen Relictenformen angetroffen wird.

\section{Über den Einfluss der äusseren Existenzbedingun- gen auf den Körper der Calaniden.}

Wie in ler Einleitung schon gesagt wurde, ist es eine bekannte Thatsache, rlass rie äusseren Existenzbelingungen nicht nur eine auswählende sondern auch eine auf rle Körpergrössse und den Bau der Thiere verändernde Thätigheit ausüben. Was speciell die Relictenformen Wer ostsee anbelangt, so hat schon Lovén in seinen Arbei- 
ten über die Relictenfauma nachgewiesen, dass dieselben verkümmert sind. So erreichen z. B. Idotea entoman und Pontoporeia femorata in der Ostsee nie dieselbe Grösse wie im Eismeere. Was die Fische betrifft hat Nalmgren ${ }^{1}$ ) gezeigt, dass die in dem nördlichen Theile der Ostsee heimischen Arten, welche auch im Eismeere vorkommen, ihren Urältern im Eismeere in allen Theilen gleichen, aber kleiner sind.

Man könnte vielleicht hieraus schliessen, dass nur die relicten Arten der Ostsee verkümmert sind, und dass dieses nicht den aus der Nordsee einigewanderten Formen. gilt. So ist es theilweise anch wirklich der Fall, aber nur wenn es sich um Wanderthiere wie z. B. Wanderfische himalelt. Solche Arten wie cottus bubalis, Sprinachio valgaris, Cisbiurs nigyer, Rhombus maximus, Ammodytes lanceoluters und Belone rulguris sind wohl bei uns in grossen Exemplatren gefangen worden, aber sie sind hier mehr zufällige (rïste. Stationäre Arten aber, welche hier schon gamz heimisch geworden sind - wenm auch ursprünglich aus der Norlsee eingewandert - sind gewöhnlich verkümmert. Besmmlers's für dic Mollusken ist eine solche Verkümmerung von Wresten mach Osten und von süden nach Norden nachgewiesen ${ }^{2}$ ) worden.

Für die Crustacéen und speciell für die Calaniden sind nir Aufgaben über die Verkümmerung aber sehr spärlich. Von den Calaniden ist - so viel ich weiss nur Temora longiremis der Kieler Foehrde als eine formal

1) Malmgren, Kritisk öfversigt af Finlands Fiskfauna. Helsingfors 1863, p. VIII u. IX.

2) Vrgl. Möbius, Die wirbellosen Thiere der, Ostsee, p. 138 und M. Braun, Physik. und. biolog. Untersuchungen im westl. Theile des finn. Meeresbusens, p. 129. 
depauperata erwähnt worden. Möbius ${ }^{1}$ ) sagt nämlich, dass sie in der letzgenamnten Foehrde nur die Hälfte der Länge derjenigen von Arendal erreicht.

In der nachstehenden Tabelle habe ich die von mir gemessene Länge der in der nördlichen Ostsee lebenden Calaniden mit den Grössenangaben, welche Giesbrecht ${ }^{2}$ ) für dieselhen Arten aus der Kieler Foehrde, Poppe ${ }^{3}$ ) au, dem Jadebusen und Claus ${ }^{4}$ ) aus der Nordsee gemacht hahen, zusammengestellt. Da der Jadehusen mit der Nordsee übereinstimmt, habe ich beide in der Tabelle unter die Rubrik Nordsee zusammengefasst.

Grösse der Calaniden in der nördlichen Ostsee, Kieler Foehrde und Nordsee ${ }^{5}$ ).

\begin{tabular}{|c|c|c|c|c|}
\hline & & $\begin{array}{l}\text { Nördl. } \\
\text { Ostsee. }\end{array}$ & $\begin{array}{c}\text { Kieler } \\
\text { Foehrde. }\end{array}$ & Nordsee. \\
\hline & & m. m. & m. m. & m. $\mathbf{m}$. \\
\hline Dias bifilosus & 오 ...... & 0,83 & 1,05 & \\
\hline$"$ & $\sigma \ldots .$. & 0,84 & 1,0 & 1,25 \\
\hline$"$ longiremis & ㅇ…... & 0,94 & 1,0 & - \\
\hline$n \quad n$ & $\delta \ldots .$. & 0,89 & 0,9 & 一 \\
\hline Temora longicornis & 우..... & 0,90 & 1,4 & 1,5 \\
\hline$n$ & $\sigma^{\prime} \ldots .$. & 0,96 & 1,4 & 1,3 \\
\hline Temorella affinis & 우.... . & $0,986)$ & - & 1,5 \\
\hline$\cdot n$ & $\delta \ldots .$. & $1,026)$ & - & 1,5 \\
\hline " Clausii & 우 .... & 1,3 & - & 1,5 \\
\hline$n$ & $\delta \ldots .$. & $1,3-1,4$ & - & 1,3 \\
\hline Centropages hamatus & s우..... & 0,91 & 1,45 & 1,6 \\
\hline$n$ & $\delta \ldots .$. & 1,02 & 1,3 & 1,6 \\
\hline
\end{tabular}

$\left.{ }^{1}\right)$ Möbius, Die wirbellosen Thiere der Osttee, p. 138.

2) Giesbrecht, 1. c.

3) Poppe, 1. c.

*) Claus, 1. c. p. 193.

5) Meine Zahlenangaben über die Grösse der Calaniden aus der nördlirhen ()stsee sind Mittelwerthe aus mehreren Messungen.

b) T. affinis $v$. hirundoides. 
Aus dieser Tabelle ersieht man, dass alle Arten, mit Ausnahme von der im brakischen und süssen Wasser lebenden Temorella Clausii, am grössten in der Nordsee sind, etwas kleiner in der Kieler Foehrde und am kleinsten in der nördlichen Ostsee.

Giesbrecht ${ }^{1}$ ) hat die Vermuthung geäussert, dass die als verschiedene Arten beschriebenen, an den Küsten der Nordsee und Ostsee lebenden Temorella-Formen nur durch den verschiedenen Salzgehalt des Wassers entstandene Varietäten lerselben Species wären, hat aber selbst diese Vermuthung willerlegt. Dass Temorella affinis und Temorella Clunsii "gute Arten" sind scheint mir auch ziemlich sicher erwiesen zu sein. Dagegen glaube ich, dass die Terkümmerung von $T$. affinis wie auch der übrigen genamnten Mepres-Calaniden in der Ostsee durch die veränlerten äusseren Verhältnisse - hauptsächlich den geringeren Salzgehalt des Wassers - verursacht sind.

Diese Vermuthung scheint durch folgende Äusserung Giesbrechts widerlegt zu sein: „- - und ferner lehrte mich die Vergleichung des von Herrn Poppe mir übersimdten Materials, dass auch die Thiere von affinis, waren sie nun in Salzwasser des Jadebusens, in der Ems bei P'ettkum, in der Theser bei Waddewarden oder in der Elbe hei Altona gefunlen, keine merklichen Abweichungen aufweisen" 2), Das keine Rassen Unterschiede zwischen den im Silzwasser des Jadebusens und der Nordsce einerseits und im brakischen oder süssen Wasser der obengenamnten Flussmündungen lebenden Thiere andererseits existiert, beruht wohl darauf, dass alle diese Orte sehr nahe bei einander stehen, so dass stets neue Individuen

1) Giesbrecht, 1. c. p. 155.

2) Giesbrecht, 1. c. p. 156. 
ins dem Meere eindringen oder durch die Fluthwelle ein. geführt werilen, und die Entstehung einer eigenen Süssoder Brackwasser-Tarietät somit in den genannten Flussmündungen, deren Areal im Verhältniss zu dem der Nordsee sehr klein ist, verhindert wird. Dieser Umstand konnte aber nicht die Entstehung ron Varietäten in der Ostsee verhindern. Der weite Abstand und die engen Verbindungen wirken isolierend, so dass eine Vermischung nur indirekt durch die Thiere des Sundes und der Belten stattfinden kann. so ist nach meiner Ansicht die Bildung der kleinen Ostsee-Varietäten möglich geworden.

Kehren wir nun zu der Tabelle zurück. Dieselbe zeigt ausser der allgemeinen Terkümmerung der Arten gegen die inneren Theile der Ostsee noch eine andere sehr merkwürdige Thatsache, nämlich, dass die Verkümmerung hei den Weibchen stärkel gewesen ist als bei den Männchen. so dass die Mämnchen, welche geröhnlich kleiner sind als die Weibchen, in der nürdlichen Ostspe im Gegentheil grösser sind ${ }^{1}$ ).

Ausser diesen Veränderungen, welche fast sämmtlivhen Arten gelten, sind die einzelnen Arten nicht selten in irgend einer Weise verändert. So sind z. B. die vordreren Antennen hei Dias bifilosus häufig länger als der Cephalothorax. was sonst nicht der Fall ist, die Furca ist hei Temorella rffinis und Diks hifilosus verhältnissmässig länger tand schmäler, bei c'rntropenge hremetus kürzer.

Schliesslich kann man sagen, dass die in der nördliohen Ostsee lebenden Calaniden seln variabel sind, sowrohl in ihrer Grösse und in den Proportionen der einzelnen Theile wie auch nicht selten in der Behaarung und

1) Eine Ausnahme macht nur Dias longiremis. 
Bedornung. Ich glaube, dass die Bildung der Ostseevaric. täten durch diese allgemeine grosse Variabilität sehr befördert wurde.

Wollen wir nun versuchen den Ursachen der Verkümmerung der Ostsee-Calaniden nachzuspüren. Von den äusseren Einflüssen, welche auf das Wachsthum hemmend wirken, hat man hauptsächlich niedrige Temperatur, mansellhafte Nahrung und für Meeresthiere ungenügenden Salzgehalt des Wassers hervorgehoben.

1) Temperatur. Die nördlichen Theile der Ostsee sind im Winter theilweise mit einer festen Eisclecke oder mit Treilheis hedeckt. Die Temperatur des Wassers muss dam sehr nienlrig, höchstens einige Grade über 0 sein. Auch im sommer ist die Temperatur des Wassers in den grossen Mrepestiefen $(100-300$ m.) nur 2 bis jo Grade C1). An f(x Oherfläche steigt die Temperatur während des Juli und Augusts im offenen Meere bis auf $11-16^{\circ} \mathrm{C}$. In flatchen Meerhusen und an Lfer steigt die Temperatux bis auf $18-20^{\circ}$ C. und mehr.

Die mittlere Jahrestemperatur des Oberflächen-Wassares ist in dem nördlichen Theile der Ostsee etwa $4-5^{0} \mathrm{C}$. in dem sünlichen Theile $8-10^{\circ} \mathrm{C}$. Dieser Untersehied ist zwall zifmlich gross, doch glatule ich nicht, dass die nielrige. Temperatur, irgend rine schmld an der Verkümmerumg der Ustsfe-Calaniden hahen kamn. Dies ersieht man aus den folgenden Thatsachen. In dem Kantalaks Meerbusen des Meissen Meeres habe ich Dias bifilosus massen. haft grefumden. Sie erreicht da eine Grösse von 1,07 mm.

1) Vrgl. Nordquist, Iakttagelser öfver hafsvattnets salthalt wh tomperatur inom Finlands sydvestra skärgard och Bottniska viken, sommaren 1887 (Bidr. t. kännedom. af Finlands natur och folk. $46 \mathrm{H}$. Helsingfor's 1888 ). 
(? und б): wird also grösser als in der Kieler Foehrde, und doch musis die Temperatur im Treissen Meere bedeutend niedriger als die der Kieler Fnehrde sein. Das reiche Thierleben in den arktischen Meeren, welches besonders von den zahlreichen unter Nordenskiölds Leitung unternommenen Expeditionen erwiesen wurde, zeigt auch, class eine niedrige Temperatur auf die Entwickelung einer grossen Anzahl ron Meeresthieren gar nicht hemmend einwirkt.

Der Temperaturwechsel, welcher unvortheilhaft einwirken könnte, ist auch in den tiefen nördlichen und mittleren Theilen der Ostsee geringer als im flachen westlichen Theile. Dif Verkümmernngsursilchen können also nicht in der Temperatur gesucht werden.

2) Nahrung. Da wir bis jetzt sehr wenig über die Jahnung der Calaniden wissen, kamn dieses Moment gegenwärtig noch nicht als ein Bekimntes in Betracht gemommen werlen. Claus sigt wohl1²): .Die Copepoden ernähren sich ron thierischen stuffen, entweder von Theilen abgestrorbener grösiserel 'Thire, orler von kleineren Ge*hoinffien, Infusorim, Rrstifren, Twrollarim, welche sie sich zur Beute machen. Sellst ihre eigenen Larven und Tichkommen verschonen sie nicht, wovon man sich täglich am Darminhalt iler Crelopiden üherzengen kann. Pflanzliche Kärrer: Algen und Diatomacten scheinen nur gelegentlich als Nahrung aufgenommen zu werden." Dies scheint mir aber nicht allgemein gültig zu sein. Ich will nur ein parr Beispiele anführen, welche dagegen sprechen. Während meiner Draggierungen auf dem Bottenmeere im Juli des vergangenen Jahres habe ich in der pelagischen liegion ausser einigen wenigen Diatomacéen nur eine

1) Claus, die freilebenden Copepod. p. 83. 
enorme Menge von Limnocalams macrurus gefunden. Die Diatomacéen waren also hier die einzige Nahrung.

Ein zweites Beispiel. Den 7. Juli fischte ich mit dem schwebnetze im Meere nicht weit von Dalsbruch. Das Netz brachte eine grosse Menge von Dias bifilosus, Ecadne Tordmanni, Diatomacéen und Phycocromalgen wie auch einige wenige Individueen ron Temorella affuis xar. hirmuldides und eine Rotatorie herauf. Die drei „Raubthiere" waren also auch hier fast ausschliesslich auf die Algen als Nahrung hingewiesen.

Hauptsächlich im Winter, wo man keine Rotatorien und Cladoceren findet, muss ihre Nahrung aus Diatomacéen und anderen Algen, die in allen Jahreszeiten vorkummen, lustehen. Wahrscheinlich ist mangelnde uni ungenügenle Nahırung eine ler Verkümmerungsursachen.

3) Salzgehalt des Wassers. Karl Semper hat in seinem an Gedanken und Thatsachen so reichem Werke

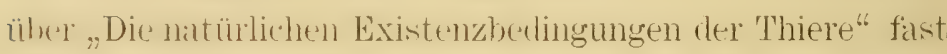
alles bis auf 1879 über den Einfluss des verschiedenen l'roentgehaltes salzigen Wassers atuf die Thiere zusammengestrellt umb ist demmach zu der Schlussfolgerung gelimmmen. .. lass Voränderungen in Salzgehalt des Wassers nivht has rinen aluswählenten Einfluss auf die ihnen ausgersteten 'Thiere ähe:1 müssen, sondern auch mitunter (ine hemerkisworthe Lmformung derselben bewirken"1). Uhmohl lirekte Experimente lis jetzt fehlen und es unhegreitlich ist, warmm dor silggehalt irgend einen Einfluss

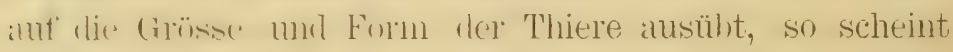

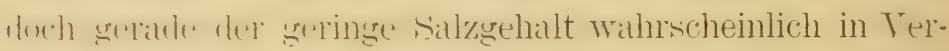
bindung mit Xilnoungsmangel dic Hauptursache der Terkümmerung der Ostsee-Formen zu sein.

2) $\mathrm{Bd}$. I, p. 195 . 
Die Verbreitung der Calaniden in den Landseen Finlands ${ }^{1}$.

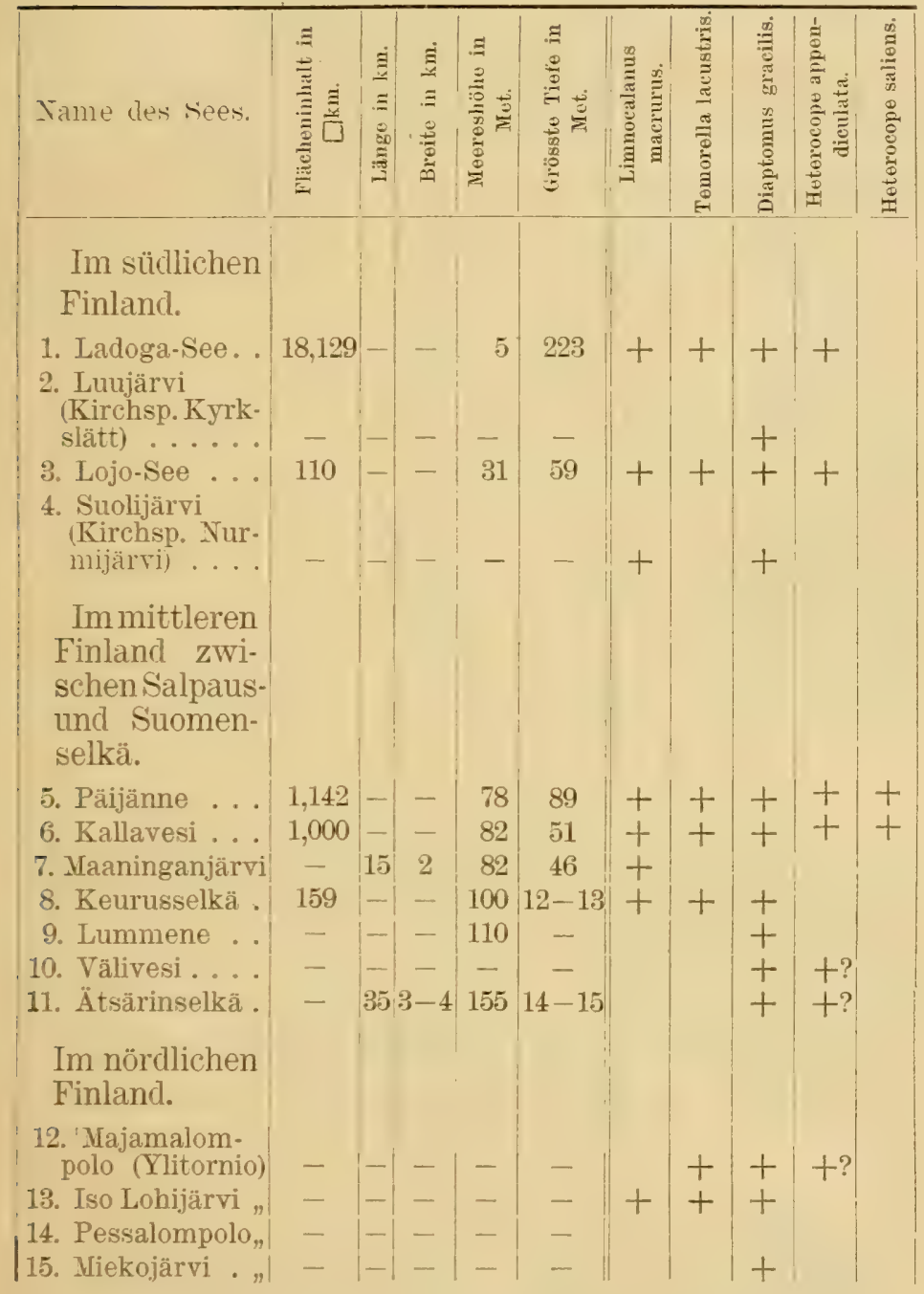

1) Das Material aus dem Lojo-See ist mir theilweise von Eläulein S. Granstedt und Herrn Stud. Ch. E. Boldt gütigst mit- 


\begin{tabular}{|c|c|c|c|c|c|c|c|c|c|c|}
\hline Name des Sees. & 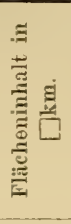 & 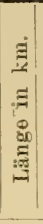 & 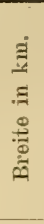 & 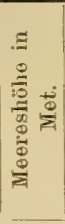 & 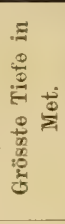 & 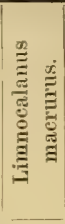 & 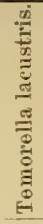 & 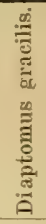 & 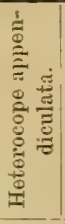 & 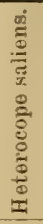 \\
\hline 16. Pääjärvi … & - & -1 & - & 92 & 34 & + & + & + & & \\
\hline $\begin{array}{l}\text { 17. Paanajärvi } \\
\text { (Kuusamo) }\end{array}$ & - & 22 & 1 & 112 & 89 & + & + & + & & \\
\hline $\begin{array}{l}\text { 18. Ylikitka- } \\
\text { järvi }\end{array}$ & 219 & -1 & - & 207 & 29 & & + & + & + & \\
\hline $\begin{array}{l}\text { 19. Kuusamo- } \\
\text { järvi }\end{array}$ & - & $1-$ & - & 224 & 7 & & + & + & & \\
\hline 20. Muojärvi & - & -1 & - & 224 & 36 & & + & + & & \\
\hline 21. Kiitämä & - & -1 & - & - & 4 & & + & + & $+?$ & \\
\hline 22. Suininki & - & -1 & - & - & 25 & & + & & + & \\
\hline 23. Saunajärvi" & - & -1 & - & - & - & & & + & & \\
\hline 24. Pyhäjärvi " & - & $|-|$ & - & 252 & 32 & & + & & & \\
\hline 25. Rukajärvi " & - & -1 & - & -1 & 8 & & & + & & \\
\hline 26. Tavajärvi " & - & - & - & 260 & 7 & & & + & $+?$ & \\
\hline 27. Oijusluoma" & - & - & - & - & 16 & & & + & & \\
\hline $\begin{array}{l}\text { 28. Kurkijärvi " } \\
\text { 29. Teich auf }\end{array}$ & - & - & - & 292 & 18 & & & + & + & \\
\hline Valtavaara " & - & $1-$ & - & 430 & - & & & + & & \\
\hline
\end{tabular}

Aus der vorstehenden Tabelle ersieht man, dass Limumerlumus marrmas ins sürlichen und mittleren Finlank nischt höher als 100 Met. über den Meeresspicgel, im nördlichen Finkand his zu 112 Met. hinatuf getht. Diese Höhen sind ahere gerate dieselluen, bis zu welchen die von Lovén als relicten Formen erkannten Mysis oculato v. re-

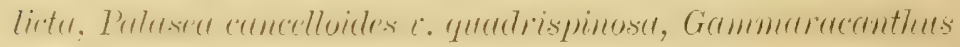
Toricatus und Pontoporeia femorata bei uns gehen. Im

getheilt, das aus den Seen Keurusselkä, Lummene, Välivesi und Ätsärinselkä von Herrn Dr. R. Hult und schliesslich die Sammlungen aus dem Majamalommolo, Iso Lohijärvi. Pessalompolo und Miekojärvi von Fräulein H. Hult. Den genannten Damen und Herren spreche ich hiermit meinen besten Dank aus. 
nördlichen Finland sind diese sogar noch etwas höher gefunden worden, nämlich von Malmngren in dem 122 Met. hoch gelegenen Uleattrïsk. Trem man ferner bedenkt. dass Limnoculamus und die genannten relicten Formen fast dieselbe horizontale Verbreitung haben, und dass Limmoculams mit der im Meere lebenden Gattung Centiopages so mahe rerwandt ist, dass ein hervorragender Forscher. de Guerne, denselben zu dieser cattung geführt hat, so muss man zugeben, dass Limnuratams mit demselben Recht wie Myssis etc. als eine relicte Form betrachtet werden kimm. In zwei früher verüffentlichten Arbeiten halse ich diese Ansicht ausgesprochen. Zu demselben Schlus: ist auch de (rueme ${ }^{1}$ ) unl nach brieflicher Mittheilung Herr Professor Lilljeborg gekommen.

Temorella lacustris hat seine nächsten Verwandten in Temorella affuris und Clansii, zwischen welchen dieselbe in ihrer Organisation steht ${ }^{2}$ ), und welche Meeres- oler Brackwasserformen sind. Durch Poppes Untersuchungen ist es bekamnt, dass T. "fffinis die norddentschen Flüsst hinaufgewandert ist und sich dals Leben im süssen $W_{\text {as- }}$ ser angewöhnt lhit. In ren innersten Theilen des fimniwehen mol bottnischen Ifeerbusens, wo das TVasser schon fast süss ist kommen T. affinis und Clausii noch vor. E. muss für dieselhen also leicht gewesen sein auch wich lem Leben in Limdseen anzupassen, und eine solche für las Leben in Landseen angepalsste form hat sich in $T$.

1) Jules de Guerne, Sur les genres Ectinosoma Boeck et Podin Lilljeborg. ets. IExtrait du Bull. de la Société zoologirque de France 1887), p. 19.

2) Darum habe jch dieselbe in meinem „Bidrag till kännedomen om Ladoga-sjös crustacéfauna" unter dem Namen $T$. intermedia beschrieben. 
lacustris gebildet. Dass sie sogar in so hochgelegenen Seen wie Pyhäjärvi (252 M.), Muojärvi, Kuusamojärvi und Ylikitkajärvi (207 M.) angetroffen wird, kann wahrscheinlich nur durch passiven Transport erklärt werden, denn selbst die Lachse (Salmo salar) können nicht aus dem Weissen Meere durch die steilen Wasserfälle hinauf zu diesen Seen dringen.

Wahrscheinilich ist T. lacustris eine noch sehr junge Art. Dies wird durch ihr ziemlich beschränktes Verbreitungsgebiet und ihr sporadisches Vorkommen bewiesen.

Dagegen muss die Gattung Diaptomus die älteste unter den Süsswassercalaniden sein. Sie hat ein sehr grosses Verbreitungsgebiet und hat schon Zeit gehabt rine Menge von Arten zu erzeugen. Imhof ${ }^{1}$ ) hat vor kurzem die bis jetzt heschriebenen Formen zusammengestellt und gefunden, dass dieselben schon eine Zahl von $26 \mathrm{er}$ reicht haben. Davon sind zwar einige wahrscheinlich als synonyme zu streichen. Dagegen hat seit dem Erscheinen von Imhofs Arbeit J. Richard ${ }^{2}$ ) zwei neue Arten aus Spanien Diaptomus Roubani und Wierzejskii beschrieben. Bei uns in Finland hat Diantomus gracilis fast jeden Landsee bevölkert und wurde von mir noch in dem Teiche auf Valtavaara (430 M.) in Kuusamo gefunden.

Die Gattung Heterocope ist wahrscheinlich auch eine alte Gattung. Ihr sporadisches Auftreten in Mittel-Europa wird dadurch erklärt, dass die Weibchen keine Eiersäckchen tragen, was den Transport erschwert. Von den bei

2) Imhof, Studien über die Fauna hochalpiner Seen ins besonlere des Kantons Graubünden. (Separatabdruck aus dem Jahreshericht der Naturf. Gesellschaft Graubündens, Jahrg. XXX.), s. 137.

2) Extrait du Bulletin de la Société Zoologique de France, T. XIII., séance du 28 février 1888. 
Lins vorkommenden zwei Arten ist $H$. appendiculatu sehr allgemein sowohl in grösseren wie in kleineren Seen bis zu einer Höhe von 292 M. (Kurkijärvi). H. saliens habe ich dagegen nur in Kallavesi und Päijänne gefunden. 


\section{Centropages hamatus, Lilljeborg.}

Ichtyophorlar hamata, Lilljeborg; De crustaceis etc., 1). 185. 1853.

" augustata, Claus, die frei lebenden Copepoden, 1. 199. 1863.

Centroprayes lumutus, Boeck, Ofversigt af Norg. Cop., 1). 244. 1864.

$n \quad$ Giesbrecht, Copepod. d. Kieler
Foehrde, p. 156.
Poppe, Copepod. d. Jadebusens,
p. 187. 1885.

Grösse $0,91 \mathrm{~m} . \mathrm{m}$.

Der Cephalothorax (Taf. I, Fig. 1 u. 3) besteht aus sechs segmenten, rom denen das eriste etwas weniger als dic Hälfte des gamzen C'ephalothorax ausmacht. Die Stim endigt in zwe splitzen; in der Mitte ist das erste Segment rom "innere Furche quergetheilt. Dis letzte unsymmetrisch getilutere segment endigt jederseits in einen Haken ron denender rechte grüsser und nach allssen gerichtet ist ${ }^{1}$ ).

Das Abdomen (Taf. I, Fig. 1 u. 3) besteht aus vier fiegmenten. rom welchen dals erste das längste und etwas länger als die Furca ist. Dis erste Segment ist mit kurzen Borsten oler Dornen besetzt, von denen beiderseits zwei

3) Die beiden von Giesbrecht erwähnten Nebenhäkchen auf dem rehten Haken habe ich chensowenig wie Poppe finden können. 
beisammenstehen und riel grösser als die übrigen sind. Be. sonders sind die zwei Dornen an der rechten Seite stark rntrickelt. Die Geschlechtsöffinung ist von einem grossen Operulum bedekt. Die Furca ist kürzer als die zweei vorhergehenden segmenten zusammengenommen. Ton den Endborsten der Furca ist die zweitinnere, die längste, ein wenig länger als das Abdomen.

Die rorderen Antenmen, welche aus 24 Gliedern bestehen. sind lïnger als der ganze Kürper und ziemlich schlank. Am achten Gliede sitzt ein Dorn.

Die hinteren Antennen bestehen 1) alus einem zweigliedrigen Basale (Protopodit), dessen crstes Glied eine Borste. Was zweitt zwei Borsten trägt: 2) einem zweiärtigen Hauptast (Emlopolit). dessen erstes Glied mit zwei Borsten versehen ist, das zweite mit 14 in zwei Bünrlel vertheilten, unı 3) einem längeren, aus (5 Gliedern zuwammengetzten Nebenast (Exoporit). Von ren Gliederm des Tehmantes trägt das erste zwei Borsten, die vier finlgenten je eine und dats letzte crlied vier lange Borsten.

Die Mandibeln bestehen aus der kräftigen Kaulado rerstes Cilier des Protopodits) und dem Palpus. Am Endr. ist jene verhreitert und in einer Reihe von Zähnchen aussezarkt. Dals ämsserste. von len ülnigen otwas entfernte Zälnn.hen ist grössstl als diese. Nach innen endigt dit Zahmeilu mit einer kleinen Federborste. Der Palpus be. steht ans einem grosien, mit drei kleinen Borsten ausge-atateten Basalglienle (zweites Glied des Protopodits), finem zweigliedrigen und reichlich beborsteten Hauptast (Enrlonenlit, und einem viergliedrigen Nebenast (Exoporrit). If siten thei proximale Glieder je eine Borste, dar vierte Glied zwei Borsten tragen. 
Maxillen. Der Kautheil ist ziemlich gross, gerundet und mit zahlreichen, kurzen, theilweise gezähnten Borsten besetzt. Der Palpus ist in fünf Lappen getheilt, ron welchen der äussere, proximale sehr breit und mit neun Federborsten besetzt ist. Die zwei inneren proximalen Lappen sind cylindrisch und tragen Borsten nur am Ende. Von den zwei distalen Lappen ist der innere zweigliedrig, beide sind mit vielen theilweise langen $\mathrm{Fe}$ derborsten besetzt.

Die vorderen Kieferfüsse sind sehr kräftig gebaut. Auf' dem Hinterrande kann man eine undeutliche Eintheilung in drei Glieder erkennen. Der Vorderrand läuft in fünf mit Federborsten besetzten Warzen aus. Die am Ende des dritten Gliedes sitzenden Borsten sind besonders kräftig, lang, gebogen und mit starken Federn besetzt.

Die hinteren Kieferfïsse (Taf. I, Fig. 4) sind bedeutend länger als die vorderen und siehengliedrig. Das frste und zweite Glied sind beide fist gleich lang und von derselhen Länge wie die fünf distalen Glierler zusam!nengenommen. Das erste Glied hat auf der Vorderseite drei Hökker, von denen der erste zwei, der zweite drei und der dritte vier Borsten trägt. Das zweite Glied trägt drei Borsten, dass dritte vier und die drei folgenden (xlieder je zwei Borsten auf der Vorderseite. Auf der Hinterseite des fünften Glierles sitzt ausserdem noch eine Borste. Das kleine Endglied ist mit vier Borsten besetzt.

Die Schwimmfïsse der vier vorderen Patare hestehen ans pinem zweigliedrigen Basale (Protopodit) und zwei dreigliedrigen Aesten (Endo- und Exopodit).

Die Füsse des fünften Paares (Taf. I, Fig. 8) sind wie die vorhergehenden zweiästig und jeder Ast dreiglie- 
drig. Dals zweite Glied des Aussenaster läuft nach innen in einen Haken aus.

$\sigma$ Grösse 1,02 m. m.

Der Cephalothorax (Taf. I. Fig. 2) besteht wie bei hem Treibchen aus b Segmenten. ron denen das Kopfregment in der Mitte eingeschnürt ist. Das 6. Segment trïgt aluch hier jederseits einen Haken. Diese sind aber hier weniger stark als bei dem Weibchen und gleich gross.

Das Abdomen (Taf. I. Fig. j) besteht aus fünf Segmenten. Die Furca ist ehenso lang wie die zwei ${ }^{1}$ ) rorhergehenden segmente zusammengenommen. Die Furatäste werlen gegen das hintere Ende etwas breiter. Die längste izweitimeley rom den Endhorsten ist fast gleich lang mit dem ganzen Abdomen.

Die vorderen Antennen. Die rechte 21-glienlige Anteme ist zu einem Greitarm ungewandelt und hat eine Genisulation zwischen dem aldehtzehnten und neunzehnten segmente. Dif Biegmukel durchsetzt die $13-18$ sergmenten. Wolche aufigetrieluen sind. Am zwölften und einmulzwanzigsten segmente sitzt ein Dorn. Die linke Antenne ist kürzer als die rechte und wie bei dem Weibchen gebaut.

Das fïnfte Fusspaar (Taff. I, fig. \& u. ఛ). Jedler Fusis besteht alls einem zweigliedrigen stamme und zwei Arsten. Jer Alumenast des rechten Fusses ist zu einer Zange: mingewamblt. dadurch dass das zweite Glied nach immen in einen langen Haken auslïuft, gegen welchen das dritte athoh grogren Glierl beweglich ist. Die Innenäste sinci

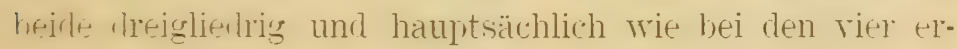

1) Also kürzer als Giesbrecht und Poppe angeben. 
sten Schwimmfusspararen gebaut. Die zwei ersten ihrer Glieder tragen je eine befiederte Borste, das Endglied sechs. Der Aussenast des linken Fusses ist zweigliedrig, das erste Glied trägt zwei Dornen ${ }^{1}$ ) das zweite drei.

Fundort und Fundzeit. Wurle während der ersten Hälfte des Juli in den Skären östlich von Åland öfters, aber immer nur in vereinzelten Individuen gefangen. Dabei waren die Männchen ungefähr 10 mal so zahlreich wie die Weibchen.

1) Nach Poppe nur eine (l. c. p. 191 und Taf. V, Fig. 10). Giesbrecht hat 7wei gezeichnet (1. c. Taf. VII, Fig. 38). 


\section{Limnocalanus macrurus G. V. Sars.}

Limnocalames macmur, Sars, Öfversigt af de indenlandske Ferskvandscopepoder, S. 226.

Centropages Grimaldii, de Guerne, Description du Centropages Grimaldii.

우 Grösse 2,2 mm. (Ladoga), 3,15 (Ålands Haf).

Die Körperform ist langgestreckt aber kräftig.

Der Cephalothorax (Taf. II, Fig. 1) besteht aus 6 Segmenten, von denen las erste gleichlang wie das zweite, dritte und vierte zusammengenommen ist. Jenes ist aut seiner Mitte eingeschnürt und endigt vorn in zwei nach unten unr hinten gehogene spitzen. Der einige feine Härchen tragente Hinterrand des letzten Segmentes ist, wenn won der seite gesehen, gewöhnlich gerundet oder ptwas eckig. Bei einigen wahrscheinlich älteren Individuen habe ich roch denselben in einen kurzen IVulst auslaufen sehen, welcher auf der einen Seite gewöhnlich stärker entwickelt war als auf der anderen.

Das Abdomen (Taf. II, Fig. 1) besteht aus vier Segmenten. Die Furca ist gleichlang wie die zwei vorhergehenden Segmente zusammengenommen. Diese beiden sinrl fast ron rerselben Länge. Das erste Segment ist etwds länger. Die Breite der Furcaaeste verhält sich zur Länge wie $1: 8,3$. Der Hinterrand des zweiten Segmentes und rie Furca sind mit kurzen Dornen von denen 
die des erstgenannten gröber sind, besetzt. Von den Endborsten ist die zweitinnere die längste und ebenso lang wie die drei letzten Abdominalsegmente zusammengenommen. Die erste und vierte Borste sind einander gleichlang und etwas länger als die Furca. Die Aussenborste sitzt auf einem Fünftel der ganzen Furcalänge von der Spitze. Die Innenborste auf der Rückenseite dicht an der inneren Endborste.

Die vorderen Antennen (Taf. II, Fig. 4) sind 25-gliedrig, von denen die zwei ersten am dicksten sind, die folgenden bis zum achten werden allmählich verjüngt, das neunte bis zum zwölften sind ungefähr von derselben Dicke, die übrigen wieder etwas schmäler und bis zum letzten sehr kleincen Segmente gleich dick. Die relative Lünge dèr Glieder kann durch folgente Zahlen ausgedrückt werden:

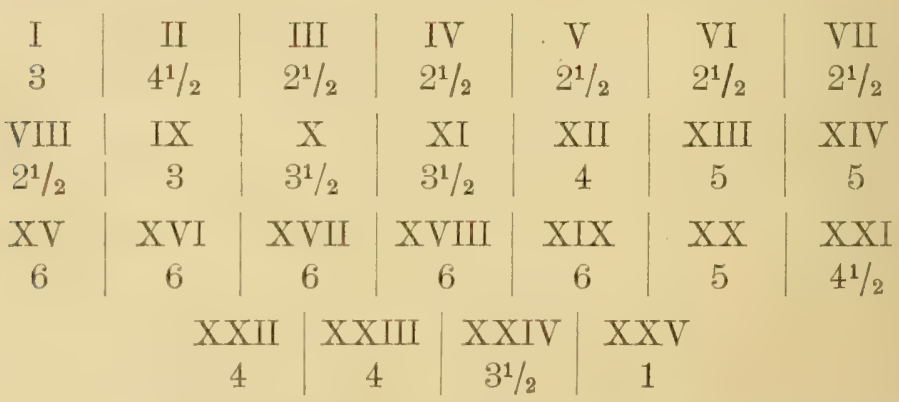

Am achten und zwölften Segmente sitzt ein hakenDorm. $\left.{ }^{1}\right)$

1) Die nahe Verwandtschaft zwischen den Gattungen Centropages und Limnocalanus wird $u$. a. auch von den Dornen an den vorderen Antennen erwiesen. Limnocalanus hat diese Dornen in beiden Geschlechtern, sowohl am achten als am zwölften Gliede. Bei Centropages hamatus haben die Geschlechter sich so differentiert, dass beim Weibchen ein Dorn nur am achten Gliede, beim Männchen nur am zwölften vorhanden ist. 
Mit Ausnahme des 6. Segments tragen alle auf der Torlerseite Borsten, einige auch blasse Kolben. Das 22 -21 Segment hat auch eine Borste am Hinterrande, das kleine Endglied einen Büschel von vier Borsten ${ }^{1}$ ).

Die hinteren Antennen (Taf. I, Fig. 10) tragen auf einem zweigliedrigen Basalstücke, dessen erstes Glied eine Borste, das zweite zwei Borsten trägt, zwei Aeste. Der Hauptast ist zweigliedrig, der Nebenast siebengliedrig, das kurze dritte Glied ist aber mit dem vorhergehenden langen zweiten Gliede verwachsen, so dass die Sutur ziemlich undeutlich ist.

Die Mandibeln (Taf. III, Fig. 1). Die Kaulade hat eine Reihe von kleineren Zähnen und einen isoliert stehenden grossen hakenförmigen Zahn. Nehen jener steht eine Reihe von Dornen, von denen die zwei innersten lang und befiedert sind. Der Palpus ist gross; sein Basale zeigt keine Einschnürungen; der Hauptast ist zwei(oder vielleicht dreigliedrig), der Nebenast fünf- (oder sechsgliedrig).

Die Maxillen (Taf. III, Fig. 2) bestehen aus dem Kautheile, welcher mit starken Hakenborsten besetzt ist, und aus dem Palpus, an welchem man fünf verschiedene Lappen unterscheiden kann.

Der erste Kieferfuss (Taf. II, Fig. 5) ist kurz und gedrungen, Ausserordentlich kräftig sind fünf auf den kurzen und undeutlichen Endsegmenten sitzende lange, hakenförmig gebogene und'stumpfe Borsten.

Der zweite Kieferfuss (Taf. I, Fig. 9) ist sehr lang und besteht aus sieben Segmenten.

Die vier ersten Schwimmfusspaare (Taf. III, Fig. 3)

1) Bei grossen Meeresexemplaren habe ich am Endgliede aus. serdem eine blasse Kolbe gesehen. 
haben einen zweigliedrigen Stamm und zwei dreigliedrige. Aeste.

Die Füsse des fünften Paares (Taf. I, Fig. 11) bestehen wie die vorhergehenden Schwimmfüsse aus einem zweigliedrigem Stamm und zwei dreigliedrigen Aesten. Jedes von den drei Gliedern des Aussenastes trägt auf seiner Aussenseite am distalen Ende einen starken Dorn, das zweite ist nach innen in einen kräftig gebogenen Haken ausgezogen, das Endglied trägt an der Innenseite drei und am Ende zwei Borsten. Das erste und zweite Glied des Innenastes ist am Innenrande mit je einer Borste versehen, das Endglied ist an der Innenseite mit zwei, am Ende mit zwei und an der Aussenseite mit zwei Borsten besetzt.

¿ Grösse 2,07 (Ladoga), 2,78 (Ålands-Haf).

Das Abomen (Taf. II, Fig. 2) besteht aus sechs Segmenten. Die Furea ist ungefähr so lang wie die drei vorhergehenden Sogmente zusammen. Nächst der Furca sind das zweite und dritte Segment die längsten, das fünfte ist das küryteste. Dals zweite, dritte und vierte Segment sind am Hinteramnde mit Dornen besetzt, die Furca mit Stachelhatren. Die Furcahorsten verhalten sich wie beim Weibchen.

Die rechte vordere Antenne (Taf. II, Fig. 3) des Männ(hens ist nur 2o-gliedrig, da die 19-21 Segmente zu einem und dis 2.2. und 2:3. ebenfalls zu einem verschmolzen sind. Das (itelenk liegt zwischen dem 18. und 19. Gliede. Die Biegmuskel des letzteren entspringt am 13. Gliede. Die segmente, welche dieselbe durchsetzt, sind nur wenig alufgetriehen. Die Zahl der hlassen Kolben ist grösser und die Borsten sind länger als beim Weibchen. Wie bei diesem trägt das achte und zwölfte Glied auch bei dem Männchen je einen Dorn. 
Das fïufte Fusspaar (Taf. III, Fig. 4). Beide Füsse bestehen aus einem zweigliedrigen Basale, einem Aussenund einem Innenast. Der Aussenast des rechten Fusses hesteht aus zwei deutlichen und einem kleinen rudimentären Gliede. Das erste Glied ist cylindrisch und trägt aussen einen Dorn. Das zweitebesteht aus einem kurzen und breiten Proximaltheile, von dessen Innenrande ein langer fingerförmiger Auswuchs nach unten ragt. Diesem gegenüber ist nach der Aussenseite des breiten Proximaltheiles eine kleine Warze und das kleine rudimentäre Endglied, welches mit zwei Spitzen endigt ${ }^{1}$ ) - Die zwei ersten Glieder des Innenastes des rechten Fusses tragen je eine Borste am Innenrande, das Endglied ist sowohl am Inmen- und Aussenrande, wie an der Spitze mit je zwei Borsten rersehen. - Das erste Glied des Basales am linken Fuss hat am Innenrande eine kleine Warze. Das erste Gilied des Aussenastes trägt am distalen Ende des Aussenrandes einen Dorn und einen kleinen abgerundeten Vorsprung. Das zweite lange Glied, welches aus dem Zusammenwachsen des zweiten und dritten Gliedes entstanden ist, ist auf der Aussenseite mit drei kürzeren unrl an der Spitze mit einem langen nach Aussen gebogenen Dorne bewaffnet.

Fundort. Limnocalanus macrures ist von mir in folgenden Landseen gefunden worden: Ladoga, Suolijärvi, Lojo-See, Keurussselkä 2), Päijänne, Kallavesi, Maaningajärvi,

1) Der fingerförmige Auswuchs des zweiten Gliedes ist wahrscheinlich mit dem langen Haken des zweiten Gliedes, das kleine rudimentäre Endglied mit dem beweglichen, auch hakenförmigen Endglied von Centropages hamatus homolog und vielleicht aus einer ähnlichen Greifzange entstanden.

2) Die Sammlungen von Keurusselkä verdanke ich meinem Freunde Dr. R. Hult. 
Pielisjärvi, Paanajärvi, Pääjärvi, Kuukaisjärvi, Mossanjärvi und Koutojärvi ${ }^{1}$ ). Von diesen Seen ist Paanajärvi der höchst gelegene (Meereshöhe 112 Meter). Im Finnischen Meerbusen wurde dieser Copepod zum ersten Male von Prinz Albert von Monaco gefunden und von J. de Guerne sehr ausführlich unter dem Namen Centropages Grimaldii beschrieben. Ich habe Limnocalames im Finnischen Meerbusen bei Helsingfors, in den nördlichen Skären zwischen Âland und Finland, im Ålandshaf, im bottnischen See, wo derselbe weiter vom Lande fast allein angetroffen wurde, und im bottnischen Wik. In all den aufyezähiten Seen kommen auch die bekannten Relicten-Arten vor. Diese sind auch in Uleâträsk (Meereshöhe 124 M.) gefunden worden. Darum ist es wahrscheinlich, dass auch Limnocalanus da lebt. Dagegen fehlt derselbe in allen höheren von mir untersuchten Seen. Auch fehlt er in flachen Seen. Ueberhaupt kann man sagen, dass Limnocalanus in Finland in allen mehr als 15-20 Meter tiefen Seen, welche im süllichen und mittleren Finland nicht höher als $100 \mathrm{Me}$ ter und im nördlichen Finland nicht über 125 Meter über dem Meeresspiegel gelegen sind, wahrscheinlich gewöhnlich und massenhaft vorkommt.

Verbreitung. In Schweden ist diese Art nur aus dem Mälarn (Lillj.) bekannt. Aus den hochgelegenen Seen in Ume-Lappmarken, welche Trybom untersucht hat, wird ihrer nicht erwähnt. In Norwegen kommt dieselbe nach G. O. Sars nur in den drei grossen Landseen Mjösen (Meereshöhe 121 Met.), Tyrifjord (Meereshöhe 63 Meter) und Storsjön in Odalen vor. Auch hier kommt sie nicht höher als in Finland vor. findlich.

1) Die vier letzteren im nördlichen russischen Karelen be- 
Aus Europa ist Limnocalanus ausser lem skandinavischen Faunagebiete nicht bekannt. Dagegen wird dieselbe ron S. A. Forbes ${ }^{1}$ ) im Lake Michigan und Geneva Lake, Wise. gefunden.

Fundzeit. Limnocalanus ist von mir zu allen Jahreszeiten gefunden, doch weniger zahlreich im Winter.

Bemerkung. TVie ich in meinen früheren Arbeiten über die Crustacéenfauna der fimnischen Seen gezeigt habe, hommt Limnoculanus am Tage nur ausnahmsweise an der Oberflache vor, und dann nur in vereinzelten Individuen. In Sordavala-Fjort des Ladoga-Sees, war diese Art am 25. Juni um 4--.j L'hr Nachm. ungefähr 12 Meter unter der ()berflïche am zahlreichsten. Von diesem Maximum nahm sie ziemlich gleichmässig nach oben und unten bis zum Boden ab, welcher in einer Tiefe von 25-26 Meter gelegen war. An der Oberfläche fehlte sie fast ganz, war aber ziemlich zahlreich schon 2 Meter unter der Oberfläche, wo sie first in gleich grosser Menge wie 24 Met. unter der Oberfläche gefunden wurde. - Nach de Guerne ${ }^{2}$ ) wurde diese Art ron Prinz Albert Grimaldi von Monaco im fimischen Meerbusen am 8. September 1884, 4 Uhr Nachm., an der Oberfläche im grellen Sonnenschein gefangen, aber nur in wenigen Exemplaren. ${ }^{3}$ )

1) Forbes, The lake as a Microcosm, p. (10).

2) De Guerne, Centropages Grimaldii, p. 10.

3) De Guerne, Sur les genres Ectinosoma Boeck et Podon Lillj., p. 19. 


\section{Clausia elongata, Boeck.}

Clausia elongata, Oversigt over de ved Norges Kyster iakttagne Copepoder, p. 10, 1864.

Lucullus acuspes, Giesbrecht, coped. d. Kieler Foehrde, p. $160,1881$.

Von dieser Art habe ich kein einziges ausgewachsenes Individuum gefunden, warum ich mich dahin beschränken muss ein Abbildung (Taf. III, Fig. 5) von dem jungen Thiere zu geben und nach Giesbrecht die Hauptmerkmale anzuführen.

"Grösse: $\bigcirc$ 1,5 m. m., $\delta 1,25 \mathrm{~m} \cdot \mathrm{m} \cdot{ }^{4}$

„Körperform. Das Oval des Vorderkörpers ist besonders beim 오 sehr regelmässig, bei $\sigma$ erinnert die Form des Vorderleibes durch durch die starke laterale Ausladung der Seitenränder des Kopfes mehr an Centropages".

„Vorderkörper. Die Zahl der völlig freien Brustringe ist in beiden Geschlechtera auf drei reducirt; denn auch beim $\delta$ hat eine Verschmelzung der beiden letzten Ringe statt gefunden, obwohl hier das fünfte Fusspaar wohl entwickelt ist. Die Stirn ist breit, vorne rund und trägt an der ventralen Seite zwei nicht sehr lange Spritzen in beiden (ieschlechtern; ausschliesslich im männlichen dagegen stehen auf der dorsalen Seite der Stirn, und zwar etwa da, wo ihre Profilcontur sich abwärts wendet, vier kurze, nackte, starre Spitzen".

„Hinterlieb. Her Hinterlieb des $\delta$ ist vollzählig gegliedert und besteht aus sechs Segmenten; doch ist, wie bei Dias das vierte, so hier das fünfte Segment ganz verkürzt; das zweite bis vierte Segment sind weit in einander geschoben; ihre längen verhalten sich etwa wie $7: 5: 4$. Die Furkalglieder sino kurz, nich ganz 
doppelt so lang als breit. Das weibliche Abdomen besteht aus fünf Segmenten; das Genitalsegment ist den zwei ersten Segmen. ten des $\delta$ homolog. Das birnförmige Genitalsegment ist das längste, und die drei folgenden werden der Reihe nach kürzer; doch ist das rorletzte Segment, obwohl auch hier das kürzeste, lange nicht in dem Grade verkürzt wie beim $\delta$. Die Furkalglieder des $Q$ sind etwas schlanker als beim $\sigma$. Die Anhänge der Furca sind in beiden Geschlechtern gleich gebildet; die vier befiederten Endborsten von gewöhnlicher Form; die längste ist kaum so lang als das Abdomen. Die äussere Randborste ist dicht an's Ende gerückt und ganz winzig; eine dorsale Furkalborste, die bei den vorher beschriebenen Calaniden regelmässig auftritt und bei Dias sehr stark ausgebildet, ist, fehlt hier völlig; dagegen findet sich auf der Bauchseise, dich am Innenrande, eine dünne gebogene Borste".

"Vordere Antennen. Beim 우 24-, beim o 19-gliedrig. Die weiblichen Antennen reichen angelegt beinahe bis zum Ende der Furca; sie sind in ihrem ganzen Terlauf etwa gleich breit, nur am Grunde etwas verbreitert; die Segmentation ist überall deutlich bis auf die zwischen dem ersten und zweiten Segment. Characteristisch für die Antenne ist die Verlängerung des achten Gliedes auf Kosten des neunten und zehnten und der Borstenbesatz. Die Borsten sind im ganzen sehr kurz, nur an einzelnen Segmenten sitzen constant merklich längere Borsten an, nämlich am dritten, siebenten achten. dreizehnten, siehenzehnten, zwanzigsten und den drei letzten Segmenten".

"Ein sehr characteristisches Ansehen hat die männliche Antenne im ganzen und Einzelnen. An das aufgetriebene, aus zwei Segmenten verschmolzene Basale setzt sich einem Bogen, den die folgenden fünf kürzern Segmente bilden, die immer geradlinig gestreckte distale Hälfte der antennen an, das of pflegt die Antennen so zu halten, dass diese Hälfte mit der Längsaxe des Körpers etwa einen halben Rechten hildet. Das VII Segment ist lang und ist dem achten bis elften des of homolog; die noch folgenden Segmente gleichen ungefähr denem beim f, doch zeigt sich noch eine Abweichung darin, dass das neunzehnte und zwanzigste segment zum XV verschmolzen sind. Die Borsten sind kürzer als heim Weibchen, mit Ausnahme der am II Segmente; die Borsten 
an den Segmenten II, IX, XIIT, XV die den obengenannten des ? homolog sind, sind auch hier länger als die andern. Den wichtigsten Unterschied von den weiblichen Antennen haben wir aber in den blassen Schläuchen, die den proximalen Theil der männlichen Antenne bekränzen. Diese Schläuche sind ziemlich dick und lang und nach der Ventralseite des Thieres hin übergebogen. Das erste Segment trägt deren vier, die folgenden fünf abwechselnd zwei und einen, das lange siebente Segment einen kürzern Schlauch, und schliesslich sitzt noch einer am Ende der letzten Segmen. tes an".

„Schwimmfüisse. Erstes bis viertes Paar. Ausser der bedeutend gestreckteren Form der männlichen Schwimmfüsse und der theilweisen Verkümmerung der Dornen am Aussenrande des Aussenastes am ersten Paare des o, finden sich hier keine geschlecht lichen Unterschiede. Die Aussenäste sind überall dreigliedrig, die Innenäste eingliedrig am ersten Paar, zweigliedrig am zweiten Paar und dreigliedrig am dritten und vierten Paare. Am Ende der Aussenäste des zweiten bis vierten Paares sitzen Sägen mit weitläufigen, spitzen Zähnen; dieselben werden am ersten Paare durch eine Fiederborste ersetzt. Am Ende des Innenrandes des zweiten Basale am ersten Paare findet sich auch hier eine Borste, die wie bei Hulitmora seschweift und auf der proximalen seite mit langen Fiedern versehen ist. In Vertheilung und Zahl der Fiederborsten zeigt das zweite bis vierte Paar keine Abweichungen".

Fünftes Fusspaar. Beim Weihchen ist keine Spur desselben vorhanden. Beim ơ besteht dasselbe aus zwei langen, dünnen viergliedrigen Atsten. Der rechte Ast läuft in eine Scharfe Spitze aus: der linke dagegen verjüngt sich gegen das Ende weniger stark und trägt am Ende einen kleinen Haken mit verdickter Basis, der vielleicht als fünftes Segment anzusehen ist". -

Fundort und Fundzeit. Ich habe diese Art ziemlich häufig im Juli in Alands Meer und im Meere zwischen den Alands Inseln und dem finnischen Festlande gefunden. Auch habe ich dieselbe im finnischen Meerbusen bei Helsingfors im December Monat gefischt, aber wie gesagt 
immer mur junge Individuen ${ }^{1}$ ). In April und Mai habe ich sie bei Helsingfors nicht gesehen. - Nach Giesbrecht soll Clunsia elongata in der Kieler Foehrde in grösster Menge im Februar auftreten und dann allmählich verschwinden, erst die Männchen die schon in April selten sind, und dann auch die Weibchen, so dass man sie nach dem Juni nur selten findet. Wenn unsere Art dieselbe wie die in der Kieler Foehrde auftretende ist, so hat sie die Zeit für ihr Auftreten in dem nördlichen Theile der Ostsee verändert.

1) Ich habe anfangs gedacht, dass die Individuen nur stark verkümmert wären. Da ich aber nie ein Nännchen mit ausgebildeten Greif-Antenne und fünften Fusspaar oder ein Weibchen mit Eiersäckchen gesehen habe, muss ich diese Vermuthung aufgeben. 


\section{Temora longicornis. F. 0. Müller.}

Cyclops longicornis, O. F. Müller, Entomostraca, p. 115, 1785.

Temora finmarchica, Baird, Brit. Entom., p. 228, 1850.

Claus, Freilebende Cop., p. 195, 1863.

" longicornis, Boeck, Overs., p. 239, 1864.

" " Giesbrecht, Cop. dər Kieler Foehrde, p. 149, 1881.

Poppe, Cop. d. Jadebusens, p. 176, 1885.

Länge $0,75 \mathrm{~m} . \mathrm{m}$. , grösste Breite $0,25 \mathrm{~m} . \mathrm{m}$.

Die Körperform (Taf. IV, Fig. 1) ist ziemlich plump und die grösste Breite befindet sich an der Mitte des Kopfsegmentes.

Der Cephalothorax. Die Länge des Kopfsegmentes verhält sich zur länge des ganzen Cephalothorax wie 1:2. Am kürzesten sind das dritte und vierte Segment, welche fast gleich lang sind. Von dem zweiten Segmente an verjüngt sich der Cephalothorax allmählich nach hinten, so dass der hintere bogenförmig ausgeschnittene Rand des fünften Segmentes nur wenig breiter als das Abdomen ist. Von der Seite gesehen ist dasselbe Segment abgerundet.

Das Abdomen besteht aus vier Segmenten, von denen die Furca etwas länger als die zwei vorhergehenden Seg- 
mente zusammengenommen, das erste unbedeutend länger als das dritte und dieses doppelt so lang wie das zweite Segment ist. Das erste Segment ist an den Seiten nicht eingeschnürt und zeigt somit nicht Spuren der Zusammenwachsung aus zwei Segmenten, wie bei der Gattung Temorella. Die Furcaäste sind von einander weit abstehend und mit einander parallel. Die Zweitinnere Borste ist in ihrem basalen Theil aufgetrieben.

Die vorderen Antennen sind 24 gliedrig und reichen bis zur Basis der Furca.

Erster Kieferfuss ist kurz und gedrungen, der zweite langgestreckt.

Schwimmfuisse. Der Innenast ist zweigliedrig der Aussenast am ersten Fusse (Taf. III, Fig. 6) dreigliedrig, an den folgenden zweigliedrig.

Die Füsse des fïnften Paares (Taf. IV, Fig. 4) sind einfach und dreigliedrig. Am zweiten Gliede sitzt eine Borste an der hinteren Seite. Das dritte Glied trägt einen Dorn auf der vorderen und einen auf der hinteren Seite nebst zwei Enddornen.

б Grösse: $0,96 \mathrm{~m} . \mathrm{m}$.

Der Cephalothorax (Taf. IV, Fig. 2) ist gebaut wie bei dem Weibchen aber weniger plump.

Das Abdomen (Taf. $T$, Fig. 2 u. 3) besteht aus 6 Segmenten. Die Länge der Furca verhält sich zu dem ülorigen Abdomen wie $1: 1$, ă4. Die Furcaäste sind nicht ron einander so weit entfernt wie bei dem Weibchen. Die Endborsten sind länger als bei diesem.

Die vorderen Antennen. Die linke ist wie bei dem Weibchen gebaut. Die rechte (Taf. III, Fig. 9) besteht aus 21 Segmenten und hat zwischen dem 18ten und 19ten Segment ein Gelenk. Das 13te bis 18te Segment sind von 
einer starken Biegmuskel durchsetzt und aufgetrieben; aber nicht so viel wie bei der Gattung Temorella. Die vordere Seite der meisten Segmente ist mit Borsten und blassen Kolben besetzt ${ }^{1}$ ).

Schwimmfrisse. Der Innenast ist zweigliedrig, der Aussenast an allen Füssen dreigliedrig, also nicht wie bei dem Weibchen.

Das fïnfte Fnsspaar (Taf. III, Fig. 7 u. 8). Die Füsse sind einästig und bestehen aus vier Gliedern. Die Basalglieder der beiden Füsse sind theilweise mit einander zusammengewachsen. Das zweite Glied des linken Fusses hat einen langen und dünnen fingerförmigen Fortsatz nach imnen, welcher zusammen mit dem dritten und vierten (alierl eine Zange bildet. Das dritte Glied trägt an der Aussenseite einen Dorn, das vierte Glied endigt mit zwei ungleich langen Dormen und trägt ausserdem einige ganz kleine Dörnchen. Das zweite Glied des rechten Fusses trägt auf der Innenseite eine weiche Warze veränderlicher Form, auf dem distalen Ende einen Stachel. - Das dritte (ilied ist hakenförmig gelogen und trägt an seinem Ende das kleine Endglied.

Fundort und Fundzeit. Wurde auf mehreren Stellen bisweilen in grosser Zahl, im Meere zwischen Aland und dem finnischen Festlande, wie auch im Ålands Meer während der ersten Hälfte von Juli gefunden.

Die Länge des Männchens ist etwas grösser als die des Weibchens. Nach den Angaben von sowohl Giesbrecht wie Poppe soll aber das Weibchen grösser sein. Die Ver-

1) Das erste und zweite Glied tragen je eine blasse Kolbe, das erste Glied ausserdem eine Borste, das zweite zwei Borsten, wie es Giesbrecht dargestellt hat. Da dieselben aber an den Inneren seite gelegen sind, habe ich sie beim Zeichnen der Fig. nicht gesehen. 
gleichung beider Geschlechter von unseren Exemplare zeigt, dass der Cephalothorax fast dieselbe Länge hat; dagegen ist das Abdomen des Männchens bedeutend Länger als bei dem Weibchen. Der Cephalothorax verhält sich zum Abdomen bei dem Weibchen wie 100:60, bei dem Männchen wie $100: 77$. Durch eine ähnliche Messung von Giesbrechts Figuren habe ich gefunden dass dieselben Körpertheile sich da wie 100:50 (\$) und 100:70 (б) rerhalten. Also ist das Abdomen bei dem nordbaltischen Exemplaren relativ grösser als bei der Kieler Form, der Cephalothorax hat sich also stärker vermindert als das Abdomen. In beiden Geschlechtern ist die Furca verhältnissmässig kürzer als bei den Kieler- und Nordseexemplaren. 


\section{Temorella, Claus.}

Temorella, Claus, Über die Gattungen Temora und Temorella, 1881.

Eurytemora, Giesbriecht, Die freilebenden Cop. d. Kieler Foehrde, p. 152, 1881.

Die Gattung Temorella unterscheidet sich von $\mathrm{Te}^{-}$ morcl hauptsächlich durch folgenden Merkmale. Der Cephalothorax besteht aus 6 Segmenten. Bei allen den von mir untersuchten Formen ist der Hinterrand des Kopfsegmentes an der Rückseite mehr oder weniger aufgetrieben. Das letzte Brustsegment besteht bei dem Weibchen ans drei Theilen, einem Mittelstück und zwei Lateraltheile, welche letztere gewöhnlich flügelartig ausgezogen sind ${ }^{1}$ ). Das Mittelstück ist sehr verïnderlich und fehlt nicht selten. Das erste Abdominalsegment des Wejbchens ist Eingreschmürt. Die vorderen Antennen reichen nicht über den Hinterrand des Cephalothorax und sind in dem proximalen Theile ziemlich dick. Bei dem Weibchen verjüngen sie sich allmählich gegen das Ende. Bei dem Männchen hat die rechte Antenne zwischen den 18ten und 19ten

1) Diese Flügel scheinen eine Blase zu enthalten. Wahrscheinlich ist sie mit irgend welcher leichter Flüssigkeit erfüllt um somit das Tragen der Eiersäcke, wie durch Schwimmblasen, zu erleichtern. Damit würde erklärt sein, warum solche flügelartige Auswächse nur bei den Weibchen, und zwar bei solchen Arten, welche Eiersäcke tragen, vorkommen. 
Segmente ein Gelenk. Das 13-18 Segment, welche von der Biegmuskel durchsetzt sind, sind viel stärker angeschwollen als bei Temora. Der zweite Kieferfuss ist kürzer als bei dieser Gattung. Der Innenast des ersten Fusspaares ist eingliedrig (bei Temora zweigliedrig). Auf dem fünften Fusspaare des Weibchens ist das vorletzte Glied in einen kräftigen Fortsatz verlängert, welcher bei Temora entweder fehlt oder nur von einem kleinen Dorn vertreten ist. Auf demselben Fusspaare des Männchens fehlt dem zweiten Gliede des linken Fusses der kennzeichnende lange Fortsatz von Temorc und auch sonst sind diese Füsse ganz anders gebaut.

Bemerkung. Bei T. himundo soll das Mittelstück des letzten Brustsegmentes nach Giesbrecht ${ }^{1}$ ) fehlen. T. affinis $r$. hispida entbehrt es auch. Bei T. affunis v. himuncloides habe ich es bisweilen ziemlich deutlich von dem ersten Abdominalsegment ahgegrenzt, bisweilen aber mit demselben zusammengeschmolzen, gefunden. Bei T. Clansii soll es nach Poppe ${ }^{2}$ ) vorhanden sein; nach Liljeborg ${ }^{3}$ ) ist es unter dem vorhergehenden Segmente versteckt. Ich selbst habe es bei dieser Art nicht sehen können. Am deutlichsten ist das Mittelstück bei T. lacustris entwickelt.

1) Giesbrecht, 1. c. p. 152.

2) Poppe, 1. c. Tab. IV, Fig. 1.

3) Liljeborg, De crustaceis etc., p. 180. 


\section{Temorella affinis Poppe var. hirundoides $n$.}

\section{오 Grösse $0,98 \mathrm{~m}$. m.}

Die Körperform (Taf. IV, Fig. 5) ist lang und schlank. Die grösste Breite des Körpers verhält sich zur ganzen Körperlänge $=1: 4,4$.

Der Cephalothorax (Taf. IV, Fig. 5, 7, 8, 9, 10 u. 11). Die lateralen Theile des letzten Segmentes sind spitz oder abgerundet und tragen an ihrem Ende einen oder zwei feine Dorne. - Die Länge des ersten Segmentes verhält sich zur ganzen Länge des Cephalothorax wie 1 zu $2,2-2,3$.

Das Abdomen (Taf. IV, Fig. 7 u. 8) besteht aus vier Sementen, von denen das erste, in der Mitte gewöhnlich scharf eingebuchtet und in seiner zweiten Hälfte schmäler ist. - Die erste lreite Hälfte dieses Segmentes trägt jederseits zwei kleine Dornen. Die Geschlechtsöffnung ist von einem triangulären Operculum (Taf. IV, Fig. 6) bedeckt. Das dritte Segment ist, wie die Furcaglieder, auf der Rückenseite, mit einer Menge von Dornen besetzt. Die Innenränder der Furcaglieder tragen in ihrer ganzen Länge einen feinen Wimperbesatz und ebenso der Theil des Aussenrandes, welcher hinter der Randborste liegt. Die Länge der Furca verhält sich zu derselhen der drei vorhergehenden Abdominalsegmente wie $1: 1,2-1,4, \mathrm{zu}$ der ganzen Körperlänge wie $1: 5,5-5,7$, die Breite der Furcaglieder zu ihrer Länge wie 1:8-12. Die Rand- 
borste ist etwa auf ein Viertel der ganzen Furcalänge von der Spitze der Furca entfernt. Von den Endborsten ist die zweitinnere am längsten, unbedeutend kürzer ist die dritte, dann kommt die erste und schliesslich die vierte. Überhaupt ist der Längenunterschied zwischen den verschiedenen Borsten sehr klein. Alle diese sowohl Randwie Endborsten sind befiedert. Auf dem Rücken sitzt zwischen der ersten und zweiten Borste eine kleine nackte Borste.

Die vorderen Antennen sind 24 gliedrig und erreichen nicht den Hinterrand des Cephalothorax. Das dritte bis fünfte Glied sind am breitesten, von wo an die Antennen sich allmählich nach dem Ende hin verjüngen. Alle Glieder sind auf der vorderen Seite beborstet, das 22 te und 23te tragen auch am Innenrande eine Borste.

Das fünfte Fusspaar (Taf. IV, Fig. 10) besteht aus einem ungegliederten Basalstücke, auf welchem jederseits ein einfacher dreigliedriger Ast steht. Das erste Glied trägt am Aussenrande eine Borste; das zweite ist nach innen in einen starken, spitzen glatten Fortsatz ausgezogen und trägt am Aussenrande zwei grosse und einen ganz kleinen Dorn ${ }^{1}$ ); das dritte kleine und ovale Glied endigt mit einem langen Dorn und trägt nach aussen von diesem einen anderen kürzeren.

$\delta$ Grösse $1,02 \mathrm{~m}$. m.

Der Cephalothorax unterscheidet sich von denselben des Weibchens durch das letzte Segment, welches nicht flügelartig verlängert sondern viel kürzer und abgerundet ist.

Das Abdomen besteht aus sechs Segmenten. Die

1) Diesen letzten konnte ich erst nach langem Suchen mit Zeiss Ocul. 2, Object. E. finden. 
Länge der Furca verhält sich zu derselben des übrigen Abdomens wie 1 : 1,3-1,6, zur ganzen Körperlänge wie 1 : 5,4-5,6, die Breite der Furcaäste zu ihrer Länge wie $1: 13$.

Die vordere rechte Antenne (Taf. VI, Fig. 3). Das 13-18 Segment ist stark aufgetrieben. Das letzte (20ste) Segment ist sehr lang. Die Glieder 8-12 tragen je einen Dorn, von denen der des 8. und 10. Segmentes der kleinste, der am 12. der grösste ist.

Das fünfte Fusspaar (Taf. V, Fig. õ) stimmt mit (ler von Poppe gegebenen Zeichnung ${ }^{1}$ ) überein, nur die kleinen Dorne auf dem Basalgliede sind von ihm nicht erwähnt worden. Auch ist der Dorn am zweiten Gliede des rechten Fusses bei unserer Form von einer kleinen Warze ersetzt.

Fundort und Fundzeit. Diese Varietät habe ich in allen Jahreszeiten und nicht selten massenhaft an unseren Küsten bei Helsingfors, im Skärenmeere, im Ålandshaf und im bottnischen Meerbusen bis zum nördlichen Ende desselben? gefunden. Nördlich von Qvarken ist sie nebst einer Bosmina die Hauptmasse der pelagischen Thierwelt.

Wie aus der Vergleichung der hier gegebenen Besichreibung und der Abbildungen mit denjenigen Poppes ${ }^{2}$ ) hervorgeht, unterscheidet sich diese Form von der von Poppe beschriebenen hauptsächlich durch ihre Kleinheit, schlankere Körperform und verhältnissmässig längerer und schmälerer Furca. Durch den zwei letzteren Eigenschaften nähert sich die Varietät hirundoides zu Giesbrechts T. himudo. Die flügelartigen Lateraltheile des letzten Thoracalsegmentes des Weibchens sind variabel,

1) Poppe 1. c. Taf. VI, Fig. 26.

2) Poppe 1. c. p. Tab. VI, Fig. $22-28$. 
bisweilen spitz ausgezogen, bisweilen mehr oder weniger abgerundet. Sie wechseln also in ihrer Form zwischen T. affinis Poppe und T. hirundo Giesbrecht. Die Bedornung derselben ist auch nicht ganz konstant. Die meisten Exemplare tragen auf dem genannten Theil nur je einen Dorn. Doch habe ich auch Individuen mit je zwei Dornen gesehn. Das dritte Glied des fünften Fusspaares bei dem Weibchen trägt auf der Aussenseite ausser den zwei grösseren Dornen noch einen dritten ganz kleinen, wie es auch Poppe gezeichnet hat. Dieser soll nach Giesbrecht bei T. himudo fehlen. Der Bau des fünften Fusspaares des Männchens scheint in der Bedornung wie auch in der Form einiger Segmenten etwas variabel zu sein. so habe ich den Dorn am Innenrande des zweiten Segmentes des rechten Fussen bei einigen Individuen gesehen, bei andern nicht. Diese Vergleichung zeigt dass $T$. "ffinis $x$. hirundoides eine Zwichenform zwischen T. affinis Poppe und T. hirundo Giesbr. ist Dies wird vielleicht deutlicher aus nachstehender Tabelle hervorgehen.

Sehr merkwürdig ist der Umstand, dass die extreme Form T. hirundo örtlich zwichen den beiden einander nä. her stehenden Formen eingeschoben ist. Vielleicht wird las dadurch erklärt, dass die Verbindung zwischen der Nordsee und Ostsee durch den Bälten und dem Sunde jüngeren Datums ist, während die alte Verbindung viel nördlicher, über die grossen schwedischen Seen Wenern und Wettern ging. 


\begin{tabular}{|c|c|c|c|}
\hline & $\begin{array}{l}\text { Temorella } \\
\text { affinis Poppe. }\end{array}$ & $\begin{array}{c}\text { Temorella } \\
\text { affinis } v . \\
\text { hirundoides. }\end{array}$ & $\begin{array}{l}\text { Temorella } \\
\text { hirundo. }\end{array}$ \\
\hline Grösse & $\frac{q}{\delta} 1,5 \mathrm{~m} . \mathrm{m}$. & $\begin{array}{lll}\text { 우 } & 0,98 \mathrm{~m} . \mathrm{m} \\
\text { o } & 1,02 \mathrm{~m} . \mathrm{m}\end{array}$ & $\begin{array}{llll}\text { ㅇ. } & 1,4 & \mathrm{~m} & \mathrm{~m} . \\
\delta & 1,2 & \mathrm{~m} . & \mathrm{m} .\end{array}$ \\
\hline $\begin{array}{l}\text { Verhältniss der } \\
\text { Länge zur } \\
\text { grössten Breite. }\end{array}$ & $\begin{array}{ll}7 & 3: 1 . \\
0 & 3,75: 1 .\end{array}$ & $\begin{array}{c}\text { 우 } 4,4: 1 . \\
-\end{array}$ & $\begin{array}{l}\text { 오 } 4,8: 1 \\
\text { 의 } 5: 1\end{array}$ \\
\hline $\begin{array}{l}\text { Lateraltheile } \\
\text { des letzten } \\
\text { Thoracalseg. } \\
\text { mentes des ㅇ․ }\end{array}$ & $\begin{array}{l}\text { In einen zulau- } \\
\text { fenden Flügel } \\
\text { jederseits ver- } \\
\text { längert und an } \\
\text { seinem Ende ei- } \\
\text { nen feinen Dorn } \\
\text { tragend. }\end{array}$ & $\begin{array}{l}\text { Die Flügel ent- } \\
\text { weder Spitz wie } \\
\text { bei affinis oder } \\
\text { abgerundet, mit } \\
\text { einen oder zwei } \\
\text { feinen Dornen. }\end{array}$ & $\begin{array}{l}\text { Weniger stark } \\
\text { verlängert, an- } \\
\text { liegend und ab- } \\
\text { gerundet, mit } \\
\text { einigen weni- } \\
\text { gen kleinen } \\
\text { Härchen. }\end{array}$ \\
\hline $\begin{array}{l}\text { Verhältniss der } \\
\text { länge der Fur- } \\
\text { caglieder zuder } \\
\text { des übrigen Ab- } \\
\text { domens. }\end{array}$ & $\begin{array}{l}\text { 오 } 1: 1,5 . \\
\text { 이 } 1: 21 / 7\end{array}$ & $\begin{array}{l}\text { 와 } 1: 1,2-1,4 \\
\text { o } 1: 1,1,3-1,6 .\end{array}$ & $\mid \begin{array}{ll}\text { 우 } & 1: 1 \\
0 & 1: 1\end{array}$ \\
\hline $\begin{array}{l}\text { Verhältniss der } \\
\text { Furcalänge zur } \\
\text { Körperlänge. }\end{array}$ & $\begin{array}{l}\text { 우 } 1: 6 . \\
\text { d } 1: 6 \frac{1}{2} .\end{array}$ & $\begin{array}{l}\text { 요 } 1: 5,5-5,7 \\
\text { o } 1: 5,4-5,6\end{array}$ & 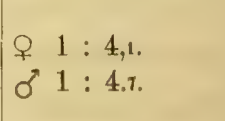 \\
\hline
\end{tabular}




\section{Temorella affinis Poppe var. hispida $\mathrm{n}$.}

우 Grösse $1,38 \mathrm{~m}$. m.

Körperform. Die grösste Breite verhält sich zur Länge wie $1: 4,3$, ist somit fast dieselbe wie bei $T$. affnis $v$. hirundoides.

Cephalothorax (Taf. V, Fig. 1 u. 10). Das letzte Segment besteht nur aus den zwei lateralen Flügeln, deren hintere Ecke spitz ausgezogen ist. Von der Seite gesehen ist der Oberrand der Flügel S-formig gekrümmt, häufig noch mehr als die Tafel V, Fig. 10 es zeigt. Dieses Segment ist mit kurzen Haaren besetzt, und auch die übrigen Segmente sind hie und da da mit solchen Härchen versehen.

Abdomen (Taf. V, Fig. 1). Das erste, in der Mitte eingebuchtete Segment trägt auf seiner unteren Seite ein ireieckiges Operculum vulvae wie $T$. affinis Poppe und car. himundoicles und ist mit einigen Dornen und kurzen Haaren besetzt. Das dritte Segment und die Furca sind auf der Dorsalseite dicht bedornt. Die Länge der Furca verhält sich zu derselben des übrigen Abdomens wie 1:1,9, zur ganzen Körperlänge wie 1 : 6,7. Die Breite der Furcaäste verhält sich zu ihrer Länge wie $1: 6,6$.

Das fünfte Fusspaar (Taf. VI, Fig. 5) stimmt ganz mit demselben der beiden übrigen Formen dieser Ar überein.

రे Grösse $1,2 \mathrm{~m}$. m. 
Abdomen. Die Furca ist etwas länger als die drei vorhergehenden Segmente zusammengenommen. Ihre Länge verhält sich zu der der vorhergehenden fünf Abdominalsegmente wie $1: 1,55$, zur ganzen Körperlänge wie $1: 6,0$, und die Breite der Äste zu ihrer Länge wie $1: 6,7$.

Die rechte vordere Antenne (Taf. VI, Fig. 4) stimmt am meisten mit derselben von $T$. affinis Poppe überein, ist aber sowohl an der vorderen, wie auch an der hinteren Seite mit kurzen, steifen Härchen, wie es die Fig. zeigt, versehen.

Das fünfte Fusspaar (Taf. V, Fig. 6 u. 7). Das Basalglied des linken Fusses trägt an der Innenseite einen stumpfen Fortsatz, wie T. hirundo. Die Glieder dieses Fusses sind verhältnissmässig länger und schmäler als bei den übrigen Formen dieser Gattung.

Fundort. Wurde von mir am Ufer bei Korpo (in den Skären von Åbo) den 4 Juli 1887 gefunden. 


\section{Temorella lacustris, Poppe.}

Temorella lacustris, Poppe, Beschreibung einiger neuer Entomostraken aus norddeutschen Seen p. 278, 1886.

" intermedia, Nordqvist, Bidrag till kännedomen om Ladoga sjös crustacéfauna, p. $132,1887$.

오 Grösse $1,1 \mathrm{~m} . \mathrm{m}$.

Die Körperform (Taf. VI, Fig. 1) ist ziemlich robust. Der Cephalothorax (Taf. VI, Fig. 1). Die grösste Breite befindet sich am hinteren Theile des ersten Segmentes. Nach hinten wird der Cephalothorax nur wenig verjüngt. Das letzte Thoracalsegment ist darum viel breiter als das Abdomen und seine Hinterecken sind - wenn das Thier von oben gesehen wird - von dem ersten Abdominalsegment weit abstehend, ziemlich spitz aber nicht ausgezogen oder nach aussen gebogen und mit einem feinen Dorn ausgestattet. Die Länge des ersten Segmentes verhält sich zu den ganzen Cephalothorax wie $1: 2,3$.

Das Abdomen (Taf. VI, Fig. 1) besteht aus vier Segmenten, von denen das zweite das kürzeste ist, während das erste und dritte fast gleich lang sind. Der vordere Theil des ersten Segmentes ist nur wenig aufgetrieben. Das Operculum vulvae ist halbmondförmig (nicht triangu- 
lär). Auf keinem Abdominalsegmente sind Dornen zu finden. Die Innenränder der Furca sind mit einer Reihe von feinen Haaren versehen. Die Länge der Furca verhält sich zu der der übrigen Abdominalsegmente wie $1: 1,7$, zu der ganzen Körperlänge wie $1: 6,7$.

Die vorderen Antennen sind 28-gliedrig, dadurch dass die achten und neunten Segmente verschmolzen sind.

Das fünfte Fusspaar (Taf. V, Fig. 4) gleicht in Gliederung und Form demselben der übrigen Arten. Das erste Glied des Aussenastes ist auf der Aussenseite mit einer Borste versehen; das zweite hat zwei Dornen auf derselhen Seite und ist nach innen wie die übrigen Arten in einen starken, spitzen Fortsatz ausgezogen, welcher hier auf der distalen Seite mit einer Reihe von feinen Dornen hesetzt ist. Das. Endglied stimmt mit demselben der übrigen Arten überein.

ơ Grösse $1,3 \mathrm{~m} . \mathrm{m}$.

Die Körperform ist viel schlanker als bei dem Weibchen.

Der Cephalothorax. Die Länge des ersten Seginentes verhält sich zu derselben des ganzen Cephalothorax wie $1: 2,1$. Der Dorsalrand des genannten Segmentes ist etwas vor der Mitte eingebuchtet, der Hinterrand aufgetrieben. Der Hinterrand des letzten Segmentes ist, ron der Seite gesehen, abgerundet. - Dornen fehlen.

Das Abdomen. Die Länge der Furca verhält sich zu der der vorhergehenden fünf Abdominalsegmente wie $1: 2,7$, zu der ganzen Körperlänge wie $1: 6$, die Breite der Furcaäste zu ihrer Länge wie 1:9. - Dornen fehlen. 
Die rechite vordere Antenne (Taf. VI, Fig. 2) ist hauptsächlich wie bei den übrigen Arten gebaut. Doch ist die Auftreibung der Glieder 13-18 weniger bedeutend als bei T. Clausii aber grösser als bei T. affinis v. hirundoides. Die Glieder 8-12, welche schmäler als die vorhergehenden sind, tragen je einen Dorn, von denen der auf dem 12. Gliede der grösste, der des 9. Gliedes ein wenig kürzer und der des 12. und 11. Gliedes der kleinste ist. Auch die linke Antenne hat die Glieder 8-12 schmäler als die vorhergehenden, wodurch dieselbe sich von der weiblichen Antenne unterscheidet.

Das fünfte Fusspaar (Taf. VI, Fig. 9). Beide Füsse sind viergliedrig, stimmen aber sonst am meisten mit denselben von T. Clausii überein.

Fundort. Diese Art, welche sehr nahe zu Temorella affinis steht und wahrscheinlich auch daraus hervorgegangen ist, scheint in einer grossen Zahl von den Landseen Finlands zu leben. Ich habe sie im Ladoga, Lojo-see ${ }^{1}$, Päijänne, Kallavesi, Kuusamojärvi, Muojärvi, Pyhäjärvi (in Kuusamo), Kitkajärvi Kiitämä und Suininki gefunden. Da dieselbe auch in den fünf letztgenannten hochgelegenen Seen (207-252 Meter Meereshöhe), welche sich aller Wahrscheinlichkeit nach nicht unter dem Meere befunden haben, lebt, so ist sie nicht in diesen Seen relict, sondern muss dahin allmählich verschleppt worden sein.

Fundzeit. Ist von mir nur im Sommer gefunden.

Bemerkung. Diese Art ist wie es auch Poppe bemerkt - sehr durchsichtig. Diese Durchsichtigkeit scheint eine Folge seines Aufenthaltes im süssen Wasser zu sein. Die Meerescopepoden - wenn auch im Wasser

1) Von Herrn Stud. Ch. E. Boldt gefischt. 
ron sehr geringer Salzgehalt lebend - sind immer viel weniger durchsichtig als die Süsswasserarten. Dieser Unterschied ist besonders auffallend bei Limnocalanus macrurus, welcher sowohl im süssen wie im salzigen Wasser lebt. 


\section{Temorella Clausii Hoeck.}

Temora velox \& Liljeborg, De crustaceis etc. p. 177, 1853. Cyclopsine lacimulata Fischer, Beitr. z. Kenntn. d. in die Umgebung von P:burg sich find. Cyclopiden, p. 86, 1853.

Temora Clausii Hoek, Vrijlevende Zoetwater-Copepod., p. 23, 1876 (nach Poppe).

Temorella Clausii Claus, Gattung Temora u. Temorella, p. 490, 1881.

ㅇ Grösse 1,3 m. m.. grösste Breite $0,4 \mathrm{~m}$. m.

Die Körperform ist plumper als bei den vorhergehenden Arten.

Der Cephalothorax. Das letzte Segment ist charakteristisch durch seine nach aussen gekrümmte lateralen Flügel, welche mit einigen spärlichen Härchen besetzt sind.

Das Abdomen (Taf. VI, Fig. 6). Von den Abdominalsegmenten ist die Furca die längste, darauf folgt, der Länge nach gerechnet, das dritte Segment, dann das erste und schliesslich das zweite, welches fast halb so lang wie die Furca ist. Die Länge der Furca verhält sich zur Länge des übrigen Abdomens wie 1:2,2, zur ganzen Körperlänge wie 1:8, zur Breite der Furca wie 5:1. Die auf der unteren Seite des ersten Segmentes gelegene Geschlechtsöffnung ist von einem halbmondförmigen Operculum bedeckt. Auf den zwei ersten Segmenten habe 
ich keine: Haare gefunden, auf dem dritten sitzen einige spärliche Härchen; die Furca ist dicht behaart. Die äussere befiederte Seitenborste' sitzt am zweiten Drittel der Furca. Von den vier auch befiederten Endborsten sind flie drei äusseren fast gleich lang, die innere etwas kürzer. Auf der Rückseite sitzt zwischen der ersten und zweiten Endborste (von innen gerechnet) eine kleine nackte Borste.

Die vorderen Antennen sind 24 -gliedrig und reichen, wenn nach hinten gestreckt, bis zum hinteren Ende des Cephalothorax.

Das fünfte Fusspaar (Taf. VI, Fig. 6). Die Füsse sind jederseits gleich gebaut und viergliedrig. Das zweite Glied trägt an der Aussenseite eine lange Borste, das dritte einen Dorn, und ist nach innen in einen ähnlichen Fortsatz wie bei den übrigen Arten ausgezogen. Die distale Seite dieses Fortsatzes ist mit kleinen Dörnchen besetzt. Das vierte Glied endigt auch hier mit einem inneren langen Stachel und einem äusseren kurzen Dorn.

$\delta$ Grösse $1,3-1,4 \mathrm{~m}$. m.

Die Körperform ist schlanker als bei dem Weibchen, die grösste Breite verhält sich zur ganzen Körperlänge wie $1: 7,5$.

Der Cephalothorax. Die Länge des ersten Kopfsegmentes verhält sich zu dem ganzen Cephalothorax wie 1 : 2,2. Das letzte Segment ist ausgezogen in nach aussen gekrümmte Flügel, welche mit mehreren Borsten besetzt sind.

Das Abdomen (Taf. VI, Fig. 7). Die Länge der Furca verhält sich zu der der vorhergehenden fünf Abdominalsegmente wie $1: 2,0-2,4$, zur ganzen Körperlänge wie 1:7,5, lie Breite der Furcaäste zu ihrer Länge wie $1: 7$. Diese 
sind nur an der Innenseite mit Haaren besetzt. Sowohl die Endborsten wie die Seitenborste sind gefiedert. Von den ersteren ist die zweitinnere die längste und so lang wie die zwei bis drei letzten Abdomialsegmente zusammen. dann folgt die dritte, erste und schliesslich die rierte. Die Seitenborste ist unbedeutend kürzer als die letztgenannte, übertriftt aber die Furca an Länge.

Die vorderen Antennen. Die rechte Antenne ist zwanziggliedrig und wie bei den übrigen Arten gebaut, aber viel dicker und gedrungener. Nach den dicken siehen ersten Gliedern folgen fünf schmälere. Die vordere Seite der von der Biegmuskel durchsetzten Glieder, besonders der 15 - 17 sind stark angeschwollen. Das achte, neunte und zwölfte Glied tragen je einen Dorn. - Die linke Antenne ist wie die Antennen des Weibchens gehaut. unterscheidet sich aher auch hier durch die schmäleren 8-12 Glieder.

Das fünfte Fusspaar (Taf. V. Fig. 8). Der rechte Fuss desselben unterscheidet sich von dem der vorhergehenden Arten dadurch, dass das lange Endglied hier in zwei getheilt ist, wodurch der Fuss fünfgliedrig wird. Der linke Fuss ist wie bei den übrigen Arten viergliedrig. Die Form des letzten Gliedes ist wie bei diesen, sehr reränderlich, selbst bei demselben Individuum. Der distale Theil dieses Gliedes, welches wahrscheinlich als ein ursprünglich fünftes Glied zu betrachten ist, ist gewöhnlich mehr oder weniger drreieckig mit einer Ausbuchtung auf seiner distalen Fläche. - Bei einem Männchen, welches ich während der Begattung auf das Objectglas legte, war dieser distale Theil des vierten Gliedes birnenförmig angeschwollen (Taf. VI, Fig. 8). An seiner vorderen Fläche rlicht über der Spitze war ein Spermatophor angeklebt. 
Fundort und Fondzeit. Wurde im finnischen Meerbusen bei Kirjola (Kirchsp. St. Johannes) nicht weit von Wiborg und auf mehreren Stellen im bottnischen Meerbusen wie bei Kristinestad, Töjbyträsk ${ }^{1}$ ) und bei Karlö im Sommer gefunden. Wahrscheinlich kommt T. Clausii überall an Finlands Küsten vor in flachen Buchten und in Strandpfützen, wo das Wasser kaum merklich salzig ist.

3) Ein kleiner flacher Sumpfsee am Ufer des bottnischen Meerbusens. Im Anfange dieses Jahrhunderts soll derselbe noch eine Bucht des Meeres gewesen sein. 


\section{Heterocope G. O. Sars.}

Heterocope, Sars. Overs. af de indenlandske Ferskwandscopepod, p. 220, 1863.

Der Cephalothorax besteht aus sechs Segmenten, von denen doch immer die zwei letzten deutlich von einander getrennt sind. Die Stirn ist abgerundet und es laufen keine Fortsätze aus. Der Kopf ist durch eine Furche in zwei Theile abgeschnürt. ${ }^{1}$ ) Das letzte Thoraxsegment verjüngt sich nach hinten, so dass sein Hinterrand dem Abdomen ziemlich dicht anliegt. Das Abdomen besteht hei dem Weibchen aus 4, bei dem Männchen aus 6 Seg. menten. Die Furcaäste sind kurz, höchstens zwei Mal so lang wie breit. Von den Furcaborsten fehlt die äussere Seitenborste immer. Die äusserste Endborste mangelt entweder ganz oder ist kurz, höchstens $1 \frac{1}{2}$ Mal so lang wie breit, und unbefidert. Dagegen sind die drei inneren

1) Diese beiden Theile werden von Sars als zwei Segmente aufgefasst, so dass er die Zahl der Segmente auf 7 angiebt (1. c. p. 220). Gruber sagt, dass bei $H$. saliens "die Zahl der freien Thoracalsegmente beträgt vier" (I. s. p. 5). Dieses ist für $H$. saliens richtig, da gerade bei dieser Art die Zusammenschmelzung der zwei letzten Thoracalsegmente am weitesten gegangen ist. Bei genauer Untersuchung kann man aber auch hier die Zusammen. schmelzungslinie erkennen. 
Endborsten lang, kräftig und befiedert und haben die Spitzen hakenförmig nach unten gebogen ${ }^{1}$ ).

Die vorderen Antennen sind lang und bestehen aus 25 Gliedern. Diese tragen auf der Vorderseite Borsten und blasse Kolben. Das 10. Glied entbehrt immer beide. Das zweitletzte Glied trägt auf der Hinterseite zwei oder drei, das drittletzte eine lange befiederte Borste. - Die rechte vordere Antenne des Männchens hat eine Genikulation zwischen dem 18. und 19. Gliede. Die vorhergehenden sechs Segmente, durch welche die Biegmuskel geht, sind kaum merklich aufgeschwollen. Die vorderen Kieferfüsse sind kurz und gedrungen, siebengliedrig; die hinteren viel länger und sechsgliedrig. Die Schwimmfüsse haben einen dreigliedrigen Aussenast und einen eingliedrigen Innenast. Die Füsse des fünften Paares sind einästig und bestehen aus drei Gliedern, von welchen die zwei ersten am Aussenrande je einen Dorn, das dritte am Aussenrande zwei, am Innenrande vier Dornen trägt und mit einem langen gekrümmten Stachel endigt. Das fünfte Fusspaar des Männchens ist unsymmetrisch ausgebildet. Der rechte Fuss ist dreigliedrig, der linke viergliedrig und mit einem langen gebogenen, vom zweiten Gliede ausgehenden Fortsatz ${ }^{3}$ ) versehen.

1) Sars Genusbeschreibung: Rami caudales ... setis modo 3 majoribus uniarticulatis et ciliatis setaque alia tennuissima intus adfixa praediti" ist nicht ganz |richtig. Bei $H$. saliens ist nämlich die äussere Endborste, obwohl ziemlich kurz, vorhanden.

2) Merkwürdigerweise ist hier der linke Fuss stärker entwickelt als der rechte. Sonst ist es gewöhnlich bei den Calaniden umgekehrt. Dieser Umstand hat wahrscheinlich Sars zur Verwechselung des linken und rechten Fusses geführt (1. c. p. 221). Dagegen hat sie. Gruber (l. c. p. 7) richtig erkannt.

$\left.{ }^{3}\right)$ Bei jungen Individuen $\nabla$ on,$H$. saliens kann man eine 
Bis jetzt sind drei Arten von der Gattung Heterocope bekannt: $H$. appendiculata G. O. Sars, H. saliens Lillj. und $H$. alpina G. O. Sars. Alle aus den süssen Gewässern von Europa ${ }^{1}$ ).

Dreigliederung dieses Fortsatzes erkennen. Dieser Umstand, wie auch, dass derselbe rom zweiten Gliede des Protopodits ausgeht, betreisen, dass dieser Fortsatz nicht wie ähnliche Bildungen bei Centropages, Limnocalanus, und Temora ein dornartiger Fortsatz ist, sondern der veränderte Innenast.

1) Dazu kommt noch wahrscheinlich die von Seb. Fischer beschriebene Cyclopsine borealis aus dem Taimyrflusse und Boganida im nördlichen Sibirien (Middendorff, Reise in den äussersten Norden und Osten Sibiriens. B. II. Theil 1. St. Petersburg 1851). 


\section{Heterocope appendiculata G. O. Sars.}

Heterocope appendiculata, Sars, Overs. af de indenlendske Ferskvandscopepoder. S. 224, 1863.

† Grösse $2 \mathrm{~m}$. m.

Die Körperform (Taf. VII, Fig. 1) ist viel schlanker als bei $H$. saliens.

Der Cephalothorax (Taf. VII, Fig. 1). Am breitesten ist der Kopftheil, von welchem an sich der Körper allmälich nach hinten verjüngt. Das letzte Brustsegment, welches von dem vorhergehenden nur undeutlich abgegliedert ist, ist am Hinterrande fast ebenso breit wie das erste Abdominalsegment.

Das Abdomen (Taf. VII, Fig. 5) besteht aus vier Segmenten, von welchen das erste das längste ist, darnach folgt das dritte, dann das vierte (die Furca) und schliesslich das zweite. Das erste Segment trägt vor der Geschlechtsüffnung eine Reihe von 8 Anhängen, von denen die zwei lateralen, zweilappigen die grössten sind. Nach innen ron diesen folgt jederseits ein dreigelappter und innerst vier einfache Anhänge. Die Furcaäste sind kurz, weniger als zweimal so lang wie breit und in einer geraden Linie abgeschnitten. Äussere Seitenborsten fehlen. Von den Endborsten sind nur drei vorhanden. Diese sind aber gefiedert und sehr kräftig. Auf der Dorsalseite am Innenrande sitzt eine winzige ungegliederte Borste. 
Die vorderen Antennen (Taf. VII, Fig. 2) sind von der Körperlänge.

Das fünfte Fusspaar (Taf. VII, Fig. 3) ist von der in der Gattungsbeschreibung gegebenen Form. Der lange Endstachel ist auf dem distalen Theile der Hinterseite gezähnt.

o Grösse $1,8 \mathrm{~m}$. m.

Das Abdomen. Von den fünf Segmenten desselben ist das vierte am längsten.

Die vorderen Antennen. Die rechte Antenne (Taf: VII, Fig. 4) besteht aus 23 Gliedern, doch ist die Gliederung zwischen dem 20. und 21, wie auch zwischen dem 22. und 23. Gliede nicht so deutlich wie zwischen den übrigen ${ }^{1}$ ). Das 17., 18. und 19. Glied tragen auf der Vorderseite gerade oder etwas gekrümmte dornartige Fortsätze. Die linke Antenne ist wie die weibliche gebaut.

Das fiufte Fusspaar (Taf. VII, Fig. 6) Der rechte Fuss ist dreigliedrig. Die zwei ersten Glieder sind kurz, das (rritte lang, mit einer Auftreibung auf der Innenseite und einer kleinen Grube an dem Ende. Der linke Fuss ist viergliedrig. Das zweite Glied läuft nach Innen in einen langen gehogenen Fortsatz aus. Das dritte Glied trägt auf der Innenseite eine kleine Warze. Das vierte Glied ist lang, endigt mit einem Stachel und trägt auf der Aussenseite drei Dornen.

Fundort. Im Kallavesi ist diese eine von den gewöhnlichsten Arten und kommt öfters in grosser Menge vor. Im Päijänne habe ich einige Individuen aus Sauselkä, im Ladoga See nur ein Exemplar (б) in 56-64

1) Sowohl Sars wie Gruber geben 22 als die Zahl der Glieder an. Es scheint mir aber, dass das letzte Paar von Segmenten nicht weniger zusammen gewachsen ist als das vorhergehende, so dass man auch diese trennen muss. 
Meter Tiefe, 2-3 Kilomet. nach S von Kexholm (17. Juni) gefunden. Häufig in Yli Kitkajärvi, Kiitämä, Suininki.

Aufenthalt. Lebt hauptsächlich in grösseren Seen, welche doch nicht immer tief seen müssen. So habe ich denselben in Kiitämä gefunden, wo die grösste Tiefe nur 4 Meter ist.

Fundzeit. Wurde nur im Sommer und Herbst gefunden. Im Winter und Frühjahr habe ich sie vergebens gesucht. Sie scheint also wie die Cladoceren zum Winter auszusterben und im Sommer aus Dauereiern sich wieder zu entwickeln. 


\section{Heterocope saliens Lilljeborg.}

Diaptomus saliens, Lilljeborg, Två Crustaceer af ordningen Ostracoda o. Copepoda, p. 395.

Heterocope robusta, Sars, Overs. af de indenlandske Ferskwandscopepoder, p. 225.

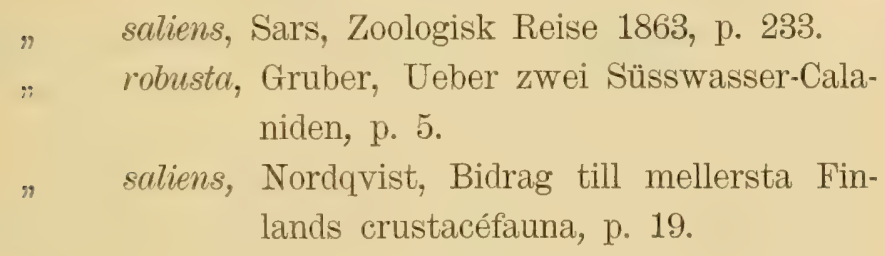

ㅇ Grösse $2,5 \mathrm{~m} . \mathrm{m}$.

Die Körperform (Taf. VII, Fig. 1) ist sehr dick und kräftig.

Der Cephalothorax (Taf. VIII, Fig. 1). Die Verschmelzung der zwei letzten Thoraxsegmente ist so weit gegangen, dass man die Verschmelzungslinie kaum sehen kann.

Das Abdomen (Taf. VIII, Fig. 1 u. 2). Das erste Segment ist das längste, dann folgt das dritte und vierte, welche unter einander gleich lang sind, und schliesslich das zweite. Die Geschlechtsöffnung an der unteren Seite des ersten Segmentes ist von einem breiten, in zwei Zapfen auslaufenden Operculum bedeckt (Taf. VIII, Fig. 5). Die Furcaäste werden von der Basis nach dem Ende breiter. Auch sind sie im Verhältniss zu ihrer Länge breiter als bei $H$. appendiculata. Von den vier Endborsten ist die äusserste kurz - bei einigen Individuen bis $1 \frac{1}{2}$ Mal so 
lang wie die Furca, bei anderen kürzer als diese und unbefiedert. Die drei inneren Endborsten sind dagegen stark entwickelt und kräftig.

Die vorderen Antennen (Taf. VIII, Fig. 1) sind viel kürzer als die ganze Körperlänge.

Das fünfte Fusspaar (Taf. VIII, Fig. 4) ist gebaut wie bei $H$. appendiculata. Der lange Endstachel ist nicht auf der Hinterseite gezähnt, sondern rundherum auf dem distalen Theile mit kleinen Dornen besetzt.

б Grösse 2,4 m. m.

Das Abdomen. Nach ihrer Länge geordnet, müssen die Segmente in folgender Ordnung aufgezählt werden: 2. (das längste), 3., 1., 6., 5. und 4. (das kürzeste). Die Furcaborsten sind wie bei dem Weibchen. Die zweitinnere Endborste (die längste) ist ungefähr so lang wie die fünf letzten Abdominalsegmente zusammengenommen.

Die vorderen Antennen sind wie bei $H$. appendiculata gebaut.

Das fünfte Fusspaar (Taf. VIII, Fig. 3). Der rechte Fuss ist kurz, einästig und dreigliedrig. Das dritte Glied ist mit drei Dornen bewaffnet. Der linke Fuss ist viergliedrig. Von seinem zweiten Gliede geht ein gebogener Fortsatz nach innen, auf den man drei undeutliche Glieder unterscheiden kamn. Das zweite und dritte Glied trägt auf der Aussenseite je einen Dorn; das vierte trägt daselbst drei Dornen und endigt mit einem langen bedornten Stachel. Die Innenseite dieses Gliedes ist theilweise behaart.

Fundort. In Kallavesi und Päijänne kommt $H$. saliens nicht selten, aber nur in vereinzelten Exemplaren, vor.

Fundzeit. Wie die vorhergehende Art nur im Sommer gefunden. 


\section{Diaptomus gracilis G. O. Sars.}

Diaptomus gracilis, Sars, Overs. af de indenlenske Ferskwandscopep., p. 218, 1863.

" $\quad$ Gruber, Ueber zwei Süsswasser-Calaniden, p. 11, 1878.

q. Grösse $0,90-1,08 \mathrm{~m}$. m.

Der Cephalothorax (Taf. IX, Fig. 1) besteht aus sechs Segmenten, von denen das Kopfsegment durch eine Rinne quergetheilt ist. Die grösste Breite befindet sich in der Mitte am zweiten Segment, von wo der Cephalothorax sich nach vorne und hinten zu allmälich verjüngt. Die Stirn ist in zwei nach unten und hinten, gebogenen Fortsätzen verlängert. Das letzte Segment ist fast rectangulär und viel breiter als das erste Abdominalsegment. Sein Hinterrand trägt jederseits zwei Dornen. Diese sind aber nicht symmetrisch gestellt.

Das Abdomen (Taf. IX, Fig. 2) besteht aus vier Segmenten, von denen das erste so lang wie die übrigen zusammen ist und in seinem vorderen breiteren Theil jederseits in einem Dorne ausläuft. Das zweite Segment ist das kürzeste. Die Furca ist von der Länge des vorhergehenden Segmentes. Die vier Endborsten und die äussere Seitenborste sind befiedert, und bei dem vollentwickelten Weibchen fächerartig ausgebreitet und mit ihren 
Spitzen stark nach unten gebogen ${ }^{1}$ ). Die kleine innere Seitenborste ist unbefiedert.

Die vorderen Antennen (Taf. IX, Fig. 3) sind 25-gliedrig und sehr schlank. Thre Länge ist etwas veränderlich. Bei einigen Individuen ragen sie, wenn zurückgestreckt, weit über die Endborsten der Furca, bei anderen haben sie kaum mehr als die Körperlänge. Auf der Vorderseite sind alle Glieder mit einer oder zwei Borsten versehen. Von diesen sind die auf den 11., 13., 14., 16., 18., 21. und 24. Gliede am längsten. Auf der Hinterseite tragen das 22., 23. und 24. Glied je eine Borste. Das 25. Glied trägt vier lange befiederte Borsten. Das 8. und 12. Glied ist ausserdem mit je einem Dorn bewaffnet.

Die hinteren Antennen bestehen aus einem zweigliedrigen Basalstücke, einen zweigliedrigen Hauptast und einem siebengliedrigen Nebenast.

Die vorderen Kieferfiisse sind kurz.

Die hinteren Kieferfiisse sind langgestreckt und siebengliedrig.

Die Schwimmfïsse. Der Aussenast ist dreigliedrig, der Innenast am ersten Fusspaare zweigliedrig, an den drei folgenden Paaren dreigliedrig.

Das fünfte Fusspaar (Taf. IX, Fig. 4). Das erste Basalglied ist gross und trägt auf der Hinterseite einen starken Dorn. Das zweite Basalglied ist klein und entbehrt Borsten und Dornen. Der Aussenast ist dreigliedrig. Das erste Glied ist langgestreckt, das zweite kurz und läuft an der inneren Seite in einen grossen nach vorne hakenförmig gebogenen Fortsatz aus. Am Aussenrande

$\left.{ }^{1}\right)$ Bei einigen Weibchen liegen sie dem Eiersack von der Hinterseite dicht an und mögen vielleicht denselben stützen. 
sitzt ein kleiner Dorn. Zwischen diesem Dorne und dem hakenförmigen Fortsatze ist das kleine dritte Glied eingeschaltet. Dasselbe endigt mit einer inneren Borste, die beinahe das Ende des Fortsatzes des zweiten Gliedes erreicht, und mit einem kürzeren äusseren Dorne. Der Innenast ist gewöhnlich undeutlich zweigliedrig und endigt mit einigen kürzeren Dornen.

$\checkmark$ Grösse $0,92-0,95$.

Der Cephalothorax hat dieselbe Gliederung, verjüngt sich aber stärker nach hinten als bei dem Weibchen. Der Dorn, mit welchem das letzte Segment (Taf. IX, Fig. 5) jederseits nach hinten endigt, ist viel kleiner als bei dem Weibchen und kaum merklich. Ausser demselben sieht man auf dem Hinterrande dieses Segmentes jederseits zwei kleine Härchen.

Das Abdomen (Taf. IX, Fig. 5) besteht aus sechs Segmenten, von welchen das zweite das längste ist. Dann folgt der Länge nach die Furca, sodann das dritte und vierte, darnach das erste und schliesslich das fünfte Segment. Die Furcaborsten sind kleiner und mehr parallel gestellt 'als bei dem Weibchen.

Die vorderen Antennen erreichen kaum die Körperlänge. Die rechte Antenne (Taf. IX, Fig. 6) ist 22-gliedrig. Wie gewöhnlich bei den Calaniden liegt das Gelenk zwischen dem 18. und 19. Gliede. Die vorhergehenden sechs, von der Biegmuskel durchsetzten Glieder, sind aufgetrieben. Das 10., 11. und 13. Glied trägt je einen Dorn. Das 20. Glied läuft in einen längeren oder kürzeren Fortsatz aus.

Das fünfte Fusspaar (Taf. IX, Fig. 7). Beide Füsse bestehen aus einem zweigliedrigem Basale und zwei Ästen. Das erste Basalglied des rechten Fusses trägt aut 
der Hinterseite eine kleine mit einem Dorne endigende Warze. Das erste Glied des Aussenastes ist kurz und hat aussen an seinem distalen Ende einen etwas grösseren stumpfen Fortsatz und innen einen solchen kleineren. Das grosse zweite Glied trägt auf der Aussenseite einen langen gekrümmten Dorn und endigt mit einem ausserordentlich gebogenen und bewegligen Stachel. Der Innenast ist klein, eingliedrig und endigt mit einigen kleinen Dornen. Der linke Fuss, welcher viel kleiner als der rechte ist, trägt auf der Hinterseite seines ersten Gliedes eine ähnliche Warze wie der rechte Fuss; das zweite Basalglied ist aussen mit einem kleinen Dorn ausgestattet. Der Aussenast ist zweigliedrig und zeigt auf der inneren Seite einige abgerundete und mit feinen kurzen Härchen besetzte Höcker. Das zweite Glied scheint zweizapfig zu sein und hat zwischen dem Zapfen eine kleine nach innen gerichtete und mit einigen kleinen Borsten endigende Warze.

Fundort. Wurde von mir in einer Menge von grösseren und kleineren Landseen, sowohl des südlichen, mittleren und nördlichen Finlands, fast überall massenhaft gefunden. Derselbe wurde noch in dem von mir untersuchten Teiche auf dem Berge Valtavaara im nördlichen Finland (Kuusamo), auf einer Meereshöhe von ungefähr 450 Meter angetroffen.

Fundzeit. Wird das ganze Jahr hindurch mit Eier säckchen und Spermatophoren gefunden.

Bemerkung. In den verschiedenen Seen scheinen lokale Varietäten sich ausgebildet zu haben. Folgende Theile sind am meisten veränderlich:

Das letzte Brustsegment ist, von oben gesehen, entweder rectangulär oder nach hinten verjüngt; die Lage 
und Grösse der auf seinem Hinterrande sitzenden vier Dornen ist veränderlich. Die vorderen Antennen des Weibchens sind gewöhnlich viel länger als der ganze Körper mit den Endborsten, doch ragen sie bei Individuen aus einigen Seen nur unbedeutend über die Furca hinaus. Das fünfte Fusspaar, sowohl bei dem Weibchen als bei dem Männchen, variirt hauptsächlich in der Länge des Innenastes. 


\section{Dias, Liljeborg.}

Dias, Liljeborg, De crustaceis etc., p. 181, 1853.

Der Cephalothorax ist ungefähr drei Mal so lang wie das Abdomen. Der erstere ist aus fünf deutlichen Gliedern zusammengesetzt, clas letztere bei dem Weibchen aus vier, bei dem Männchen aus sechs, von denen das vierte sehr kurz ist. Die Furca ist ziemlich kurz, höchstens $2 \frac{1}{2}$ Mal so lang wie breit, und bei dem Männchen immer verhältnissmässig kürzer als bei dem Weibchen ${ }^{1}$ ). Sie trägt sechs befiederte Borsten, von welchen die innere, auf der Rückenseite gelegene grösser als gewöhnlich bei den Copepoden und ausserdem durch ihre breite Ansatzfläche characterisirt ist. Die vorderen Antennen reichen bis zum hinteren Rande des Cephalothorax oder darüber. Mehrere der Glieder desselben sind mehr oder weniger zusammengeschmolzen und an den Ansatzstellen der Borsten, welche theilweise lang und befiedert sind erweitert, so dass die Antennen dadurch ein „knotiges" Aussehen bekommen. Die rechte Antenne des Männchens hat ein Gelenk und eine Biegmuskel. Die Glieder, durch welche

1) Die Länge des rechten Astes ist immer etwas grösser als die des linken Astes. Auch ist die innere Seitenborste immer näher dem Ende der Furca auf dem rechten als auf dem linken Aste gerückt. Dies gilt sowohl Dias longiremis wie bifilosus und für beide Geschlechter gleich. 
diese geht, sind aber fast gar nicht aufgetrieben. Die hinteren Antennen bestehen aus einem zweigliedrigen Basale, einem aus zwei langen Gliedern zusammengesetzten Hauptast, und einem kurzen dreigliedrigen Nebenast. Die vorderen Kieferfüsse sind kurz und undeutlich gegliedert. Auf ihrer vorderen Seite sitzt eine Anzahl von langen und mit starken Fiedern besetzten Borsten. Die hinteren Kieferfüsse sind dreigliedrig. Das erste Glied trägt fünf lange auf Warzen sitzende Fiederborsten, das zweite eine kurze und das dritte fünf kurze Borsten. Die Schwimmfüsse haben einen dreigliedrigen Aussenast und einen zweigliedrigen Innenast. Die Füsse des fünften Paares sind bei dem Weibchen sehr rudimentär und nur aus zwei Gliedern ${ }^{1}$ ) zusammengesetzt, von denen besonders das zweite klein ist. Jedes Glied trägt eine Borste. Bei dem Männchen sind diese Füsse auch einfach (nicht zweiästig) und zu einem Greiforgan umgewandelt.

Eiersäckchen werden nicht gebildet.

1) Diese Deutung scheint mir richtiger zu sein als Giesbrechts und Poppes, nach welcher sie eingliedrig wären. Dass das zweite Glied wirklich ein solches und nicht bloss eine Auftreibung der Borste ist, zeigt auch der von Poppe gezeichnete abnorme Fuss von Dias intermedius (l. c. Taf. V, Fig. 25). 


\section{Dias Iongiremis, (Liljeborg) Giesbrecht.}

Dias longiremis, Liljeborg, De Crustaceis, p. 181, 1853.

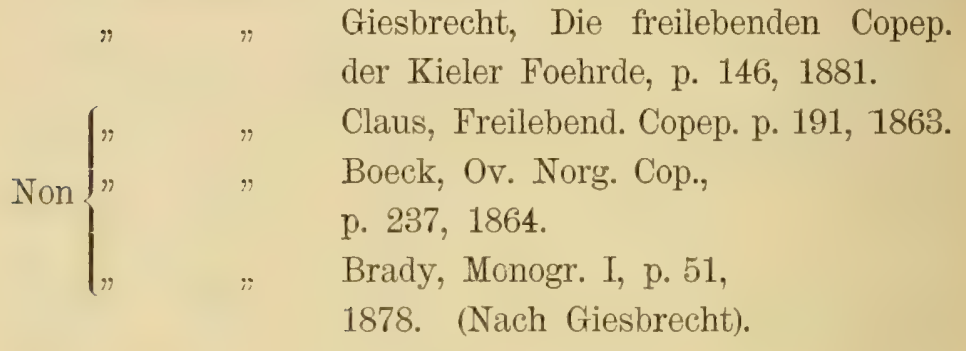

Grösse $0,94 \mathrm{~m}$. m.

Der Cephalothorax (Taf. X, Fig. 1) ist ungefähr dreimal so lang wie das Abdomen. Das erste Segment enthehrt die für Dias bifilosus characteristischen Stirnfäden. Das letzte Segment trägt am hinteren Theile seines Aussenrandes einen langen Dorn und hinten zwei kurze Haare.

Das Abdomen (Taf. X, Fig. 2). Das erste Segment ist ungefähr so lang wie die zwei folgenden zusammen und an den Seiten und am Hinterrande, das zweite nur am Hinterrande mit einige Dornen besetzt. Das dritte Segment trägt jederseits, einen Dorn. Der Furca fehlen diese ganz. Die Furcaäste sind $2^{1} \frac{2}{2}$ mal so lang wie breit. Von den Endborsten, welche wie die beiden Seitenborsten befiedert sind, ist die zweitinnere etwas mehr als $1 \frac{1}{3}$ so lang wie das Abdomen. 
Die vorderen Antennen (Taf. IX, Fig. 11) reichen zum zweiten Abdominalsegment. Auf dem vierten Gliede sitzt ein Dorn.

Das fünfte Fusspaar (Taf. X, Fig. 10). Jeder Fuss besteht aus zwei Gliedern von welchen das erste an seinem distalen Ende vorne das kleine ovale, in eine lange geknickte Borste endigende zweite Glied trägt, hinten aber eine lange und dünne Borste. Dorne oder Haare auf den Borsten fehlen.

б Grösse $0,89 \mathrm{~m}$. m.

Das Abdomen (Taf. X, Fig. 3) besteht aus 6 Segmenten, welche alle, mit Ausnahme des dritten und sechsten (der Furca) Dornen tragen ${ }^{1}$ ). Die Länge der Furcaäste verhält sich zu ihrer Breite wie 15 : 9.

Vordere Antennen (Taf. IX, Fig. 11). Die rechte Antenne hat den Dorn des vierten Gliedes nicht wie bei Dias biflosus verloren. Auch habe ich einen gleichen Dorn auf dem siebenten Gliede von welchem die Biegmuskel entspringt gesehen.

Das fünfte Fusspaar (Taf. X, Fig. 5) besteht aus einem rechten viergliedrigen und einem linken dreigliedrigen Fusse. Auf dem Basalgliede jedes Fusses sitz eine befiederte Borste. Das zweite Glied des rechten Fusses ist ron der Innenseite eingeschnitten, und der proximale Lappen trägt einen Dorn ${ }^{2}$ ). Das dritte Glied hat einen Fortsatz nach Innen, auf welchem ein kleiner Dorn sitzt und das vierte ist hakenförmig gebogen und trägt auch ei-

1) Giesbrecht (1. c. p. 147) sagt dass Dornen auf allen Segmenten vorkommen, ausgenommen der Furca und dem ersten Segment des $\delta$. Auf seiner Taf. II, Fig. 16 sind doch zwei Dornen auch auf dem ersten Segmente gezeichnet.

$\left.{ }^{2}\right)$ Bei der Kieler-Form mangelt nach Giesbrecht (l. c. Taf. VIII, Fig. 30) der Einschnitt und der Dorn. 
nige Dornen. Das Endglied des linken Fusses ist sehr plump und trägt zwei Dornen, von welchen der eine wahrscheinlich beweglich ist.

Fundort. Diese Art kommt sowohl im finnischen Meerbusen bei Helsingfors als auch in der nördlichen Ostsee zwischen Åland und Finland vor. Dagegen habe ich sie im bottnischen Meerbusen zwischen Sideby und Töjby nicht gesehen. Dias longiremis kommt nie in solcher Menge wie $D$. bifilosus vor, ist aber gar nicht selten.

Fundzeit. Wurde in Juli und December erhalten, scheint also das ganze Jahr vorzukommen. 


\section{Dias bifilosus, Giesbrecht.}

Dias bifilosus, Giesbrecht, Die freilebenden Copepoden der Kieler Foehrde, p. 147, 1881.

\& Grösse $0,85 \mathrm{~m} . \mathrm{m}$.

Der Cephalothorax (Taf. X, Fig. 6) ist etwas mehr als dreimal so lang wie das Abdomen. Seine grösste Breite liegt am zweiten Segmente und beträgt 0,21 m. m. Die Stirn trägt zwei nach unten und hinten gerichtete Fäden. Das letzte Segment entbehrt der Dornen und Härchen.

Das Abdomen (Taf. X, Fig. 11). Von den vier Segmenten des Abdomens ist das erste länger als die zwei folgenden zusammengenommen. Die Furcaäste sind fast zweimal so lang wie breit ${ }^{1}$ ). Von den Endborsten ist die zweitinnere die längste und zwar $1 \frac{1}{3}$ so lang wie das ganze Abdomen. Dornen und Härchen fehlen gänzlich auf demselben.

Die vorderen Antennen sind etwas variabol in ihrer Länge und reichen bisweilen nur zum Hinterrand der Cephalothorax, bisweilen aber bis zum zweiten AbdominalSegmente. Die beiden Antennen sind gleich lang. Ihre Länge ist $0,74 \mathrm{~m} . \mathrm{m}$.

Das fünfte Fusspaar (Taf. X, Fig. 9) ist gebaut wie

1) Giesbrecht (1. c. p. 147) sagt wohl dass die Furca nur $1 \frac{1}{2}$ Mal so lang wie breit ist, aber seine Taf. III, Fig. 20 zeigt doch eine etwas grössere Länge. 
bei Dias longiremis, nur ist das zweite Glied etwas dicker und die Borste desselben nicht geknickt. Dorne und Haare auf den Borsten habe ich hier ebensowenig wie bei Dias longiremis finden können.

$\sigma$ Grösse $0,86 \mathrm{~m} . \mathrm{m}$.

Das Abdomen (Taf. X, Fig. 7) ist glatt und ohne Härchen. Die Furcaäste sind viel breiter als bei dem Weibchen. Thre Länge verhält zur Breite wie $7: 5 \frac{1}{2}$. Von den Endborsten ist die zweitinnere die Längste und etwas mehr als $1 \frac{1}{3}$. so lang wie das Abdomen.

Die vorderen Antennen (Taf. IX, Fig. 10) des Männchens sind etwas kürzer als bei dem Weibchen.

Das fünfte Fusspaar (Taf. IX, Fig. 8) ist wie bei Dias longiremis gebaut. Der eine Dorn auf dem Endgliede des linken Fusses ist aufgetrieben und wie ein selbständiges Glied gebildet ${ }^{1}$ ); der andere Dorn ist an der Basis breit.

Fundort. Wurde im finnischen Meerbusen bei Helsingfors, in der Ostsee zwischen Åland und Finland und im bottnischen Meerbusen bis Töjby (nach S. von Qvarken) gefunden.

Fundzeit. Kommt wenigstens so lange das Meer eisfrei ist vor. Ich habe diese Art bei Helsingfors von April bis December gefischt.

1) Hierin uterscheidet sich die nordbaltische Form von der von Giesbrecht beschriebenen. Vielleicht ist dieser Dorn ein rudimentäres viertes Glied? Auf dem rechten Fusse unterscheidet sich das dritte (rlied von Giesbrechts Abbildung und nähert sich Dias discaudatus. 


\section{Verzeichniss der Litteratur, die mir zugänglich war.}

W. Baircl: Natural History of the British Entomostraca. Ray Society 1850 .

Axel Boeck: Oversigt over de ved Norges Kyster iagtagne Copepoder. Vidensk.-Selsk. Forhandl. Christiania. 1864.

M. Braun: Physikalische und biologische Untersuchungen im westlichen Theile des finnischen Meerbusens (Arch. f. Naturk. Liv., Ehst- v. Kurlands Ser. II, B. X. Lief. 1. (Dorpat 1884).

Farunistische Untersuchungen in der Bucht von Wismar (S.-A. ans Arch. d. Frde der Naturgesch. in Mecklenb. Jahrg. 42, 1888).

A. H. Cajander: Bidrag till kännedomen om sydvestra Finlands krustaceer (Not. Sällsk. pro Fauna et Flora fennica förh. X. 1869).

C. Claus: Die freilebenden Copepoden. Leipzig 1863.

- Ueber die Gattungen Temora und Temorella nebst den zugehörigen Arten (Sitzungsber. d. k. Akad. d. Wissensch. Wien. LXXXIII Bd. 1 Abth.). 1881.

S. Fischer: Beiträge zur Kenntniss der in der Umgegend von St. Petersburg sich findenden Cyklopiden (Bull. de la Soc. Imp. des Natural. de Moscou. 1853).

S. A. Forbes: The lake as a Microcosm (Bull. Peoria Sci. Association. 1887).

Wilh. Giesbrecht: Die freilebenden Copepoden der Kieler Foehrde (VII. Bericht d. Comm. z. wiss. Untersuch, d. deutsch. Meere in Kiel 1881).

0. А. Гриммъ: Къ познанію фауны, Балтійскаго моря и исторіи ея воз. никновенія. St. Petersburg 1877.

August Giuber: Über zwei Süsswasser-Calaniden. Leipzig 1878. 
Jules de Guerne: Description du Centropages Grimaldii copépode nonveau du golfe de Finlande (Bull. de la Soc. zool. de France 1886).

- Sur les genres Ectinosoma Boeck et Podon Lilljeborg, à propos de deux entomostracés (Ectinosoma atlanticum G. S. Brady et Robertson, et Podon minatus G. O. Sars) trouvés à la corogne dans l'estomac des sardines (Extr. du Bull. d. l. Société zoolog. de France, t. XII, 1887).

O. E. Imhof: Über die „blassen Kolben“ an den vorderen Antennen der Süsswasser-Calaniden (Zool. Anz. 1885).

_...- Studien über die Fauna hochalpiner Seen insbesondere des Kantons Graubünden (Jahresber. d. Naturf. Gesellsch. Graubündens, Jahrg. XXX) 1887.

K. Кесслерь: Матеріалы для познанія Онежскаго озера и обонежскаго края. С.-Петербургъ 1868.

C. Koelbel: Carcinologisches (Sitzungsber. d. K. Akad. d. Wissensch. Math.-Naturw, classe. XC. B. I Abth. Jahrg. 1884. Wien 1885).

Wilh. Liljeborg: De crustaceis ex ordinibus tribus: Cladocera, Ostracoda et Copepoda in Scania occurrentibus. Lund 1853.

- Beskrifning öfver två arter Crustaceer af ordningarne Ostracoda och Copepoda (Öfv. K. Vet.-Ak. Förh. 1862).

Collection of chiefly freshwater crustacea from Sweden (Great International Fisheries Exhibition, London 1883. Division 50).

Lindström: Bidrag till kämmedomen om Östersjöns Invertebratfauna (Öfv. af K. Vet.-Ak. Förh. 1855).

K. Möbius. Die wirbellosen Thiere der Ostsee (Jahresber. d. Comm. z. wiss. Unters. d. deutschen Meere in Kiel für das Jahr 1871. 1 Jahrg.). Berlin 1873.

_ Nachtrag zu dem im Jahre 1873 erschienenen Verzeichniss der wirbellosen Thiere der Ostsee (Jahresber. etc. VII bis XI Jahrgang. I. Abth. Berlin 1882).

o. F. Müller: Entomostraca seu Insecta testacea quae in aquis Daniae et Norvegiae reperit. 1785.

Osc. Norlquist: Bidrag till kännedomen om Crustacéfaunan i några af mellersta Finlands sjöar (Acta Soc. pro Fauna et Flora fennica, T. III. N:o 2). 
Osc. Nordqvist: Bidrag till kännedomen om Ladoga sjös crustacéfauna (Meddel. af Soc. pro Fauna et Flora fennica, 14: 1887).

_ Die pelagische und Tiefsee-Fauna der grösseren fimnischen Seen (Zoolog. Anzeiger 1887).

S. A. Poppe: Die freilebenden Copepoden des Jadebusens I. (Abhandl. d. naturwiss. Vereins zu Bremen. IX B. 1885).

- Ein neuer Diaptomus aus dem Hirschberger Thal (Zeitschr. f. wiss. Zoologie 43. B. 1886).

Beschreibung einiger neuer Entomostraken aus norddeutschen Seen (Zeitschr. für wiss. Zoologie XLV B. 1887).

G. Pouchet et $J$. de Guerne: Sur la faune pélagique de la mer Baltique et du golfe de Finlande (Compt. rend. Acad. Sc. 1885).

J. Richard: Entomostracés nouveaux ou peu connus (Extrait du Bulletin de la Société Zool. de France, t. XIII, 1888).

G. O. Sars: Oversigt af de indenlandske Ferskvands copepoder (Forh. i Vidensk.-Selsk. i Christiania 1862).

- Beretning om en i sommaren 1862 foretagen zoologisk Reise i Christiania och Trondhjems Stifter (Nyt Magazin f. Naturvidensk. XII B. Christiania 1863).

- Beretwing om en i Sommeren 1863 foretagen zoologisk Reise i Christiania Stift. (Nyt Magaz. f. Naturwil. XIII B. Christiania 1864).

A. Wierzejski: 0 krajowych skorupiakach z rodziny Calanidae (S.-A. aus T. XVI. Rozpraw i Sprawozdań Wydzia lu matem.-przyr. Akad. Umiej. Kraków. 1887). 


\section{Inhaltsverzeichniss.}

Einleitung . . . . . . . . . . . . . . . s. 3.

Über die Verbreitung der Calaniden in der nördlichen Ostsee . " 9.

Über den Ursprung der Calaniden-Fauna der Ostsee . . . . . , 12.

Über den Einfluss der äusseren Existenzbedingungen auf den

Körper der Calaniden. . . . . . . . . . . . . ” 13.

Die Verbreitung der Calaniden in den Landseen Finlands . . . „2 21.

Arten und Gattungsbeschreibungen:

Centropages hamatus . . . . . . . . . , 26.

Limnocalanus macrurus . . . . . . . . . . " 31.

Clausia elongata . . . . . . . . . . . " 38.

Temora longicomis . . . . . . . . . . " 42.

Temorella. . . . . . . . . . . . . . 446.

affinis $\nabla$. hirundoides. . . . . . . . 48 .

" affinis $\mathrm{v}$. hispida . . . . . . . . " 53.

n lacustris . . . . . . . . . " 55.

» Clausii . . . . . . . . . . . .

Heterocope . . . . . . . . . . . . . . . 63.

n appendiculata . . . . . . . . . " 66.

n saliens. . . . . . . . . . . $" 69$.

Diaptomus gracilis . . . . . . . . . . . " 71 .

Dias . . . . . . . . . . . . . n 76

" longiremis . . . . . . . . . . . " 78 .

${ }^{n}$ bifilosus . . . . . . . . . . . . . 81 .

Litteraturverzeichniss . . . . . . . . . . . . . . . 83. 


\section{Berichtigungen und Zusätze.}

Seite 6, Zeile 13 von oben steht:

verwechselt, statt: vermengt.

" $7, \quad, 2$, unten steht:

vog D. nracilis, statt: von D. gracilis.

In der Zahl der Abdominalsegmente ist die Furca immer mitgerechnet. 




\section{Tafel I.}

\section{Centropages hamatus.}

Fig. 1. ค. $90 \times$.

, 2. ठ. $90 \times$.

" 3. Erstes Abdominalsegment nebst dem Haken des letzten Brustsegmentes $(\rho)$ von der rechten Seite gesehen. $375 \times$.

" 4. Hinterer Kieferfuss (q). $375 \times$.

"5. Abdomen des of von oben. $150 \times$.

"6. Linker füfter Fuss des $\delta .375 \times$.

" 7. Rechter fuinfter Fuss des $\delta .375 \times$.

" 8. Fünfter Fuss des 오. $375 \times$.

\section{Limnocalanus macrurus.}

"9. Hinterer Kieferfuss. $180 \times$.

"10. Hintere Antemne. $180 \times$.

"11. Fünfter Fuss des f. $180 \times$ 。 



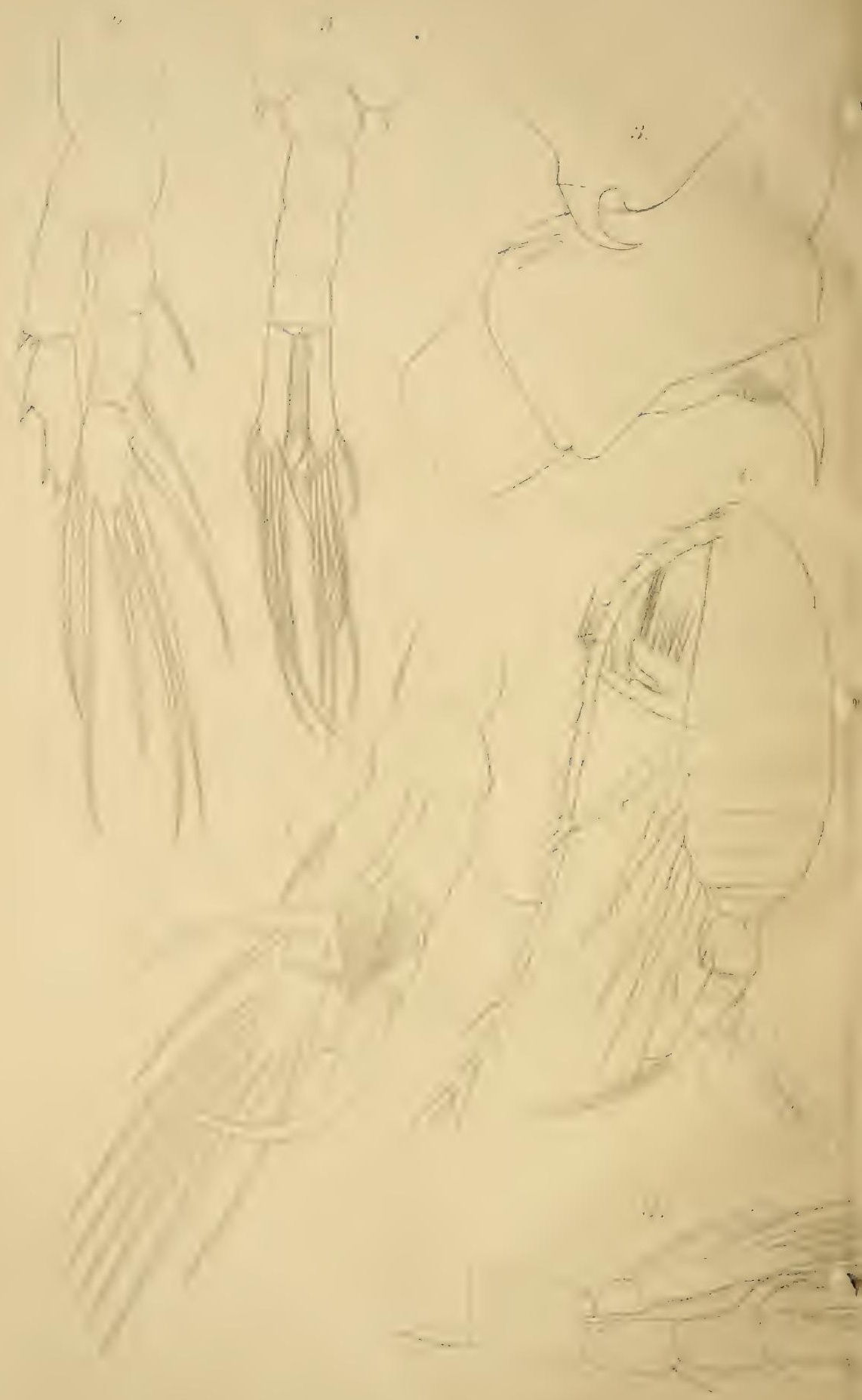


Tinf. I.

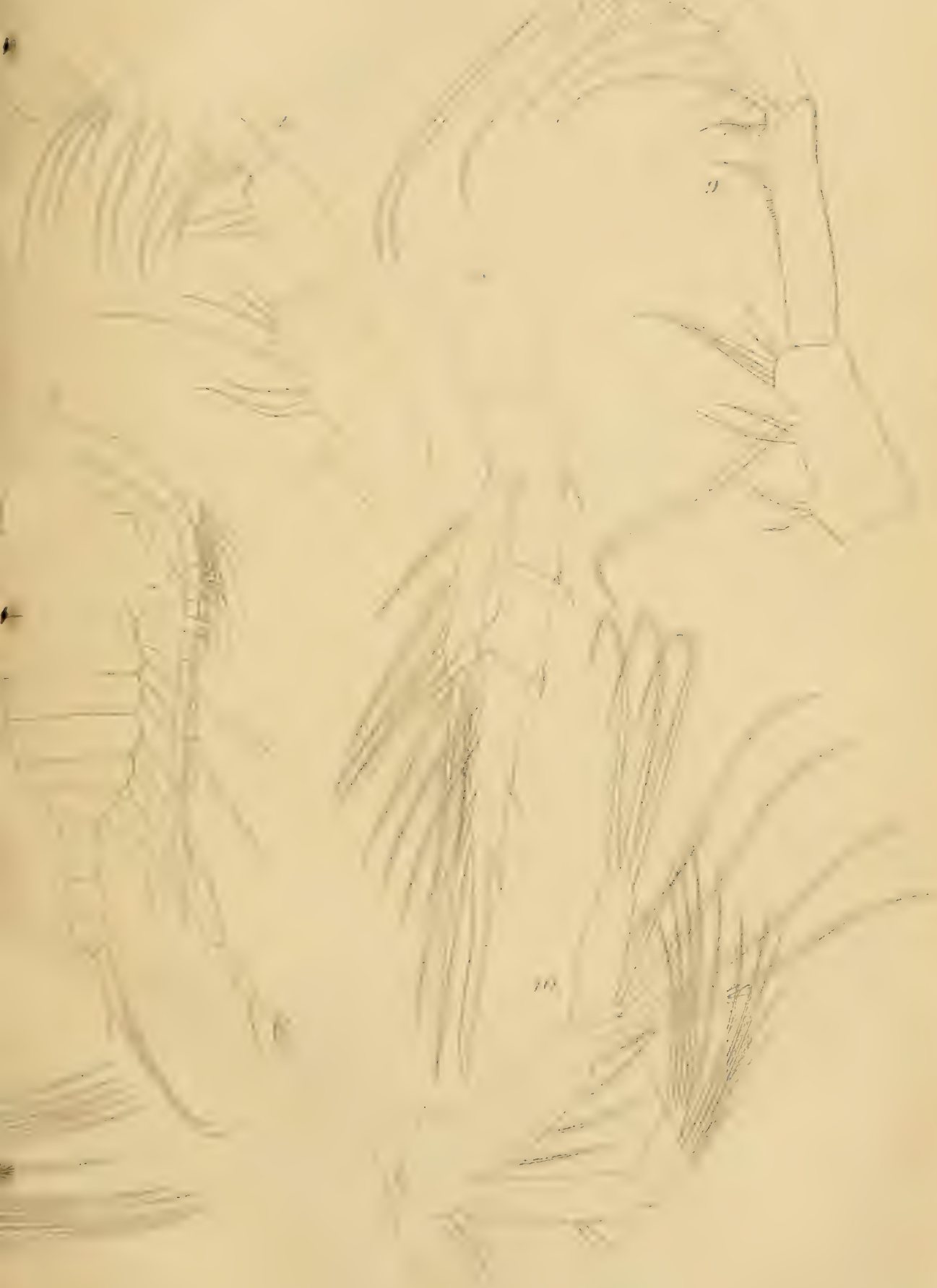





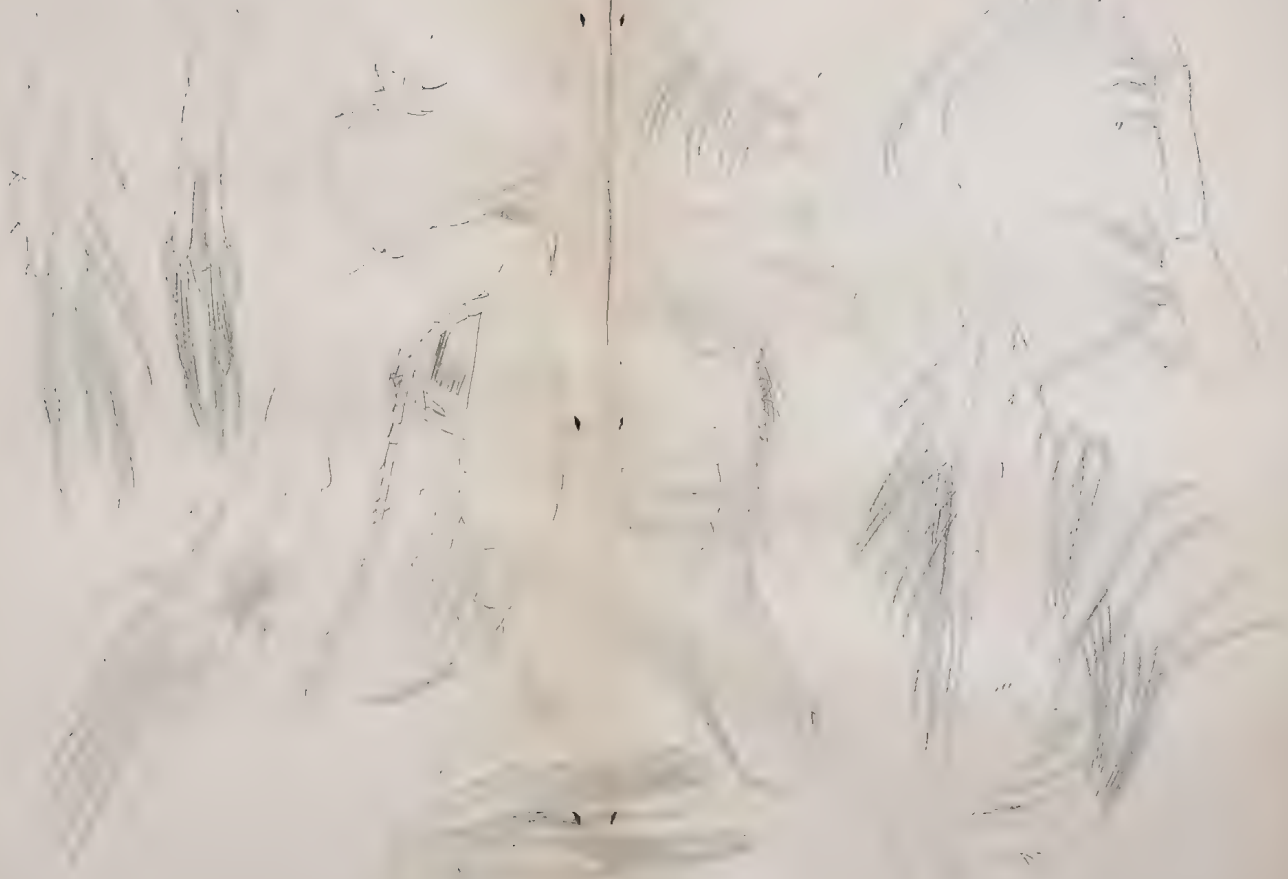






\section{Tafel II.}

\section{Limnocalanus macrurus.}

Fig. 1. $\%$ von der Seite. $90 \times$.

"2. Abdomen des $\delta$ von oben. $150 \times$.

"3. Rechte vordere Antenne des $0.180 \times$.

, 4. Vordere Antemne des \&. $180 \times$.

" 5 Vorderer Kieferfuss des o. $160 \times$. 





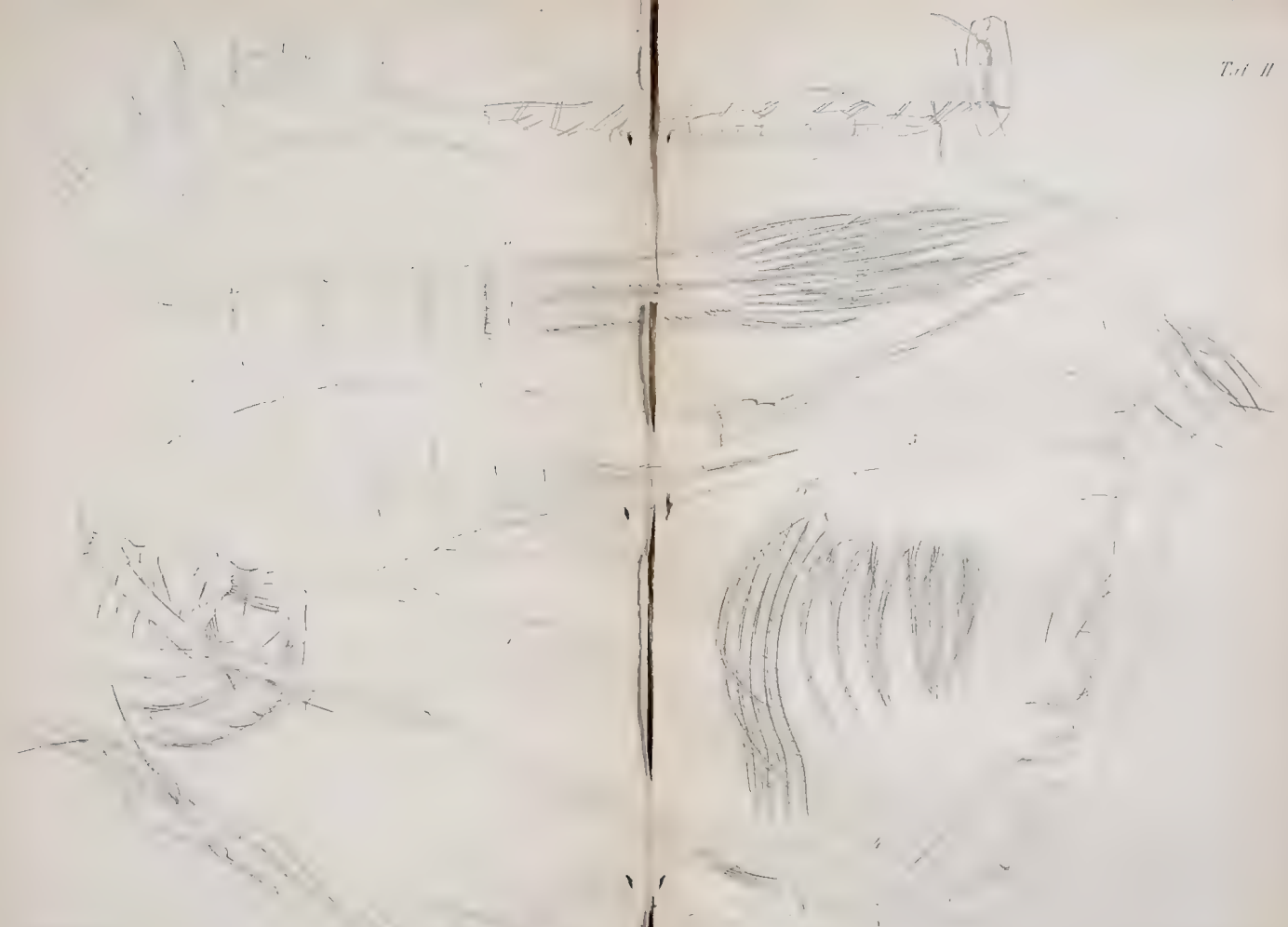



\section{Tafel III.}

\section{Limnocalanus macrurus.}

Fig. 1. Mandibel des 오. $375 \times$.

"2. Maxille des ㅇ․ $375 \times$.

$\leadsto$ 3. Dritter Schwimmfuss des $\subsetneq$. $150 \times$.

" 4. Fünftes Fusspaar des $\delta .180 \times$.

Clausia elongata.

"5. Junges $f$ von der Seite. $90 \times$.

\section{Temora longicornis:}

"6. Erster Schwimmfuss des .. $375 \times$.

"7. Linker fünfter Fuss des $\delta$. $375 \times$.

" 8. Rechter fünfter Fuss des $\sigma .375 \times$.

" 9. Rechte vordere Antenne des б. $375 \times$. 



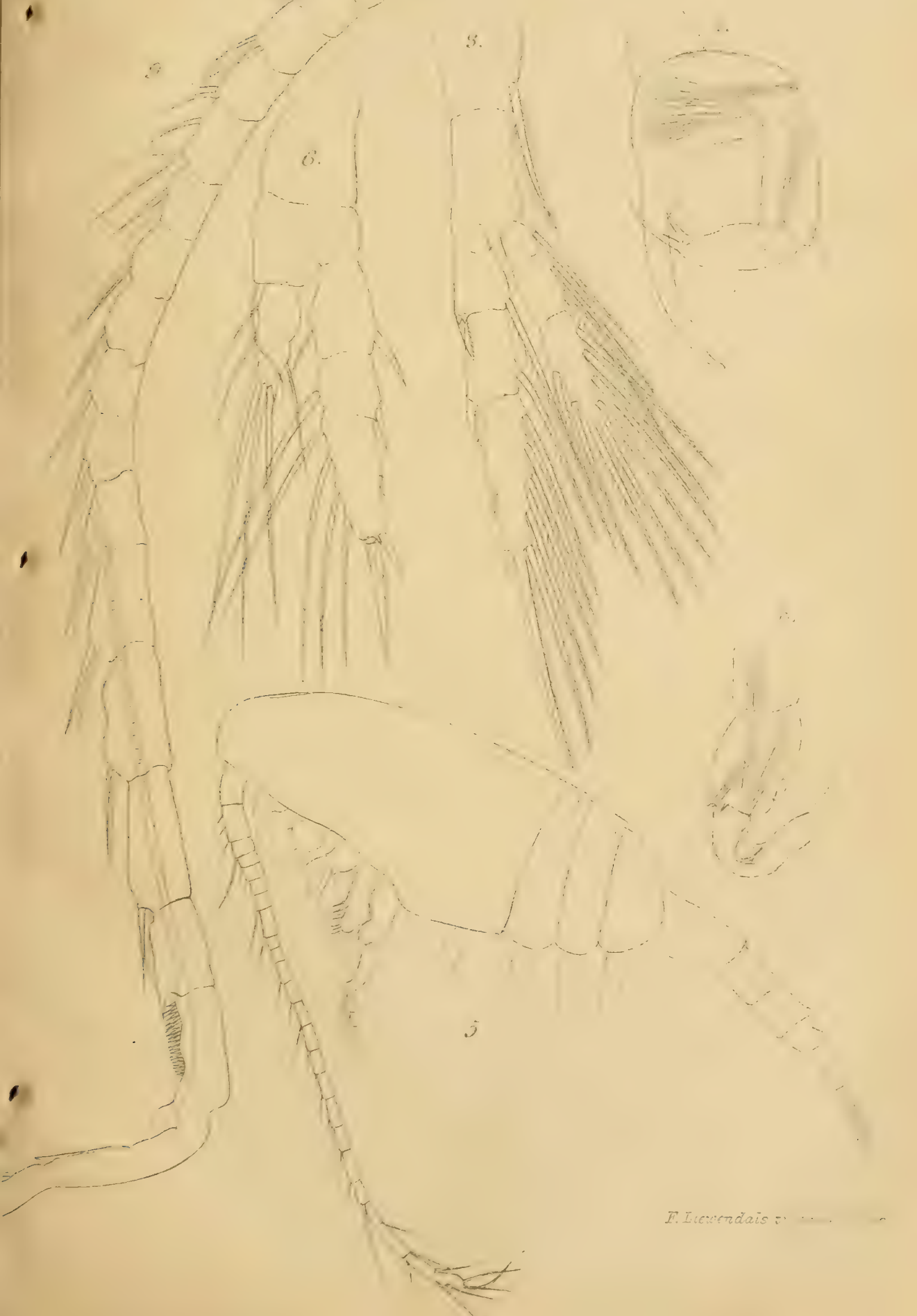





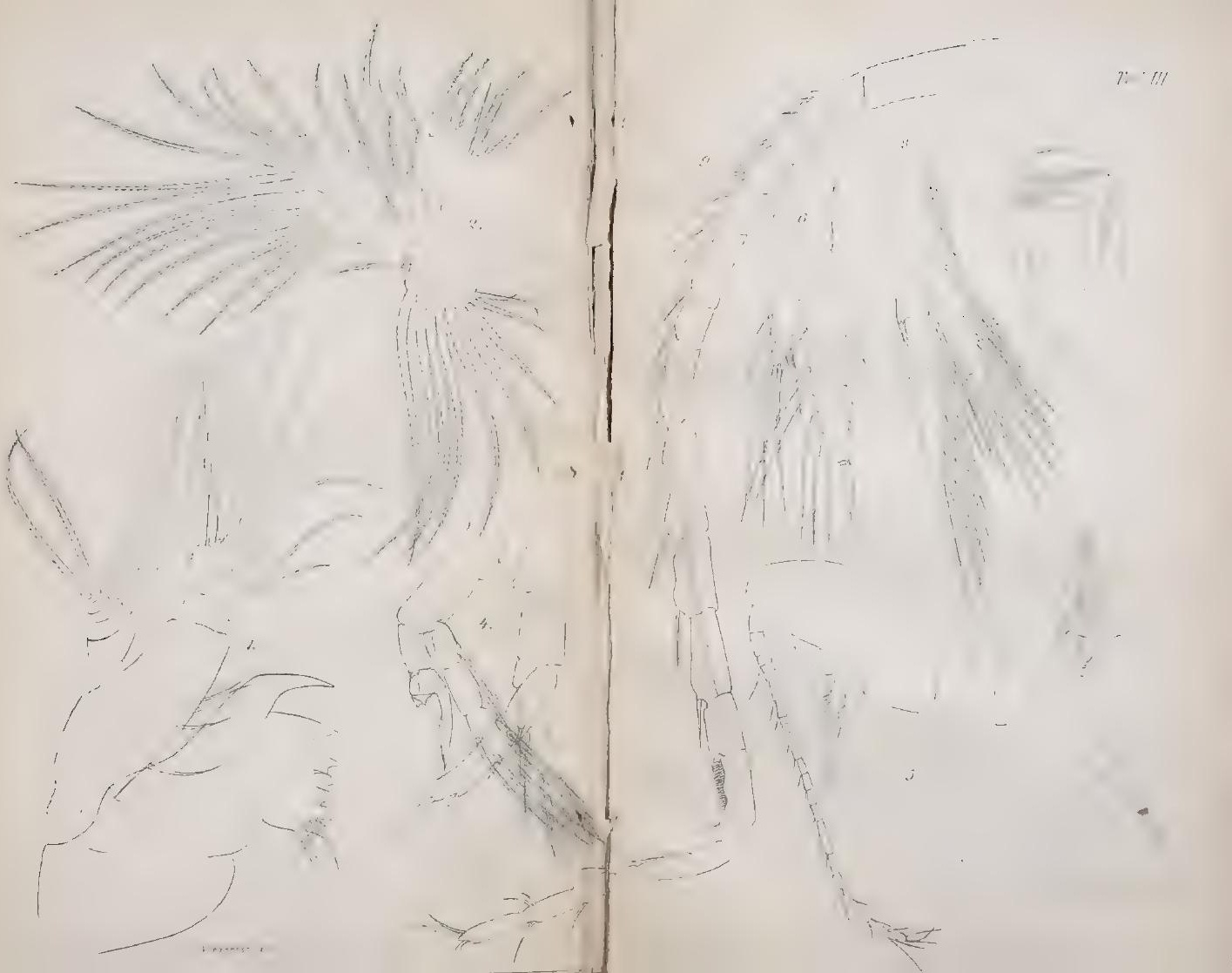





\section{Tafel IV.}

Temora longicornis.

Fig. 1. $q$ von oben. $90 \times$.

»2. $\delta$ von oben. $90 \times$.

"3. Abdomen des $\delta$ von oben. $375 \times$.

". F. Fünfter Fuss des - . $375 \times$.

\section{Temorella affinis $v$. hirundoides.}

"5. 오 von oben. $90 \times$.

" 6. Das erste Abdominalsegment schräg von unten. $375 \times$.

"7. Abdomen des $q$ von oben. $375 \times$.

" 8. Der hinterer Theil des Cephalothorax und das Abomen des f von oben. $150 \times$.

"9. Das letzte Thoracal- und erste Abdominalsegment des 우 von der Seite. $375 \times$.

„10. Der hintere Theil des Cephalothorax mit einem fünften Fusse (ㅇ) von der Seite. $375 \times$.

"11. Der hintere Theil des Cephalothorax des 우 von der Seite. $375 \times$. 


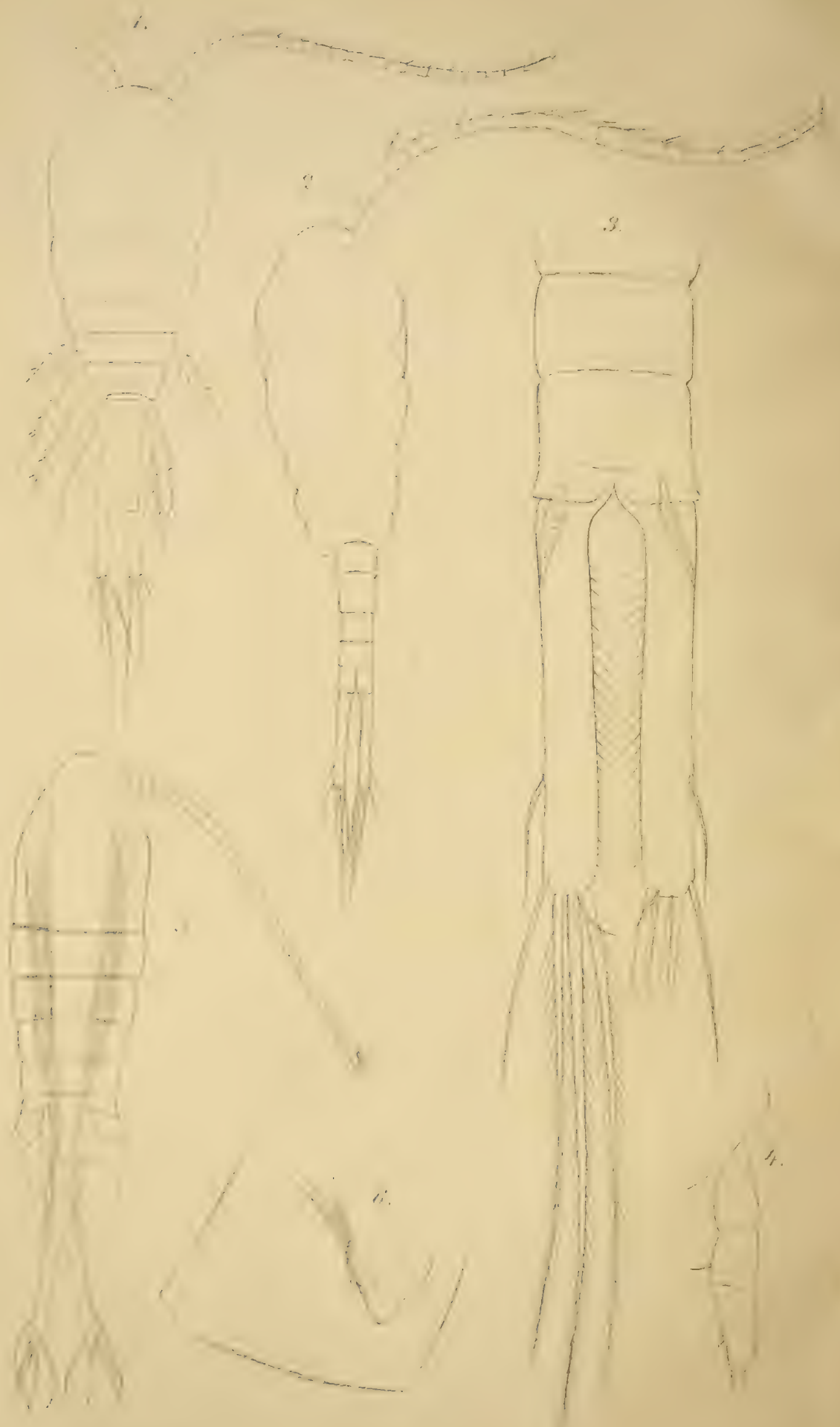






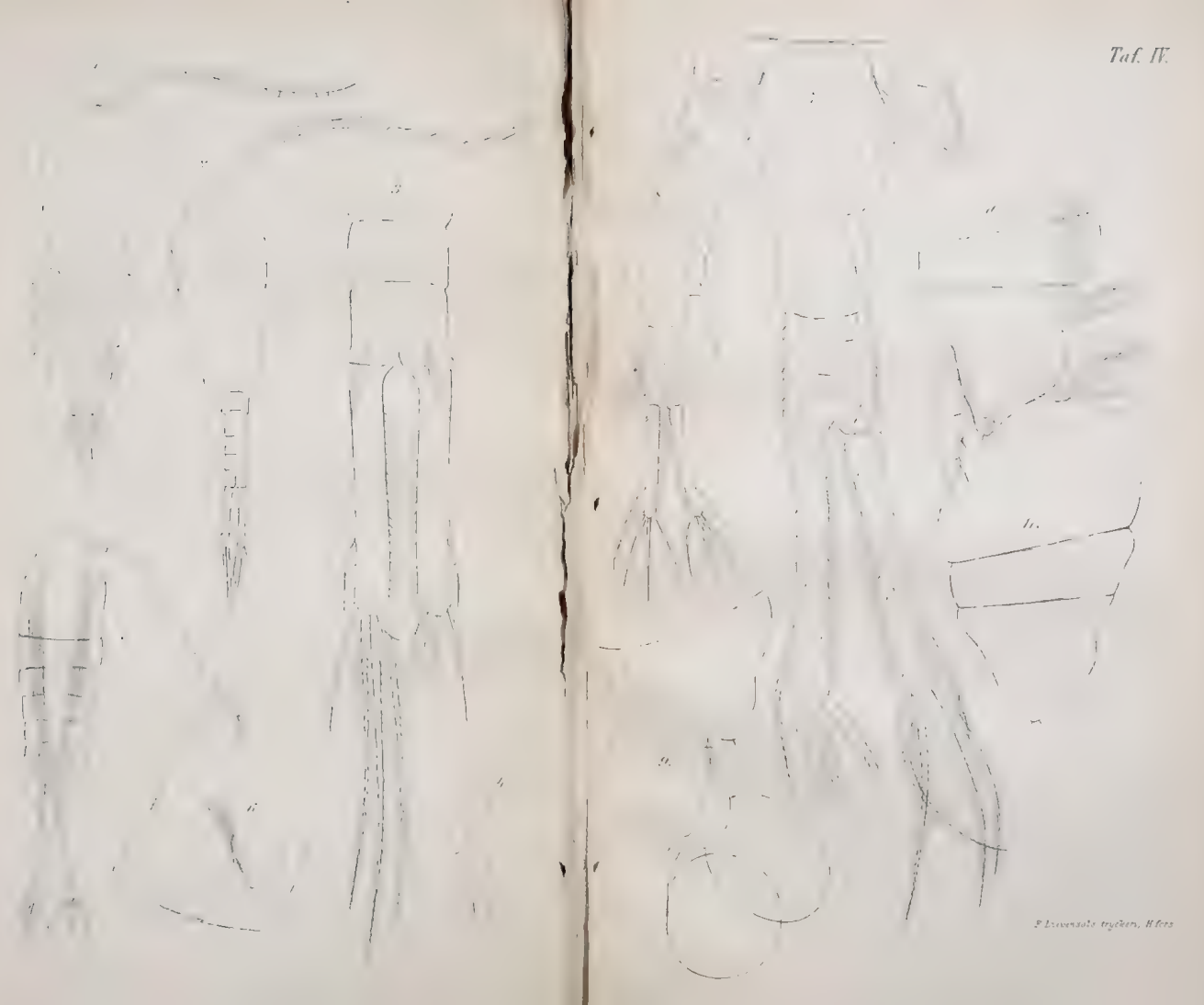





\section{Tafel V.}

Fig. 1. Abdomen und das letzte Brustsegment von Temorella affinis v. hispida f. $150 \times$.

" 2. Der hintere Theil des Cephalothorax und das erste Abdominalsegment von Temorella lacustris $f .150 \times$.

" 3. Das erste Abdominalsegment von T. lacustris of von unten. $180 \times$.

" 4. Das fünfte Fusspaar von T. lacustris f. $375 \times$.

" 5. Das fünfte Fusspaar von T. affinis v. hirundoides $\delta .375 \times$.

" 6. Der linke, fünfte Fuss von T. affinis v. hispida $\delta .375 \times$.

„ 7. Der rechte, fünfte Fuss derselben. $375 \times$.

" 8. Das fünfte Fusspaar von T. Clausii o. $375 \times$.

" 9. Das fünfte Fusspaar von T. lacustris $\delta .375 \times$.

"10. Das letzte Brustsegment von T. affinis v. hispida of von der Seite. $150 \times$. 


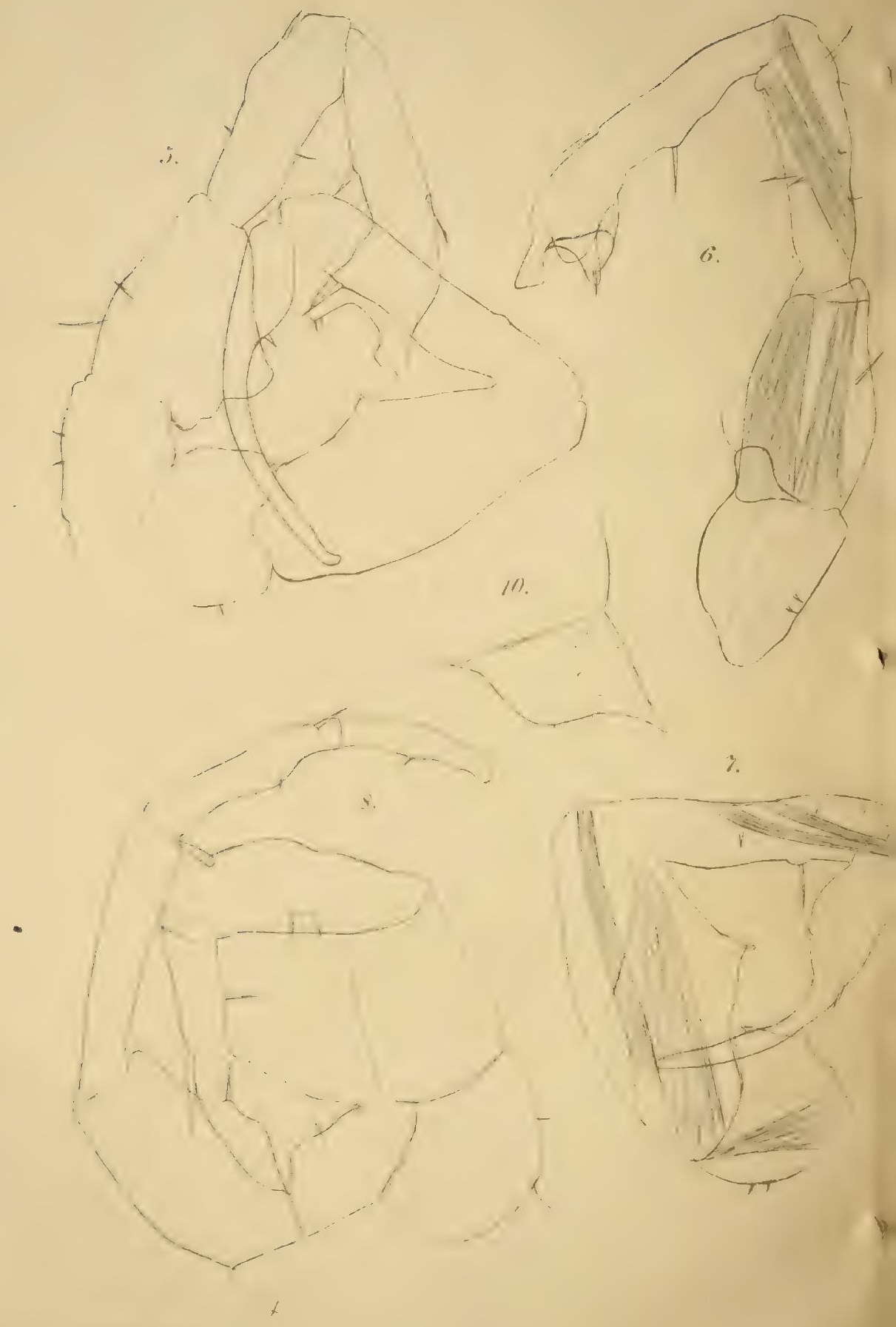

0. Mordy: 't dei 




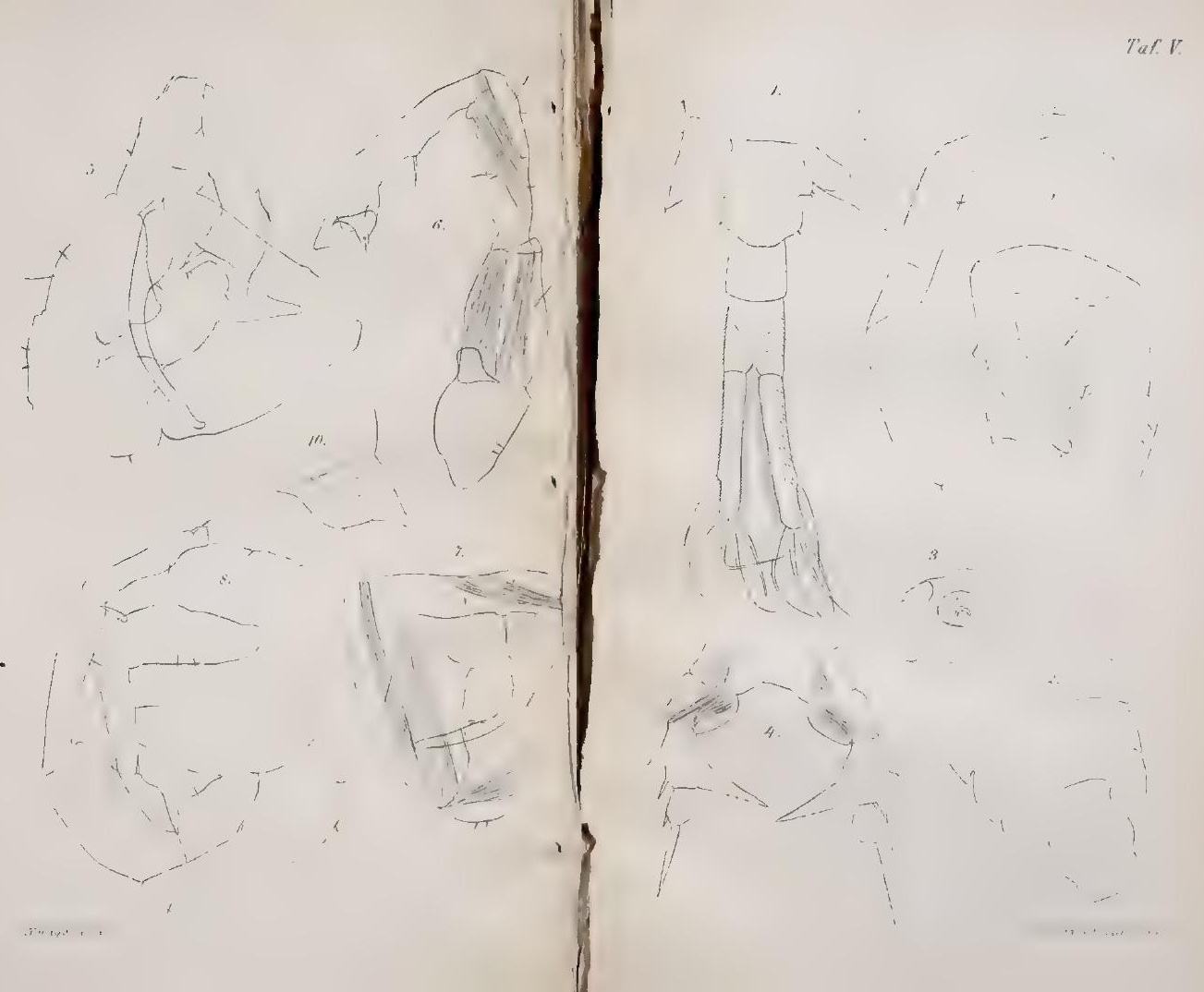





\section{Tafel VI.}

Temorella lacustris.

Fig. 1. \%. $150 \times$.

"2. Rechte vordere Antemue des o. $150 \times$.

Temorella affinis $v$. hirundoides.

. 3. Rechte vordere Antenne des o. $150 \times$.

\section{Temorella affinis $v$. hispida.}

" 4. Rechte vordere Ancenne des o. $160 \times$.

" 5. Fünfter Fuss des ㅇ. $375 \times$.

\section{Temorella Clausii.}

" 6. Der hintere Theil des Cephalothorax, ein fünfter Fuss und das Abdomen des 9 , von der Seite gesehen. $180 \times$.

" 7. Der hintere Theil des männlichen Abdomens von oben. $375 \times$.

" 8. Linker fünfter Fuss während und gleich nach der Copulation gezeichnet. Ein Spermetophor war am Innenrande des letzten Segmentes, dicht über der Spitze befestigt. C. $450 \times$. 


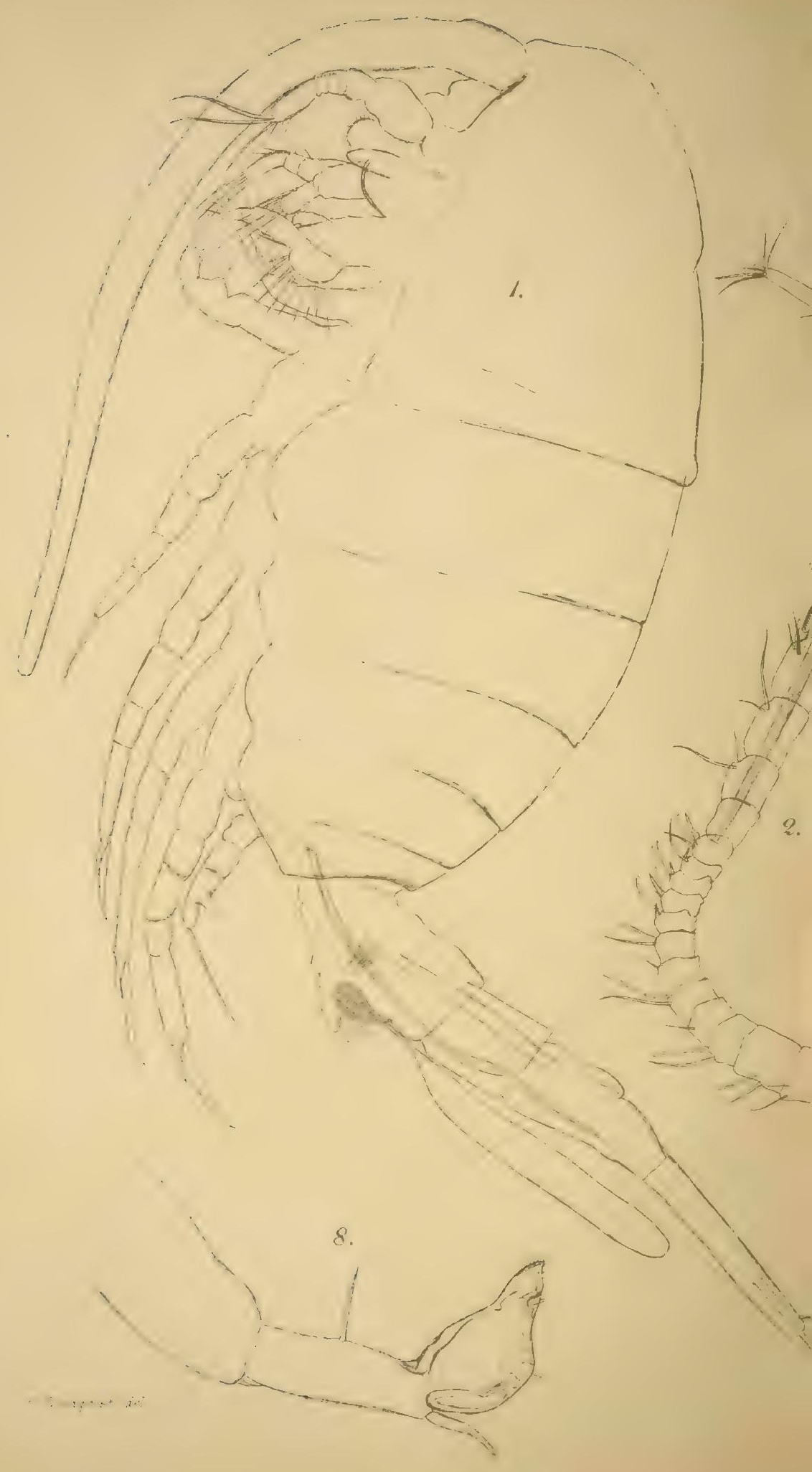



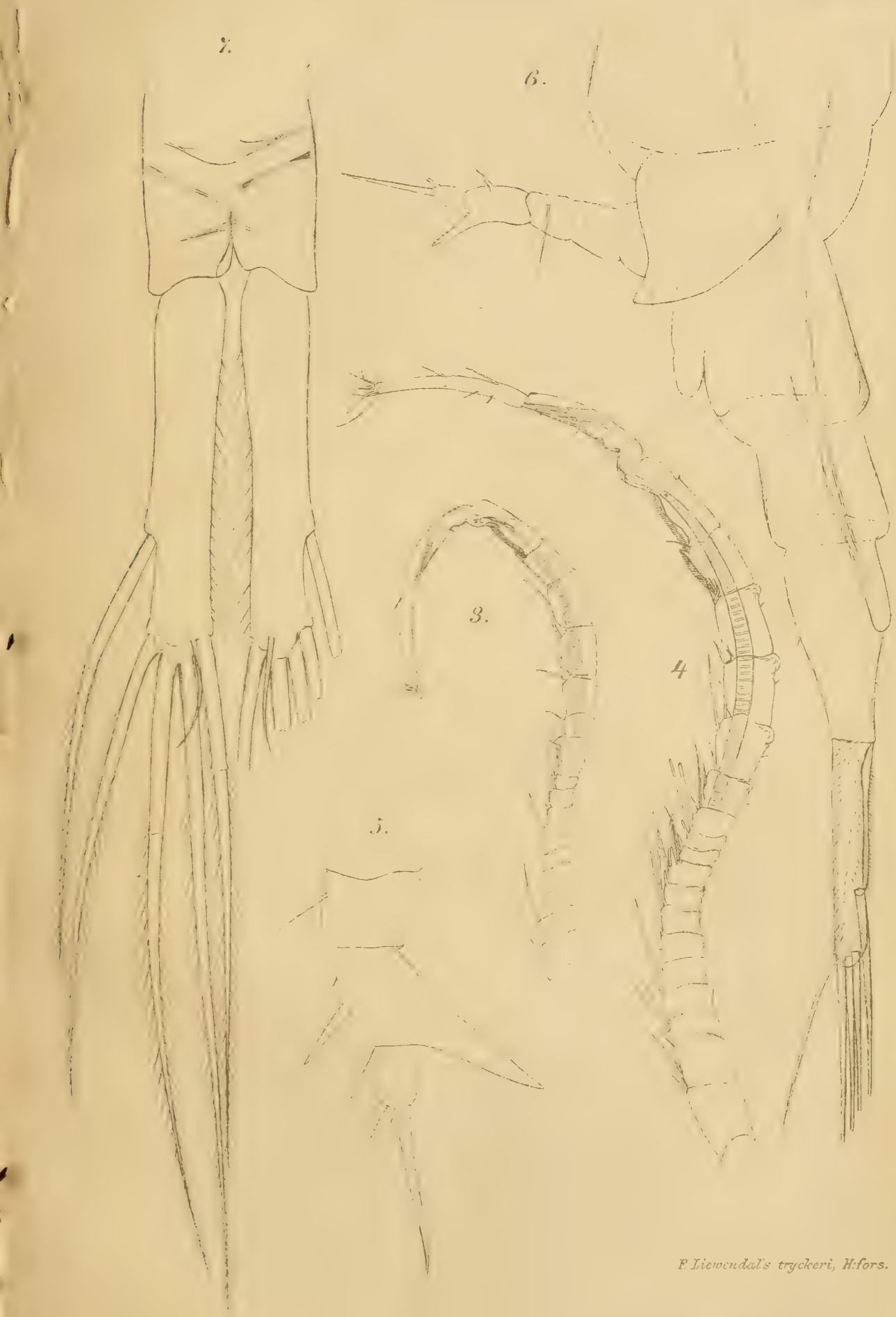



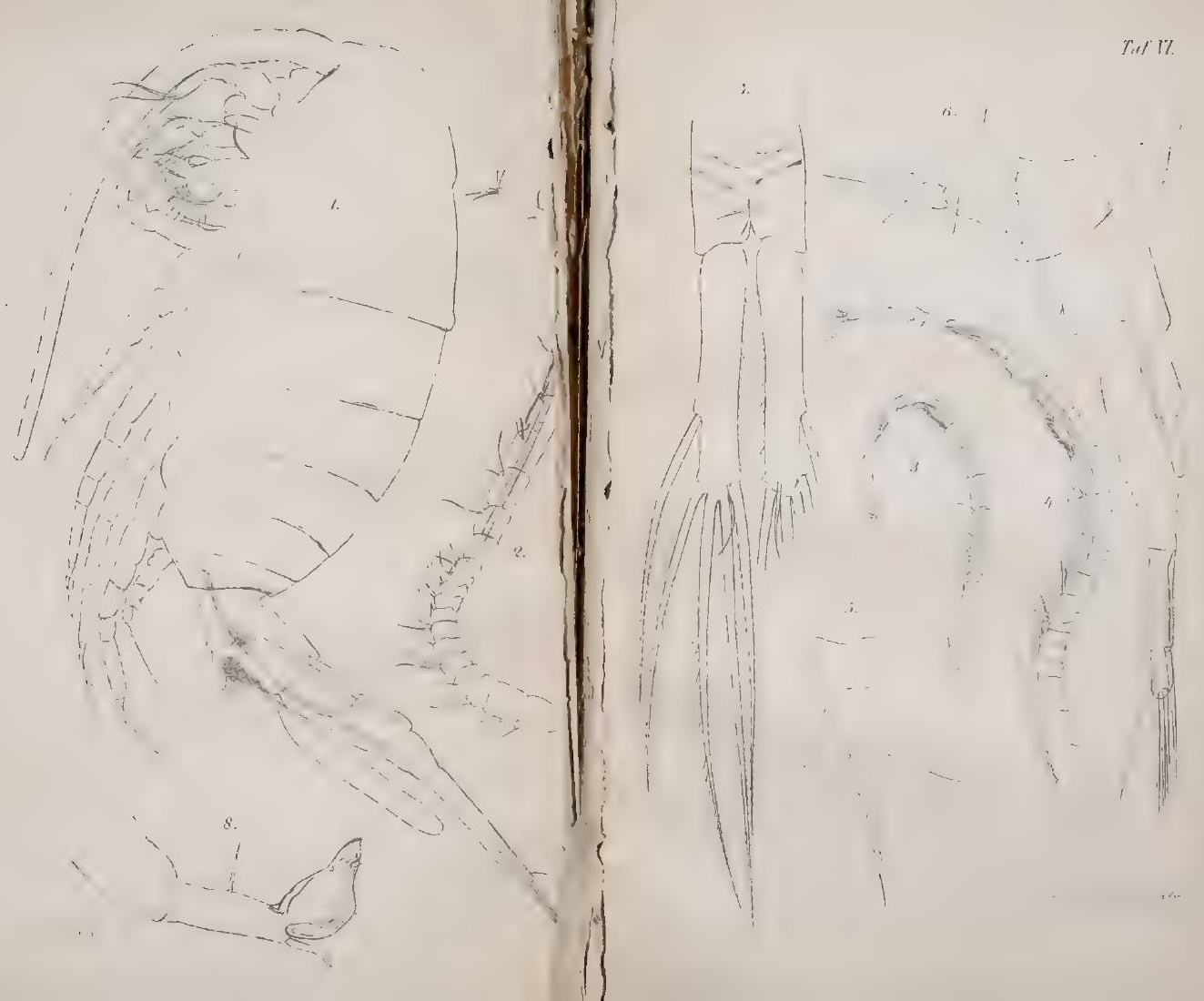



$$
\text { . }
$$$$
\text { ...... }
$$ 


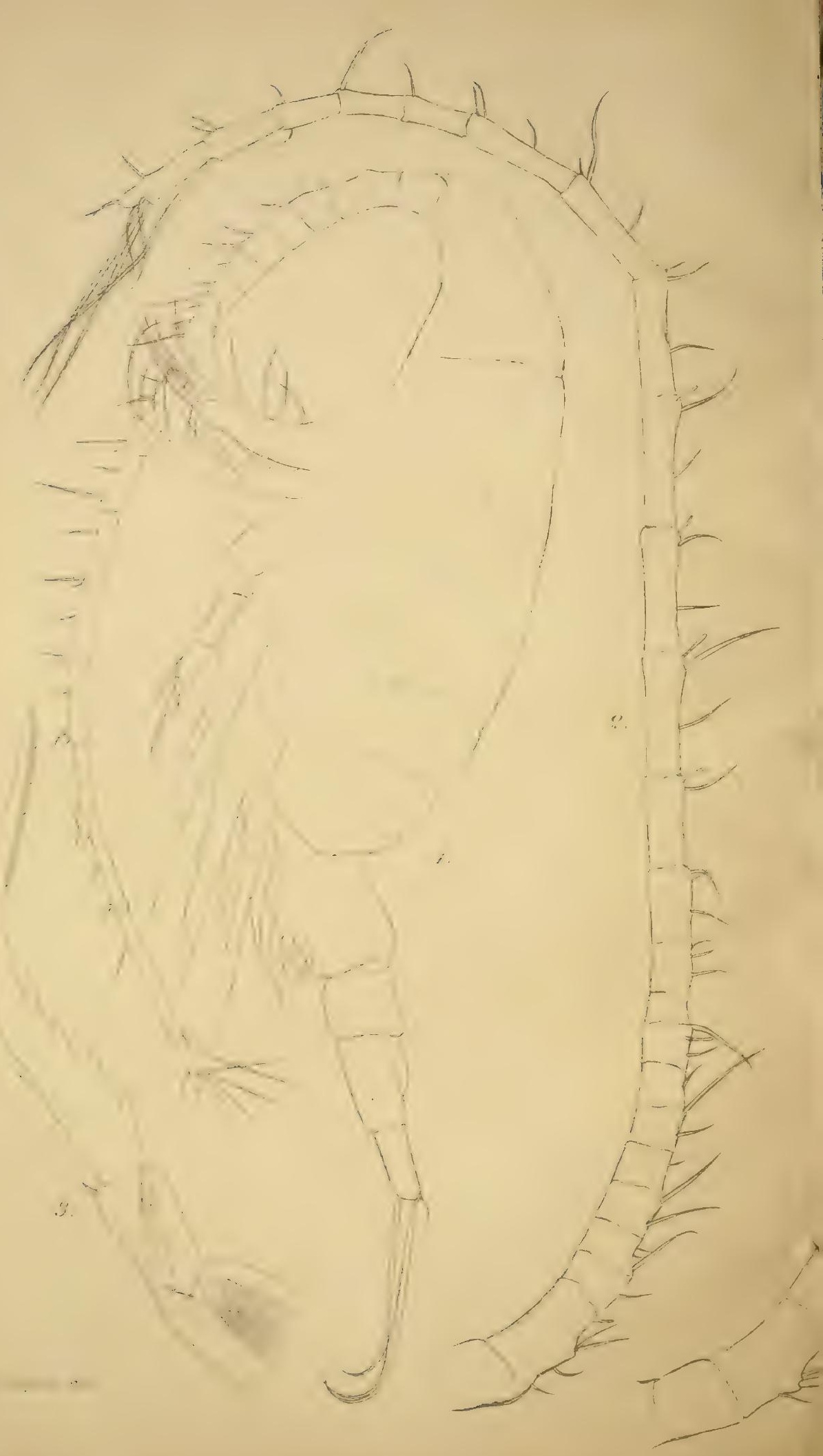




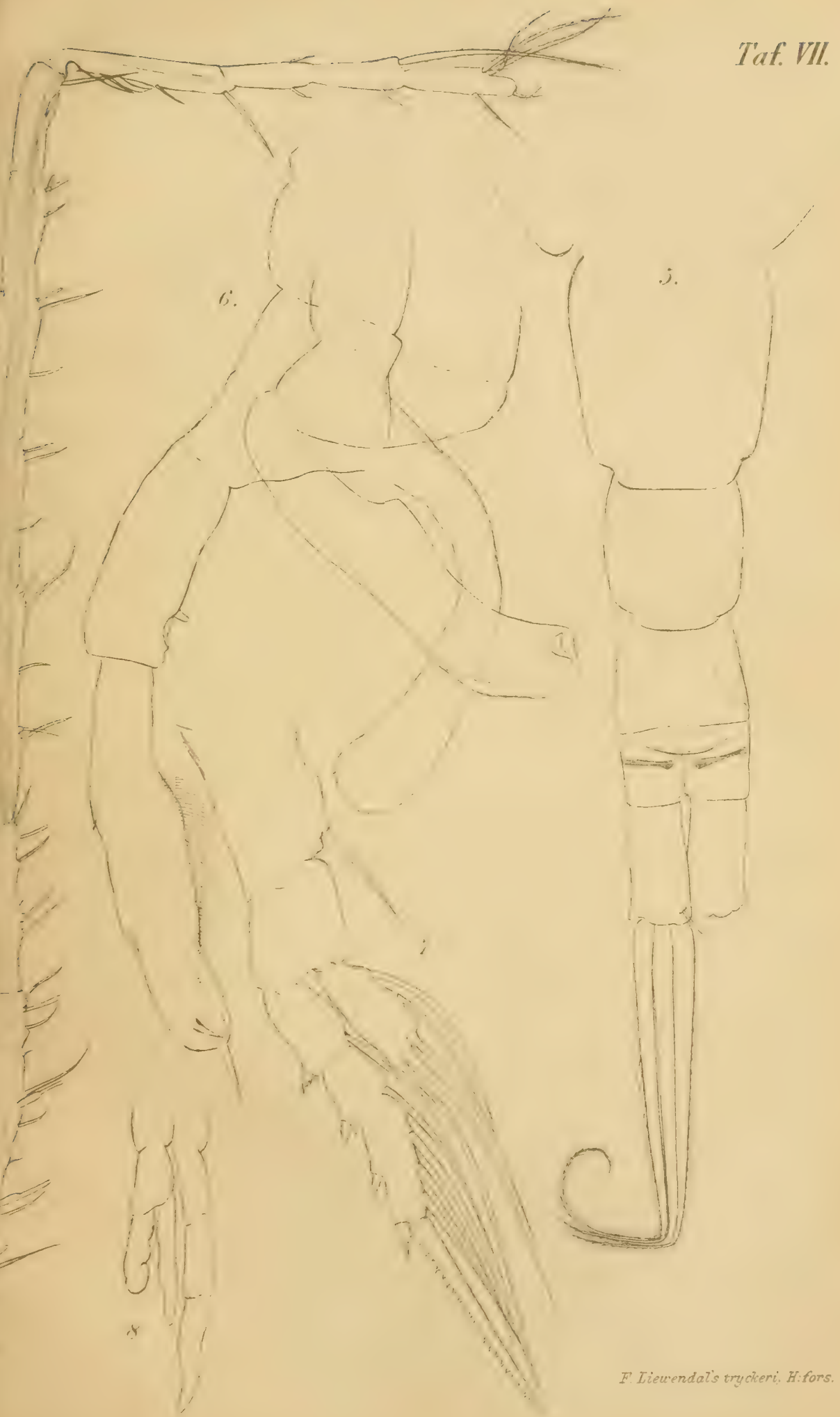







\section{Tafel VIII.}

\section{Heterocope saliens.}

Fig. 1. \& von der Seite. $90 \times$.

`2. Abdomen des 우 von der Seite. $150 \times$.

" 3. Fünftes Fusspaar des 3. $180 \times$.

"4. Fünfter Fuss des ㅇ. $160 \times$.

"5. Erstes abdominalsegment von unten. $150 \times$.

\section{Heterocope appendiculata.}

, 6. Erstes abdominalsegment von unten. $150 \times$. 
7 
\{
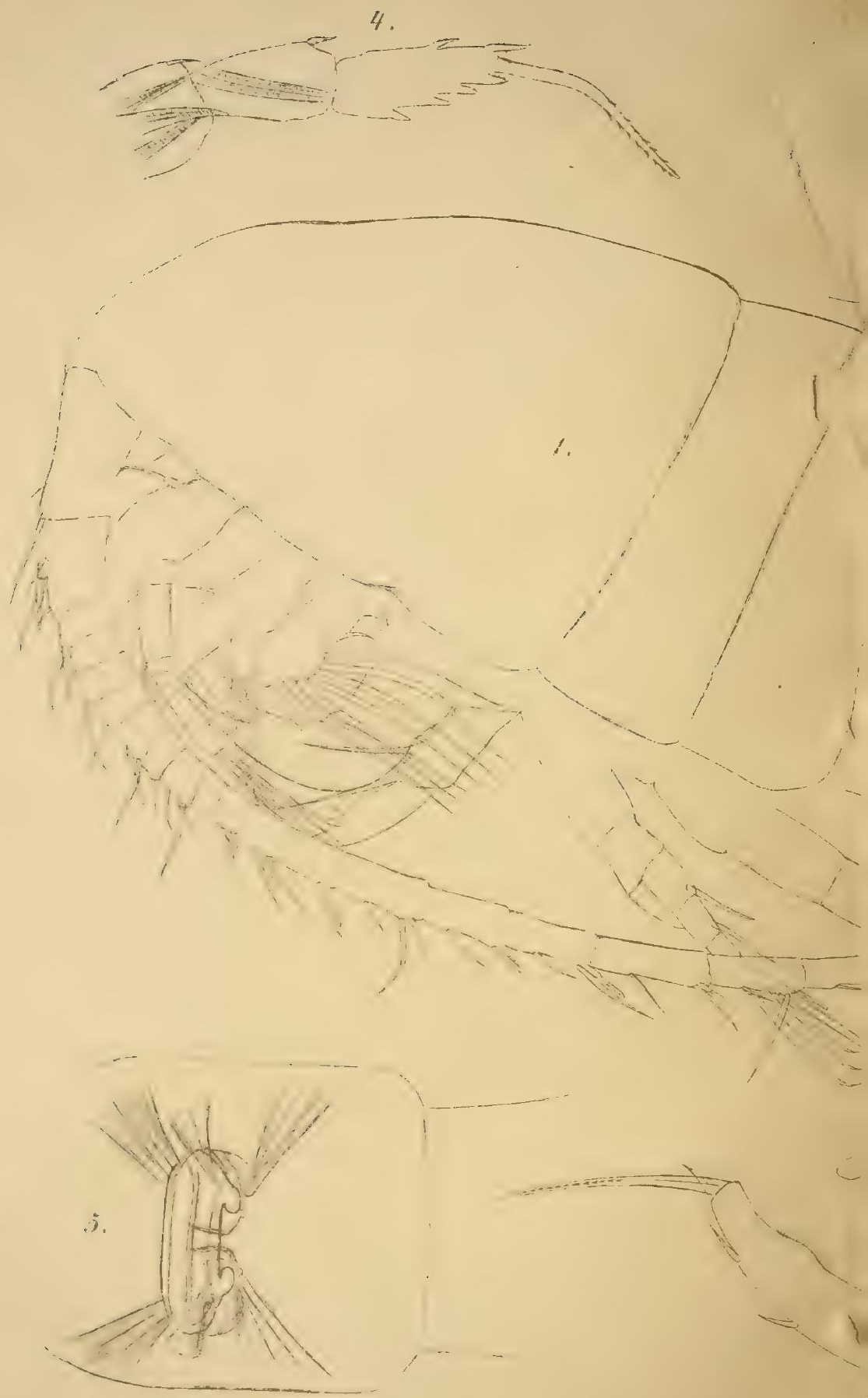
Taf lill.

2.

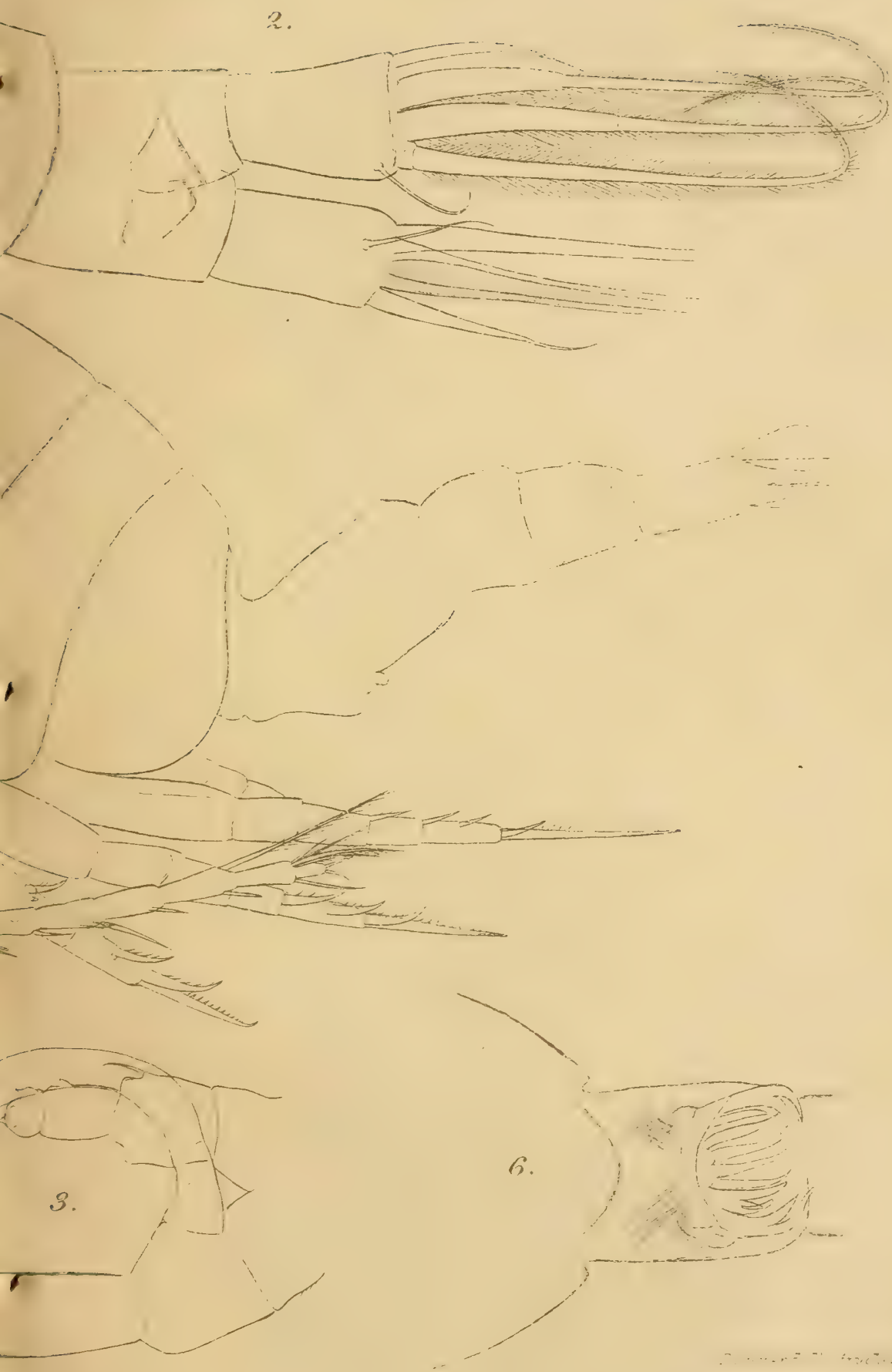





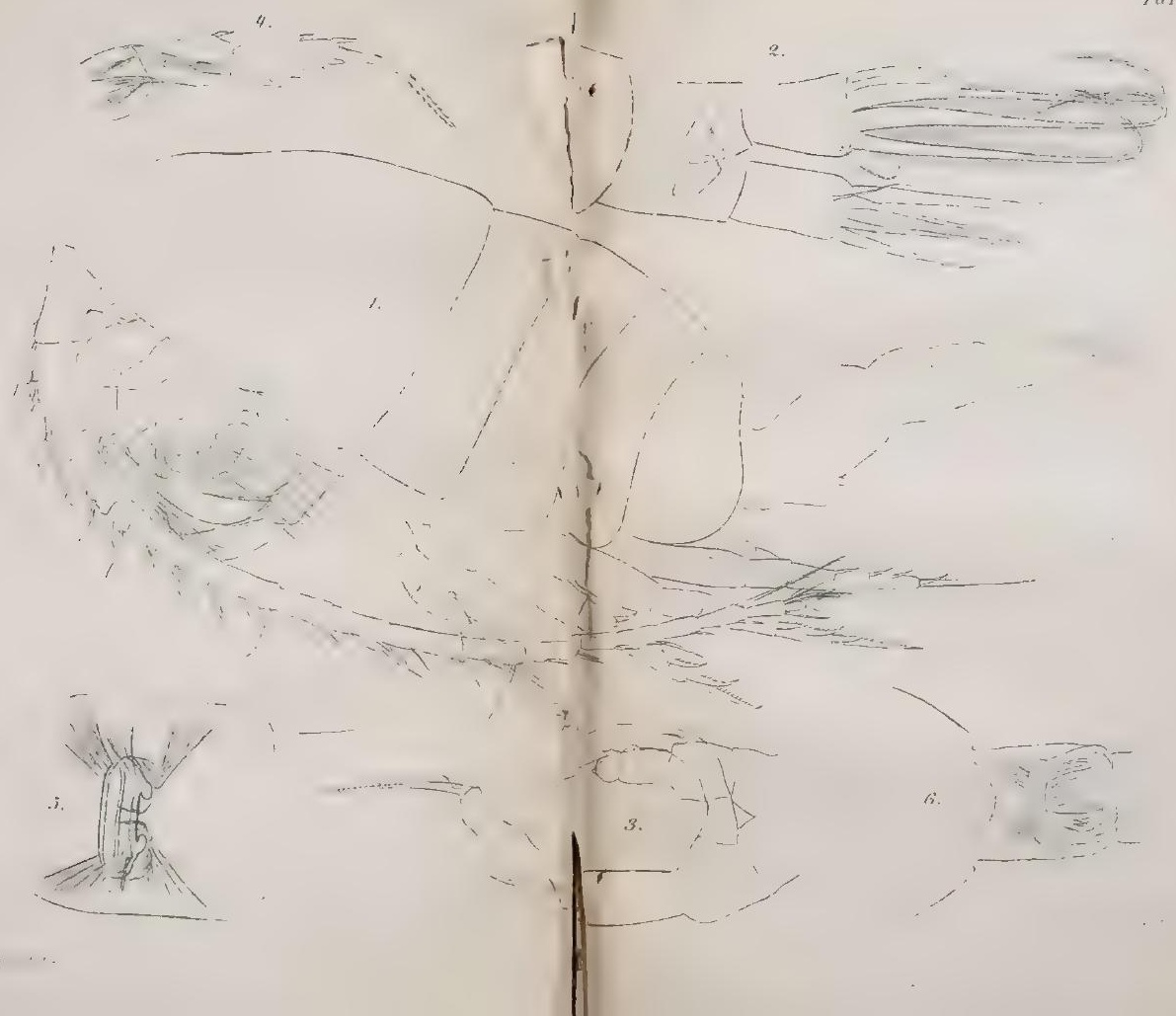





\section{Tafel IX.}

\section{Diaptomus gracilis.}

Fig. 1. \& von der Seite, $60 \times$.

"2. Abdomen des $q$ von der rechten Seite. $150 \times$.

"3. Vordere Antenne des 우 $150 \times$.

"4. Fïnfter Fuss des $\bigcirc .375 \times$.

.. 5. Abdomen, hinterer Theil des Cephalothorax und rechter fünfter Fuss des o von der linken Seite. Von dem linken Fuss ist nur das Basalglied gezeichnet. $150 \times$.

"6. Rechte, vordere Antenne des . $6.180 \times$.

" 7. Finftes Fusspaar des $\delta .375 \times$.

\section{Dias bifilosus.}

" 8. Die Kieferfüsse des б. $375 \times$.

"9. Erster Schwimmfuss des f. $375 \times$.

"10. Rechte vordere Antemne des d. $150 \times$.

\section{Dias longiremis.}

"11. Vordere Anteme des f. $160 \times$. 


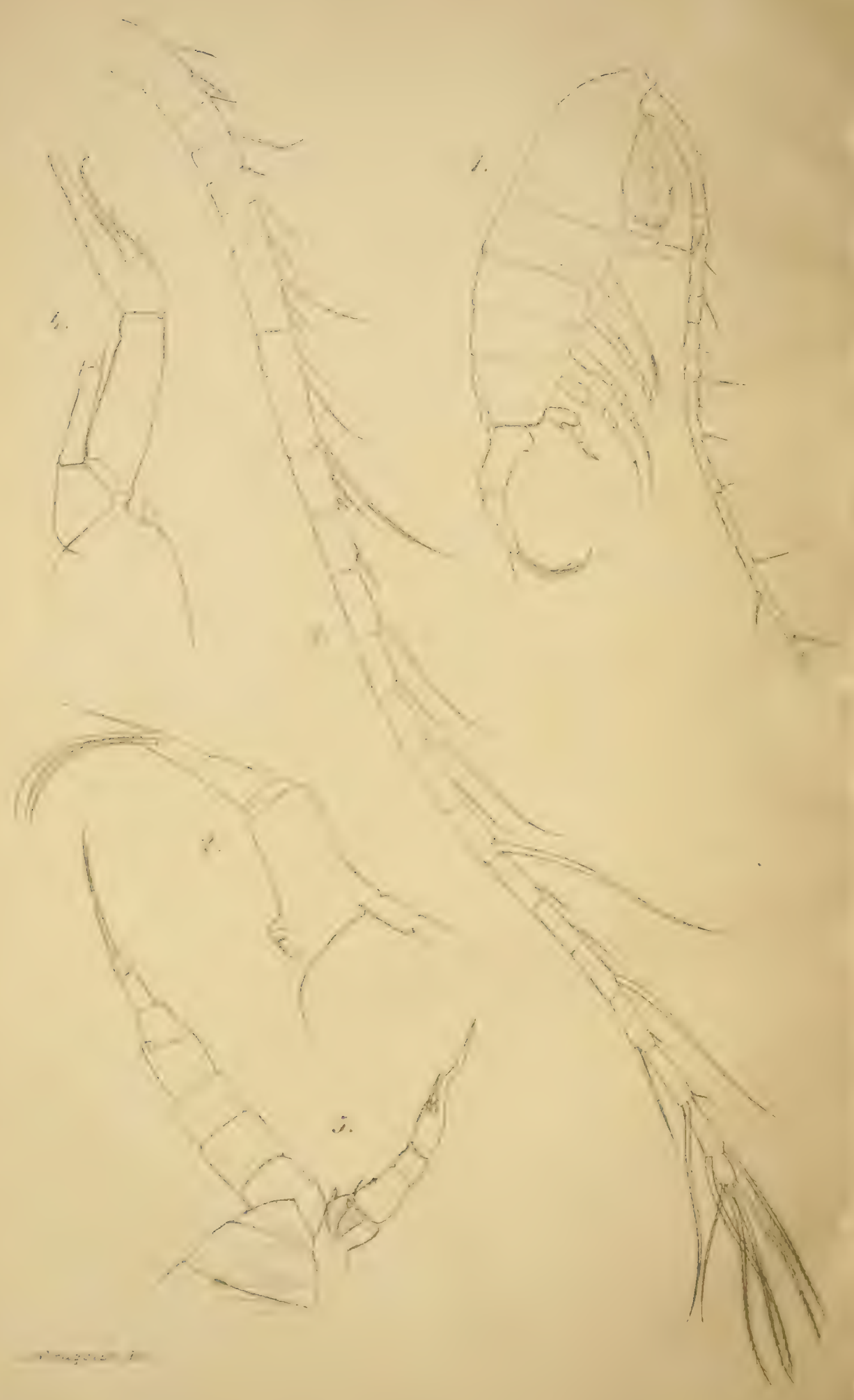




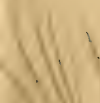

:

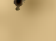
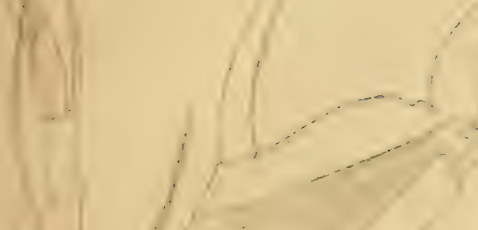

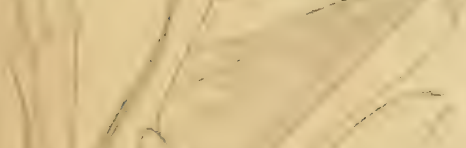

$4^{2} / 9 / 6=$

$\int 13 x+3$

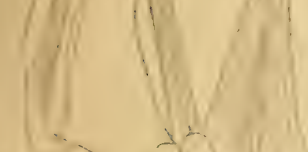





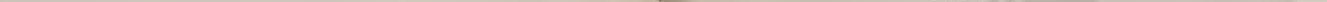






\section{Tafel X.}

\section{Dias longiremis.}

Fig. 1. \& von der Seite. $90 \times$.

"2. Abdomen des 오 von oben. $375 \times$.

"3. Abdomen des of von oben. $375 \times$.

"4. Rechte vordere Antenne des $\delta .150 \times$.

5. Finftes Fusspaar des o. $375 \times$.

Dias bifilosus.

" 6. 우 von der Seite. $90 \times$.

"7. Abdomen des ơ von oben. $375 \times$.

, 8. Fünftes Fusspar des $\sigma .375 \times$.

» 9. Fünfter Fuss des 우. $375 \times$ 。

\section{Dias longiremis.}

"10. Fünfter Fuss des ㅇ․ $375 \times$. 



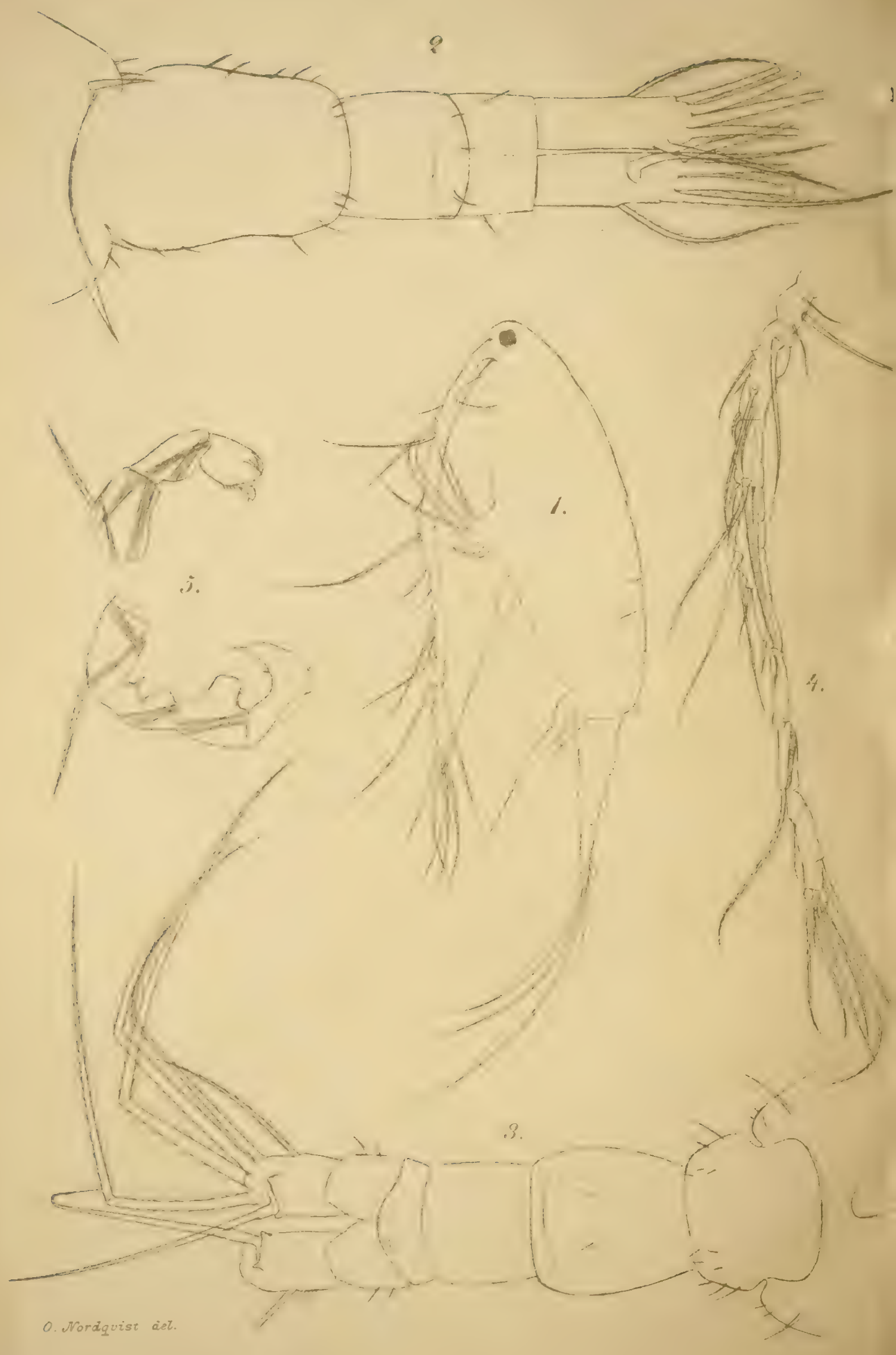




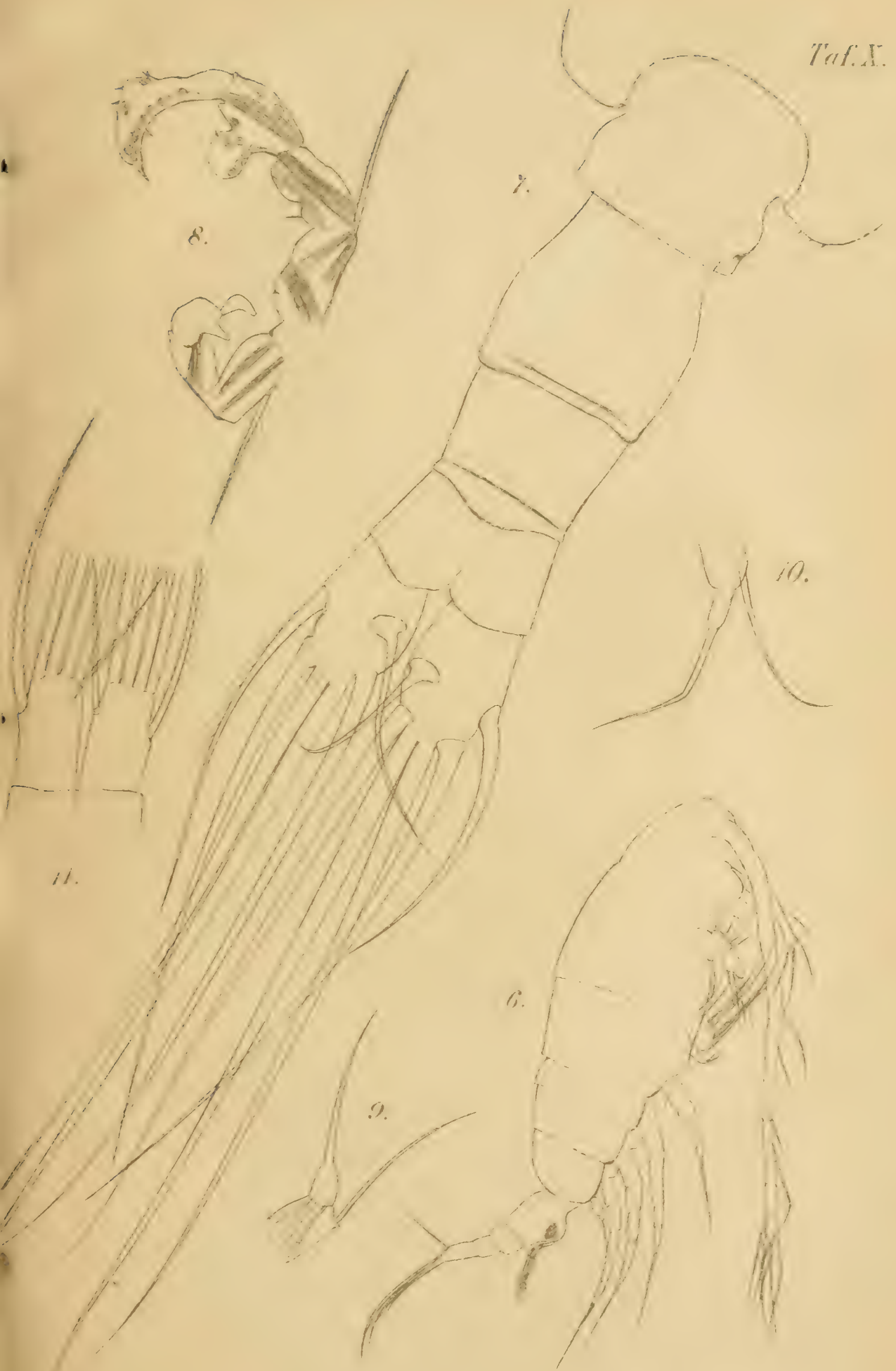





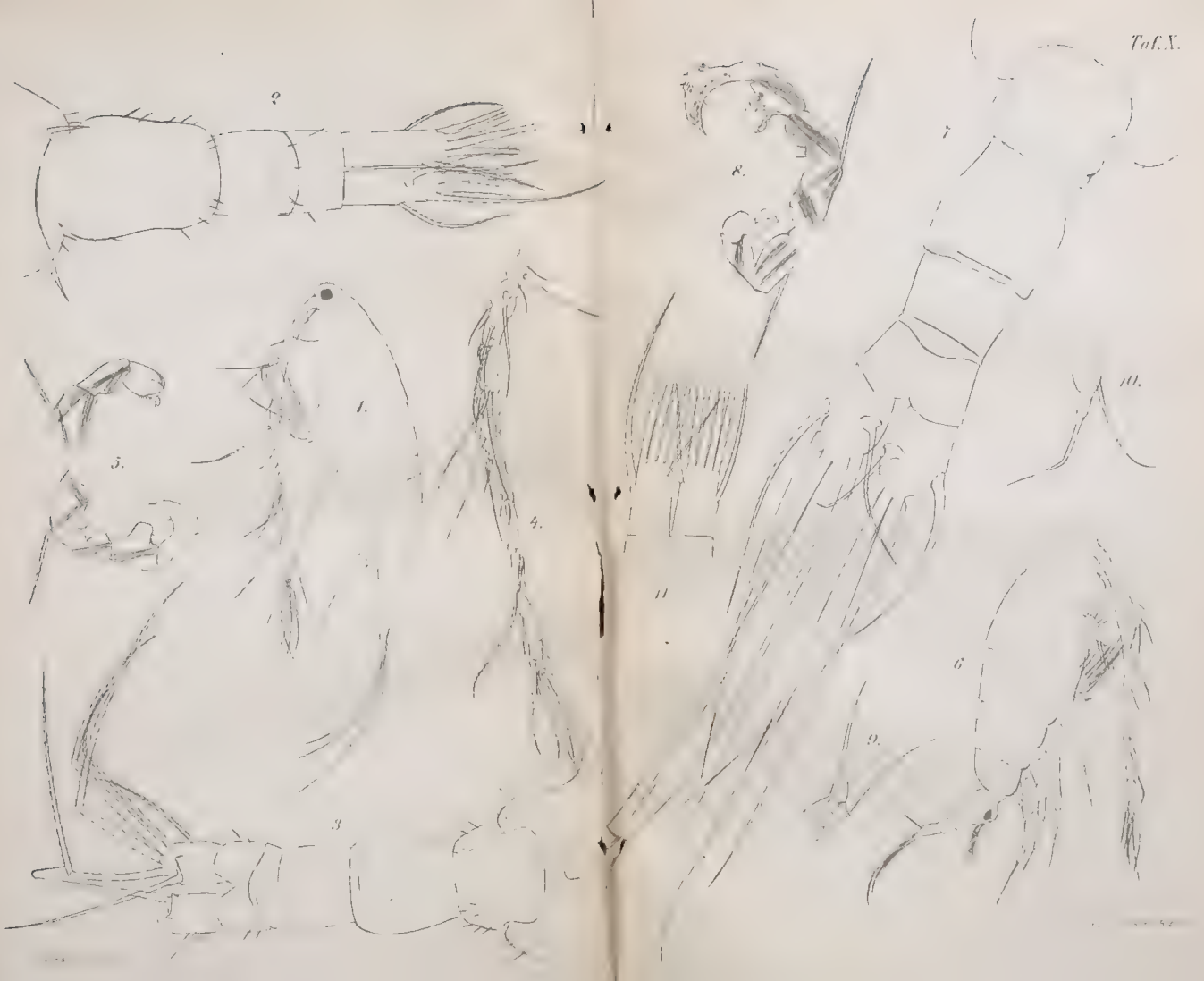







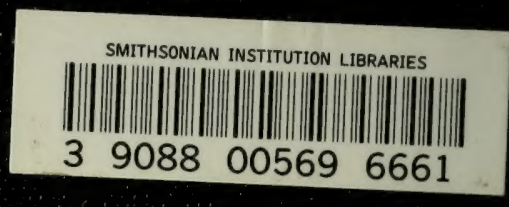

